Report No. 69132-HN

\title{
Republic of Honduras \\ Country Environmental Analysis
}

\section{December 23, 2007}

Environmentally and Socially Sustainable Development Department Latin America and the Caribbean Region

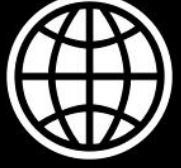

Document of the World Bank 


\title{
CURRENCY EQUIVALENTS
}

Currency unit $=$ Honduran Lempira $(\mathrm{HNL})$

US $\$ 1=18.95 \mathrm{HNL}$

FISCAL YEAR

January 1 - December 31

\author{
Vice President: Pamela Cox \\ Country Director: Jane Armitage / Laura Frigenti \\ Sector Director: Laura Tuck \\ Sector Manager: Laura Tlaiye \\ Sector Leader: John Kellenberg \\ Task Manager: Juan Carlos Belausteguigoitia
}




\section{Table of Contents}

Acronyms and Abbreviations .................................................................................................... i

Acknowledgements ..........................................................................................................ii

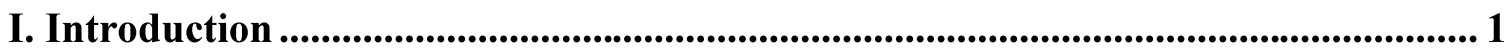

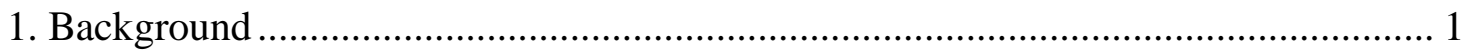

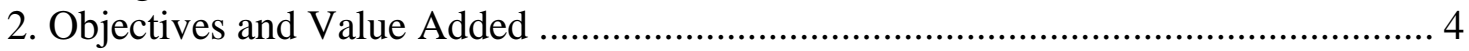

II. Institutional Framework ............................................................................................... 11

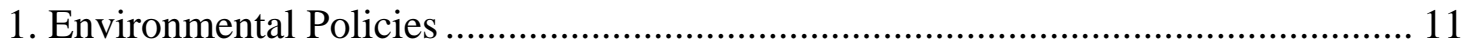

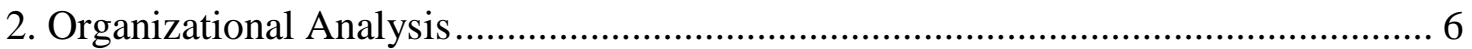

3. Institutional and Organizational Strengths and Weaknesses .................................... 11

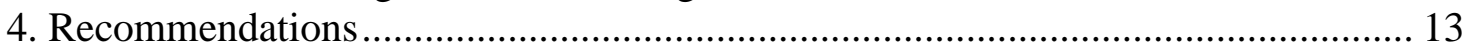

III. Environmental Health in Honduras ........................................................................ 15

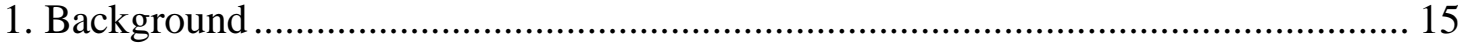

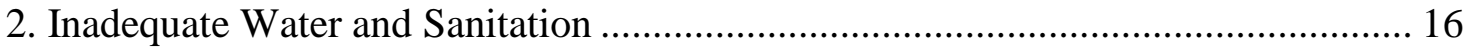

3. Rural Energy and Indoor Air Pollution............................................................... 21

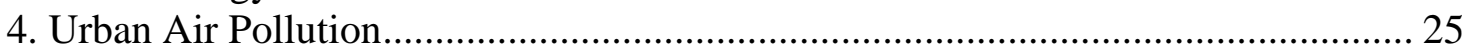

IV. Infrastructure and the Environment-Toward Sustainability and Efficiency .. 30

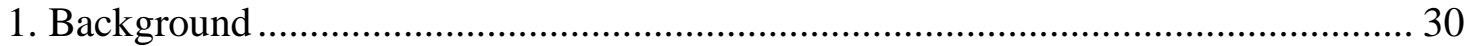

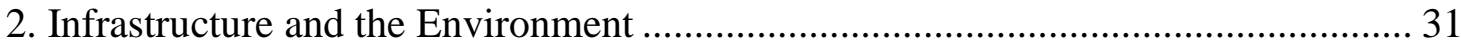

2. Planned Expansion in Key Infrastructure Sectors ................................................. 34

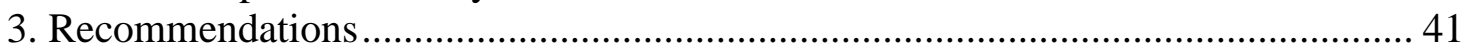

V. Forest Resources and Management............................................................................... 46

1. Forest resources - a source of income and economic opportunities in Honduras .... 46

2. Main Areas of Potential Contribution of the Forest Sector to Reducing Poverty .... 48

3. Policy, Institutions, and the Legal Framework …………..................................... 51

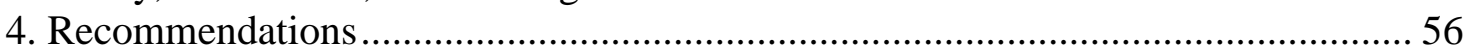

VI. Conclusions and Recommendations ........................................................................ 58

1. Operationalize the Environmental Policy of Honduras ........................................... 58

2. Strengthen the Role of SERNA as a Sectoral Leader .............................................. 58

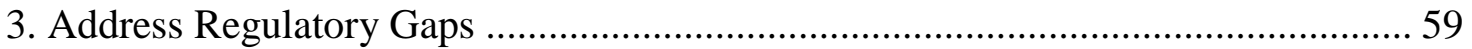

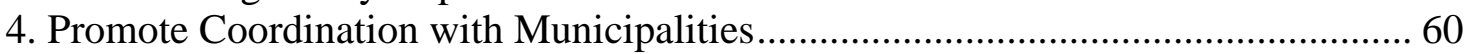

5. Improve Effectiveness and Efficiency of the EIA System ……………………......... 60

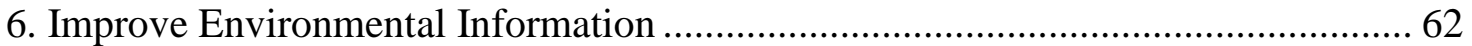

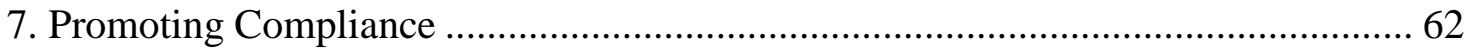

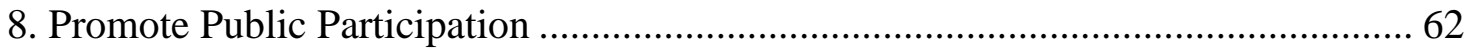

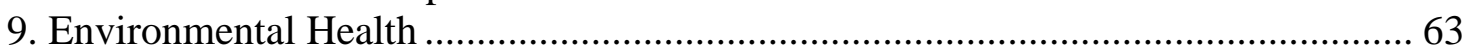

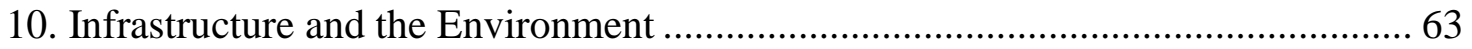

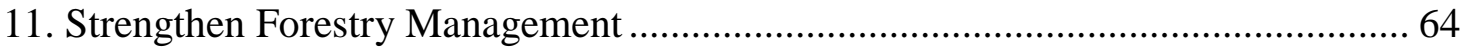

\section{References}




\section{Figures}

Figure I.1. Intangible, Produced, and Natural Capitol as a Percent of Total Wealth, Selected Comparators

Figure II.1. Projected Demand for New Licensing Applications by Year

Figure II.2. Actual and Projected Citizen Complaints (2001-15)

Figure II.3. Organization of the Ministry of Natural Resources and Environment (SERNA)

Figure II.4. Budgetary Allocations of Ministries of Natural Resources and Environment, Education, Health, and Infrastructure

Figure II.5. Ministry of Natural Resources and Environment Budgetary Allocation (2004-07)

Figure III.1. Honduras Revealed Comparative Advantage

Figure III.2. Honduras's Sectoral Share in Total Exports, 2005

Figure IV.1. Costs of Environmental Degradation (as percent of GDP)

Figure IV.2. Annual Costs by Category (Million L)

Figure IV.3. Marginal Costs/Marginal Benefits Relating to Interventions for WSH in Honduras

Figure IV.4. Annual Costs of Indoor Air Pollution (million L)

Figure IV.5. Marginal Costs/Marginal Benefits Relating to Interventions for Indoor Air Pollution in Honduras

Figure IV.6. Monitoring Stations in Tegucigalpa

Figure V.1. A Rising Shortfall in Electricity Generation

\section{Tables}

Table I.1. Current MDG Situation and Baseline Performance in Honduras

Table II.1. Environmental Treaties, Conventions, and Protocols

Table II.2. Binding Environmental Management Regulations

Table II.3. New Licensing Applications by Year

Table II.4. Applications for Services Managed by SERNA

Table II.5. Structure of Environmental Indicators

Table II.6. Institutional Responsibilities of the Environmental Attorney General's Office and Environmental Prosecutor's Office

Table II.7. SERNA's Personnel, by Department

Table IV.1. Aggregate Environmental Health Costs for Honduras

Table IV.2. Estimated Annual Health Effects (Diarrhea) from Water, Sanitation, and Hygiene

Table IV.3. Benefits of Reductions in Diarrheal Morbidity and Mortality in Rural Honduras

Table IV.4. Estimated Annual Health Effects of Indoor Air Pollution (Rural and Urban)

Table IV.5. Scenarios for IAP Interventions

Table IV.6. Benefits and Costs of Rural Indoor Air Pollution Control in Rural Honduras

Table IV.7. Estimated Annual Health Effects of Urban Outdoor Air Pollution

Table V.1. Specific Recommendations by Sector and Issue

Table VI.1: Implications of Forest Resource Management for the Rural Poor 


\section{Boxes}

Box III.1. Key Environmental Challenges

Box III.2. Structural Reforms in Honduras

Box III.3. Environmental Provisions in the DR-CAFTA

Box V.1. Ecological Compensation Program in Yacyretá's Hydroelectric Project II Box V.2. The National Fund for Protected Areas: a Promising Alternative for the Conservation of Biodiversity in Honduras. 



\section{Acronyms and Abbreviations}

\begin{tabular}{|c|c|}
\hline FE-COHDEFOR & State Forest Administration \\
\hline AHDESA & Honduran Association for Development \\
\hline ARI & Acute respiratory infections \\
\hline CAS & Country Assistance Strategy \\
\hline CBFM & Community-based forest management \\
\hline CEA & Country Environmental Analysis \\
\hline CEM & Country Economic Memorandum \\
\hline CESSCO & Center of Pollution Studies \\
\hline COCONA & National Advisory Council for the Environment \\
\hline COHDEFOR & Honduran Forestry Corporation \\
\hline CONASA & National Council on Potable Water and Sanitation \\
\hline COPD & Chronic obstructive pulmonary disease \\
\hline DALYs & Disability adjusted life years \\
\hline DECA & Office of Environmental Assessment and Control \\
\hline DPL & Development Policy Loan \\
\hline DR-CAFTA & Dominican Republic-Central American Free Trade Agreement \\
\hline EHS & Environmental Health Safeguards \\
\hline EIA & Environmental Impact Assessment \\
\hline $\mathrm{EKC}$ & Environmental Kuznets Curve \\
\hline ENDESA & (Encuesta Nacional de Demografía y Salud) \\
\hline ENEE & National Electricity Company \\
\hline ENP & National Port Enterprise \\
\hline ERSAPS & Regulatory Authority for Potable Water and Sanitation Services \\
\hline FDI & Foreign direct investment \\
\hline FEHCAFOR & Federation of the Honduran Forestry Corporation \\
\hline FTZs & Free-trade zones \\
\hline GDP & Gross domestic product \\
\hline $\mathrm{HCA}$ & Human Capital Approach \\
\hline HONDUTEL & Honduran Telecommunications Enterprise \\
\hline IAP & Indoor Air Pollution \\
\hline $\mathrm{ICF}$ & Institute for Forestry Conservation and Development \\
\hline IFC & International Finance Corporation \\
\hline IIASA & International Institute of Applied Systems Analysis \\
\hline $\mathrm{IMF}$ & International Monetary Fund \\
\hline INFOP & National Vocational Training Institute \\
\hline JAS & (Juntas de Agua y Saneamiento) \\
\hline $\mathrm{Km}^{2}$ & Square kilometers \\
\hline $\mathrm{L}$ & Lempira \\
\hline LPG & Liquefied petroleum gas \\
\hline MDGs & Millennium Development Goals \\
\hline $\mathrm{MFN}$ & Most-favored nation \\
\hline MW & Megawatt \\
\hline NAFTA & North American Free Trade Agreement \\
\hline NGO & Nongovernmental organization \\
\hline
\end{tabular}




\begin{tabular}{|c|c|}
\hline $\mathrm{NO}_{2}$ & Nitrogen dioxide \\
\hline $\mathrm{O}_{3}$ & Ozone \\
\hline OAS & Organization of American \\
\hline $\mathrm{OHA}$ & Honduran Accreditation Agency \\
\hline $\mathrm{OHN}$ & Honduran Normalization Agency \\
\hline PBPR & Forests and Rural Productivity Project \\
\hline PEMAPS & Honduras Strategic Modernization Plan of the Water and Sanitation Sector \\
\hline PLANFOR & Forestry Action Plan \\
\hline $\mathrm{PM}_{10}$ & Particulate matter less than 10 micros in size \\
\hline $\mathrm{PM}_{2.5}$ & Particulate matter less than 2.5 micros in size \\
\hline PPPs & Public Private Partnerships \\
\hline PRONAFOR & National Forestry Program \\
\hline PRS & Poverty Reduction Strategy \\
\hline SAG & Secretariat of Agriculture and Livestock \\
\hline SANAA & $\begin{array}{l}\text { National Water and Sewerage Service (Servicio Autonomo Nacional de } \\
\text { Acueductos y Alcantarillados) }\end{array}$ \\
\hline SEA & Strategic Environmental Assessment \\
\hline SERNA & Ministry of Natural Resources and Environment \\
\hline SIAM & Environmental Information System \\
\hline SINEIA & National Environmental Impact Assessment System \\
\hline SINAPH & National System of Protected Areas of Honduras \\
\hline SINIA & National Environmental Information System \\
\hline SINAP & National Property Administration \\
\hline SINIT & National Territorial Information System \\
\hline SOPTRAVI & Ministry of Public Works and Housing \\
\hline SSF & Social Forestry System \\
\hline TSP & Total suspended particles \\
\hline TWP & Trees, Water, \& People \\
\hline UNDP & United Nations Development Programme \\
\hline WHO & World Health Organization \\
\hline WSH & Water Sanitation and Hygiene \\
\hline WSSH & Water Supply Sanitation and Hygiene \\
\hline
\end{tabular}


Acknowledgements 


\section{Introduction}

\section{Background}

\section{Importance of the Environment and Natural Resources and Policy Challenges}

Honduras has accomplished important political, economic, and social achievements in the recent past. The country underwent a successful transition from an authoritarian military regime to a pluralistic democracy. The list of economic achievements of the last four years includes: macroeconomic stability, improvements in the business climate and the performance of the financial sector, and putting in place a sound framework for public sector financial management. Progress toward achieving the Millennium Development Goals (MDGs) has also been significant (see Table I.1). Despite these achievements, state institutions are still fragile and the governance framework is weak. Furthermore, notwithstanding the country's economic and social improvement, almost two-thirds of the population still lives below the poverty line and key structural constraints on growth have still to be addressed. The key development challenges for Honduras are: (a) strengthening governance and improving the effectiveness of the government, and (b) accelerating its recent growth performance and translating growth into poverty reduction.

Table I.1. Current MDG Situation and Baseline Performance in Honduras

\begin{tabular}{|c|c|c|c|}
\hline & \multicolumn{3}{|c|}{ Honduras } \\
\hline & 1990 & 2004 & $\begin{array}{r}2015 \\
\text { (Target) }\end{array}$ \\
\hline $\begin{array}{l}\text { MDG 1: People living below the national } \\
\text { poverty line ( } \% \text { of pop.) }\end{array}$ & 84 & 64 & 42 \\
\hline $\begin{array}{l}\text { MDG } 2 \text { : Primary completion rate ( } \% \text { of } \\
\text { relevant age group) }\end{array}$ & 65 & 76 & 100 \\
\hline $\begin{array}{l}\text { MDG 4: Under-five mortality rate (per } \\
1,000 \text { births) }\end{array}$ & 59 & 31 & 20 \\
\hline $\begin{array}{l}\text { MDG 5: Maternal mortality rate (per } \\
100,000 \text { live births) }\end{array}$ & 180 & 108 & 70 \\
\hline $\begin{array}{l}\text { MDG 7a: Access to an improved water } \\
\text { source ( } \% \text { of population) }\end{array}$ & 73 & 82 & 95 \\
\hline $\begin{array}{l}\text { MDG } 7 \mathrm{~b} \text { : Access to improved sanitation } \\
\text { facilities ( } \% \text { of pop.) }\end{array}$ & 66 & 77 & 95 \\
\hline
\end{tabular}

Note: The table lists individual goals (2015 levels) as defined by national authorities, which may be more or less ambitious than the percentage improvements from 1990 levels, which are used as the official definition by the UN. Source: www.developmentgoals.org; www.sierp.hn; millenniumindicators.un.org; G-JAS (2007); AMCOW (2006).

Sound environmental and natural resource management can and must make substantive contributions to meet these challenges. For many developing countries, natural capital is a very important source of income. Honduras is no exception. Natural resources play two 
basic roles in development. The first is the role of local natural resources as the basis of subsistence of poor communities. The second is as a source of development finance. Despite declining shares, agriculture, forestry, and fishing accounted for one-quarter of gross domestic product (GDP) and one-half of exports from 2000 to 2006. Similarly, natural capital is an important share of total wealth (at 26 percent, it is more than double the average in Latin America and the Caribbean; see Figure I.1). ${ }^{1}$ These facts suggest that managing natural resources must be a key part of development strategies in Honduras.

In addition, pollution of the air and water in Honduras is resulting in premature deaths and illnesses, especially among children under 5 years of age. These health impacts have associated economic costs - estimated at around 2 percent of the country's GDPrelating to lost work productivity and treatment expenses, apart from the pain and suffering they impose. Moreover, for young children, repeated infections from poor air quality and contaminated water also contribute to malnutrition and subsequent cognition and learning impacts later in life. All this indicates that environmental quality must be a pillar of development strategies in Honduras.

Figure I.1. Intangible, Produced, and Natural Capital as a Percent of Total Wealth, Selected Comparators

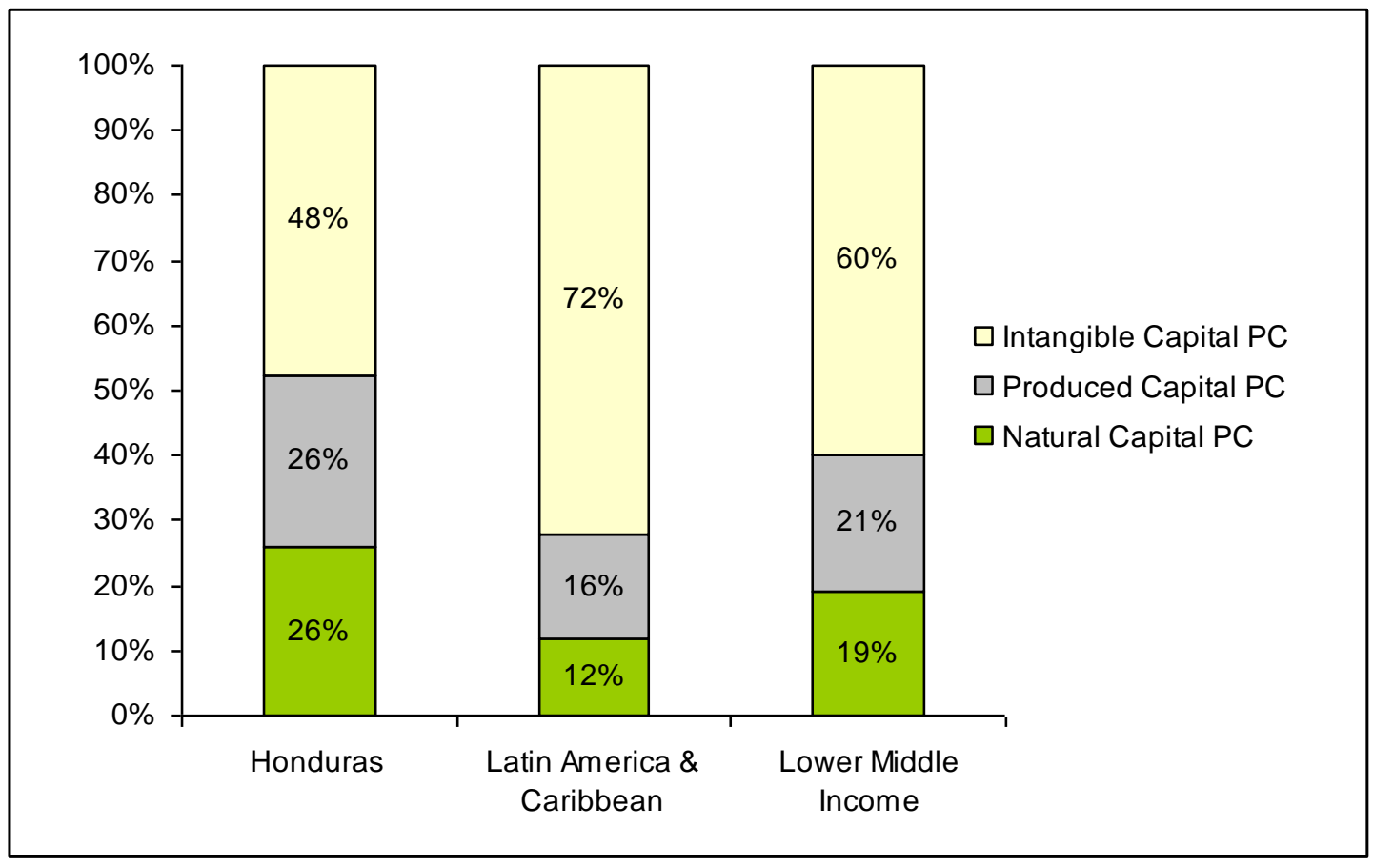

\footnotetext{
1 "Where is the Wealth of Nations?" (World Bank 2006). The estimates presented measure total wealth as composed of: (1) produced capital - the sum of machinery, equipment, structures (including infrastructure), and urban land; (2) natural capital —including land resources, forests, and sub-soil assets; and (3) intangible capital - a wide array of assets such as human capital, quality of institutions, and governance.
} 
Honduras has developed institutions and organizations to manage natural resources and protect the environment, including: (a) legal and regulatory frameworks, (b) specialized ministries, (c) pollution control and natural resource management policies, and (d) policy coordination and information systems. But despite these and other institutional efforts, Honduras still faces significant environmental challenges, including:

Deforestation: The country has the highest annual rate of deforestation in Latin America (2.5 percent, compared with the Latin America and the Caribbean Region and world averages of 0.4 percent and 0.1 percent, respectively, during 1990-2005).

Poor water quality: Inadequate access to water and sanitation and a lack of hygiene cause over 4 million diarrhea episodes and more than 1,500 deaths per year among children under 5 years of age (diarrhea being the main cause of disease and the second cause of death among children under age 5). Twelve percent of the total population lacks access to an improved water source and around 25 percent do not have access to sanitation. Most industrial water effluents receive no treatment at all (for example, in Tegucigalpa, the effluents of 9 out of 10 industries are directly released into the sewer system or into the Choluteca River). More than 50 percent of rural water is contaminated with feces.

Indoor air pollution: Acute respiratory infections affect mainly women and children in rural areas, where 9 out of 10 households burn fuelwood in inefficient stoves in poorly ventilated areas. More than 2.5 million people in rural areas are exposed to high levels of indoor air pollution.

Urban air pollution: Average annual concentrations of particulate matter less than 10 micros in size $\left(\mathrm{PM}_{10}\right)$ in Tegucigalpa (the only city that monitors air quality) in 2001 were three times the recommended limit set by the World Health Organization (WHO). Air pollution causes more than 500 premature deaths per year. In addition, air pollution (both ambient and indoor) contributes to making acute respiratory infections the most frequent form of illness in the country.

Vulnerability to natural disasters: Because of its geographic location, Honduras is highly vulnerable to natural disasters such as flooding, volcanic eruptions, hurricanes, and earthquakes; these events provoke human suffering and high economic costs, like Hurricane Mitch (1998), which caused close to 7,000 deaths and whose damage was estimated at 79.23 percent of GDP.

These problems compromise Honduras's long-term economic growth as well as poverty reduction, and impose significant socioeconomic costs (particularly for vulnerable groups such as poor children and women). ${ }^{2}$ The administration's commitment to sustainable development provides an opportunity to review and improve environmental management and policy based on an analysis of the performance of environmental institutions performance and the key areas/sectors that will require intervention. This will help the environmental authorities develop policies and cost-effective interventions that benefit

\footnotetext{
${ }^{2}$ This report will include an estimate of the costs of environmental degradation in Honduras.
} 
the poor and promote growth, taking advantage of potential win-win opportunities, assessing tradeoffs, and finding the economic and social balance between protecting and restoring an already deteriorated environment and avoiding unrealistic and ineffective regulations that might hinder competitiveness and investment.

\section{Development Plan and Bank's Assistance}

Honduras's development vision is laid out in its Poverty Reduction Strategy (PRS), originally prepared under a Liberal Party administration in 2001, and subsequently endorsed by President Maduro in 2003 and by President Zelaya in 2006. The strategy is structured around six pillars: (a) accelerating economic growth, (b) reducing rural poverty, (c) reducing urban poverty, (d) investing in human capital, (e) strengthening social protection for needy groups, and (f) ensuring the sustainability of the strategy. Three overarching themes cut across these six pillars: gender equity, environmental sustainability, and decentralization. The Government updated the PRS to reflect President Zelaya's government program by giving greater attention to education, employment generation, environmental protection, and public transparency, and to a stronger results orientation across the public sector.

Within the broad framework of the PRS, the FY2007-10 Country Assistance Strategy (CAS) has been aligned with the priorities identified in President Zelaya's Government Program, which has four pillars: (a) equitable economic growth, (b) good governance through state modernization and civic participation, (c) environmental protection and risk management, and (d) development of human capital.

\section{Objectives and Value Added}

\section{Objectives}

The main objective of the Honduras CEA is to provide an objective foundation for analysis. This will enhance the country's capacity to establish environmental policy priorities that both address poverty reduction and support sustained economic growth.

Linking environmental considerations to sector-specific projects and policy-that is, mainstreaming — would provide important information on key synergies and tradeoffs involving the environment, economic growth, and poverty. In this way, the CEA can be used to strengthen the environmental policies of President Zelaya's administration. The CEA can also provide the analytical inputs needed to enhance World Bank operations in areas such as infrastructure and competitiveness. The CEA is only an analytical tool, and as such the study is not meant to directly help the Honduran Government implement its recommendations. It can, however guide environmental assistance and capacity-building supported by the Bank and/or other development partners through the assessment of capacity issues, especially in regards to specific priorities. 


\section{Value Added}

To promote economic growth and poverty alleviation within a framework of long-term sustainability, the CEA identifies information, research, regulatory, and policy gaps that will allow the Bank to provide strategic direction to priority interventions. The CEA will help the Government identify policy priorities and address difficult tradeoffs related to: (a) protecting and restoring key environmental services essential for long-term sustainability, (b) using Honduras's natural capital in a sustainable way to promote growth and alleviate poverty, (c) the environmental impact of rapid expansion of infrastructure; (d) reducing logistical and regulatory costs to improve competitiveness; and (e) reducing the health costs of environmental degradation.

The report also provides policy options and practical guidance for decisions related to a more efficient and effective coordination of environmental policy both within the executive power at a national level and between the national government and local governments, including decentralization issues.

\section{Approach and Organization}

The key to achieving sustainable development in Honduras is to end poverty and at the same time create conditions for improving the quality of life for all people. From an economic point of view, this will require substantive increases in both productivity and income, but at the same time it will be necessary to both maintain the vital services provided by Honduras's ecosystems and strengthen the social fabric on which this development must be based.

Achieving this requires proper management of the country's assets, in particular its natural resources, without creating bureaucratic impediments to economic activities. Natural resources offer goods and services that are essential both to the welfare of the population (clean air and water) and for economic growth (agriculture, forestry). Unfortunately, the depletion and degradation of Honduras's natural capital affects the quality and quantity of goods and services it can provide. Only the proper management of natural resources can ensure a permanent and continuous flow of these goods and services.

The management of the environment and natural resources requires institutions that are capable of receiving and recognizing the signals that identify (and to the extent possible, anticipate) problems. These institutions must formulate - and execute - effective policies that equitably and efficiently balance the interests of different social groups.

This report is based on analysis of the capabilities of Honduras's existing institutions to perform these essential tasks (identifying problems, designing and implementing policies to solve them). The report therefore places greater emphasis on the clarity of the policies, mechanisms for coordination, the use of and access to information, participation and consultation, and mechanisms to promote compliance with obligations and responsibilities. The premise of the institutional approach is that only strong institutions are able to offer efficient, equitable, and durable solutions to the increasingly complex problems faced by modern societies. 


\section{Organization of this Country Environmental Analysis}

The issues analyzed in this report were chosen not only because of their environmental importance but also for their strong links with poverty alleviation and economic growth. The report contains the following sections.

\section{$\underline{\text { Institutional Analysis }}$}

Honduras has developed a number of institutions and organizations to manage natural resources and protect the environment; including the 1993 General Law for the Environment. The legal and regulatory frameworks have been strengthened to address, among other issues, water, protected areas and forestry management, land use planning, pollution prevention, environmental health, and rural development.

The government has issued national policies on a wide variety of subjects, including:

- Honduras Environmental Policy (2005)

- $\quad$ Agriculture and Rural Environment (2004), containing sections on Forestry and Productive Development, Forestry and Community Development, as well as Forestry and Biodiversity

- $\quad$ Action Plan for a Sustainable Energy Policy (2005)

- Environmental Mainstreaming (2005)

- Simplification and Decentralization of Environmental Management -licensing(2002)

In addition, Honduras created the National System of Environmental Information (SINIA) to be responsible for developing data bases; web sites; geographic information systems; remote sensing; and indicators.

In spite of this notable list of institutional accomplishments, however, the country still faces significant environmental problems, and there are apparent weaknesses in a number of important areas of governance. As shown in Figure 3, these weaknesses include voice and accountability, government effectiveness, and regulatory quality, which compares measures of governance (compiled by the World Bank Institute) for 1998 with those for $2004 .^{3}$

\footnotetext{
${ }^{3}$ These governance indicators refer to all governmental sectors, and are therefore not exclusive to the environmental and natural resources management sectors.
} 
Figure 3: Assessment of Honduran Governmental Effectiveness (1998-2005)

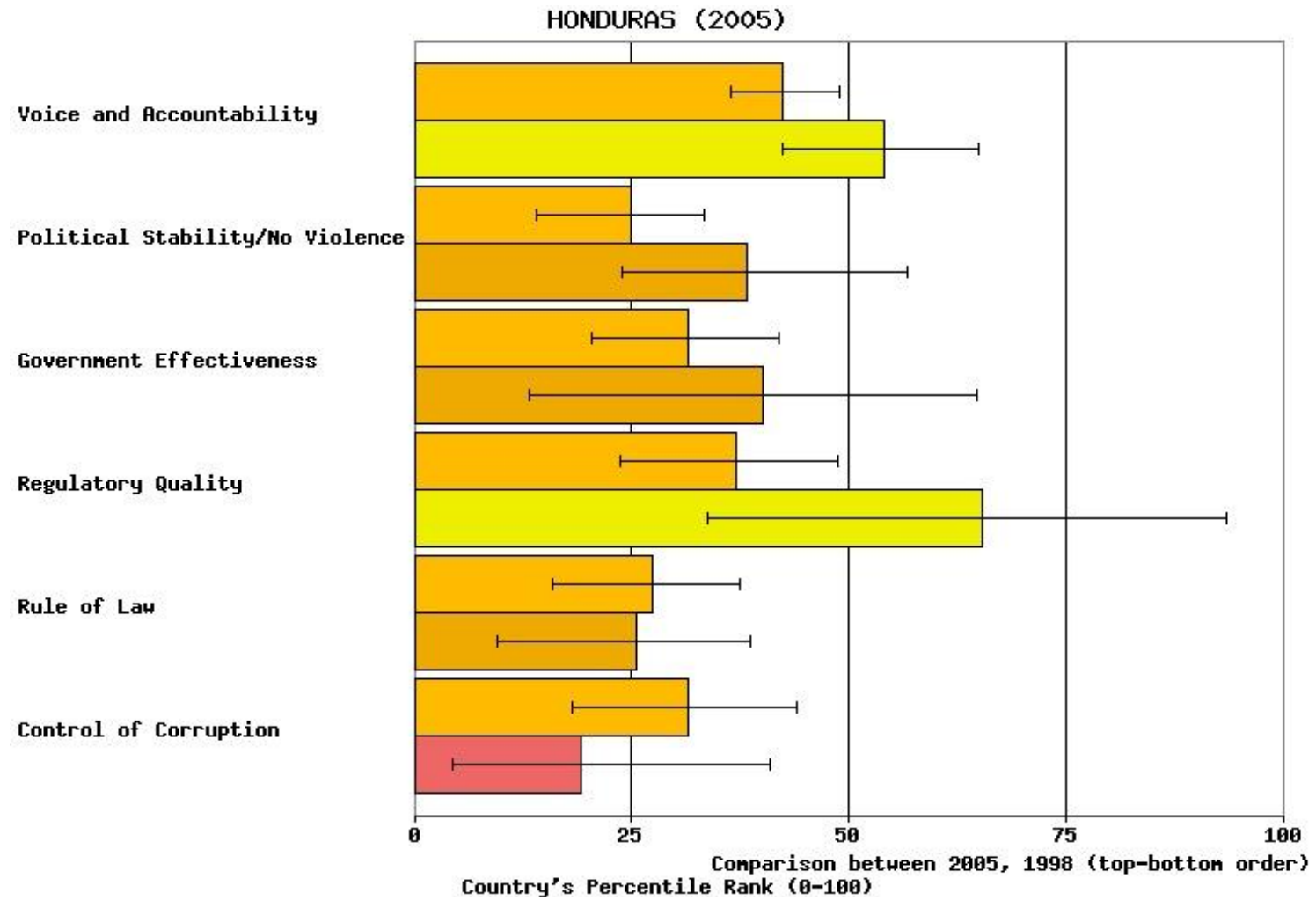

Note: This figure depicts the percentile rank of each governance indicator. Percentile rank indicates the percentage of countries worldwide that rank below the selected country (subject to margin of error). Higher values indicate better governance ratings.

This section describes and analyzes the institutional and organizational frameworks (i.e. the rules of the game and the players), and underlines the most important strengths and weaknesses of each. As part of the Bank's approach to preparing a CEA, this report explores not only the basic institutional framework in place (policies, laws, regulations, instruments, etc.), but also the organizational and human capacities to apply them in an effective, efficient, transparent, and accountable way. ${ }^{4}$ It is the synthesis of these two dimensions that provides the key strengthens and weaknesses in the country's institutional and organizational frameworks. This section includes a discussion of the Environmental Impact Assessment process, and offers strategic recommendations to improve environmentally-sound management of economic activities.

\footnotetext{
${ }^{4}$ The process was based on an extensive review questionnaire approved by the Government and a series of bilateral discussions with key stakeholders.
} 


\section{Environmental Health}

Preliminary estimations from this report indicate that polluted water and inadequate sanitation may be the cause of more than a thousand deaths from diarrheal diseases among children under-five years of age in Honduras. In addition, indoor air pollution from use of biomass for cooking is resulting in premature mortality from respiratory infections and lung disease in young children (about 500 premature deaths) and women (about 300 premature deaths). Urban air pollution -a growing concern in Tegucigalpa and other urban areas in Honduras -is contributing to a further 500 premature deaths, as particulate matter emissions rise with continued vehicular growth.

Globally, an estimated 24 percent of the disease burden (healthy life years lost) and an estimated 23 percent of all deaths (premature mortality) is attributable to environmental risks (WHO, 2006). The burden of disease is unequally shared, with the children and the poor being particularly affected. Among children age 0 to 14 , the proportion of deaths attributable to environmental risks -such as poor water and sanitation, indoor air pollution and vector-borne diseases -is estimated to be as high as 36 percent (WHO, 2006). In children, malnutrition and environmental infections are inextricably linked with malnutrition not only the result of lack of food intake, but more often a consequence of bad sanitation and repeated infections (World Bank et al. 2006). Very recent estimates which include the total health effects of environmental risks (including those effects mediated through malnutrition) highlight the even greater importance of environmental health interventions in child survival and development (WHO, 2007 and World Bank, 2008)

This section answers two fundamental sets of questions related to environment-related health problems in Honduras. The first set helps to demonstrate the significance of environment-related health problems: (a) How much disease and how many deaths are attributable to environmental risks? (b) Which groups bear the highest burden of disease? (c) What are the economic costs of the health impact of these environmental risks? The second set of questions refers the appropriate choice of interventions that the GOH can undertake to reduce these environmental risks to human health: (a) which interventions are the most cost-effective?

\section{Infrastructure and the Environment}

Improving access to infrastructure services has been one of the Governments' priorities in the recent past, and they have achieved considerable progress. National coverage reaches 90 percent of the population for water, 68 percent for sanitation, and 68 percent for electricity. Honduras has achieved similar progress in the road sector, particularly through improved maintenance. Infrastructure is especially needed in the countryside. There is growing evidence that infrastructure is one of the key determining factors for the economic growth of rural areas. ${ }^{5}$ In Honduras, however, infrastructure (like poverty) is

\footnotetext{
5 The Bank's Pro-Poor Growth Study (2005), analyzing the experiences of 14 countries in the past decade demonstrates that insufficient access for poorer households to infrastructure services (particularly
} 
unequally distributed between urban and rural areas. The lack of access to basic infrastructure services constrains the potential for economic and social development, and compounds the problem of isolation and poverty of the rural population in Honduras.

Section IV describes the colossal challenges facing Honduras in order to mitigate the environmental implications of the necessary infrastructure expansion. The existing policy instrument intended to meet these challenges - the Environmental Impact Assessment (EIA) - is already overburdened. The section recommends measures to improve the EIA, as well as to complement it with other policy instruments in order to address the environmental implications of infrastructure expansion in a more effective way. At the same time, it is essential to avoid unrealistic regulations that might hinder competitiveness and investment.

\section{Forestry}

To achieve growth and especially poverty reduction in Honduras, rural development is critical. Poverty is far more prevalent and severe in rural areas. Rural areas are home more than one-half of the population, but account for three-quarters of the poor. Because forestry is responsible for about one-tenth of aggregated value generated in the primary sector, the evolution of a sustainable and commercially viable forestry industry must be a key part of rural development. Honduras is heavily forested and predominantly mountainous. Arable land available for cultivation is limited. Together with a high concentration of land ownership and rapid population growth, this has led to increasing cultivation on marginal lands, as well as deforestation and soil erosion. It is estimated that about forty percent of the country's forest lands have been deforested. Further deforestation and degradation affect a large share of the remaining forests.

The reasons include changes in land use (e.g., conversion of forest for agricultural and livestock production), unmanaged exploitation for fuel wood and illegal logging, land tenure insecurity, and lack of production support and market access. In addition, the government forestry department (COHDEFOR) generates income from timber extraction sales, in clear conflict with its presumed role of forest management and environmental protection.

Section $\mathrm{V}$ analyzes the forestry sector, focusing on the institutional requirements to implement the new Forestry Law. This section also includes a discussion of potential interventions to improve governance, along with programs to promote the sustainable management of forest resources.

\section{Conclusions and Recommendations}

This section summarizes the main conclusion, and identifies specific policy recommendations to assist the Government of Honduras to strengthen its institutional capacity. The goal is to develop policies and cost-effective interventions that protect and restore an already deteriorated environment, while avoiding unrealistic and ineffective regulations that hinder competitiveness and impede economic growth.

electricity and roads) has constrained the ability of rural households to tap into country-wide higher growth rates, particularly in nonagricultural sectors. 
$\underline{\text { Annexes }}$

The annexes contain extended analyses of:

- Key environmental issues

- Institutional analysis

- Environmental impact assessment

- Health and the environment

- Forestry sector analysis

- The new forestry law report 


\section{Institutional Framework}

To face its environmental challenges, Honduras requires effective and efficient environmental policies and laws, and organizations to implement them. This chapter focuses on the existing institutional situation and analyzes the current key players within the institutional setting. It concludes with a synthesis of strengths and weaknesses in an effort to outline key avenues for action.

\section{Environmental Policies}

To support the country's sustainable development, the government approved the Honduran Environmental Policy in 2005. This policy was established with the goal "that the country shall have institutional leadership capable of governing and administering policies for the management of the environment and natural resources, in order to ensure and improve the quality of life of the people of Honduras, as well as future generations." Although this policy contains general objectives that provide an important dimension to the country's management of the environment, none rely on a solid analytical foundation or information system that would permit the country to identify its environmental priorities and orient the policy toward these priorities. The policy also does not define specific goals and targets, nor does it identify individual interventions or priority tasks. Thus, while the policy provides a guideline toward an environmentally responsible institutional approach, it lacks a framework from which the State could systematically undertake interventions to achieve its general objectives.

\section{Regulatory Framework}

The country's regulatory framework comprises a number of instruments that regulate environmental management. These instruments, by hierarchy, include (a) constitutional articles, (b) treaties and agreements, (c) general laws; (d) special laws, (e) legislative agreements or regulations, and (f) technical standards and resolutions. Management of the environment and natural resources is governed by over 19 constitutional articles, which among others, place restrictions on property use. They regulate production of food, chemical, pharmaceutical, and biological products; establish the State's responsibility to designate sites of natural beauty and historical significance and demarcate protected areas; establish the responsibility of the Armed Forces in conserving natural resources, recognize agrarian reform as an important part of development; establish the State's obligation to protect the interests of indigenous peoples; and declare the primary use of agricultural land for ensuring food supply. Honduras is a party to 49 environmental treaties, international conventions, and protocols (Table II.1). However, the country has limited capacity to implement or support the commitments arising from these conventions and treaties, in particular the assimilation of these obligations in a timely fashion into national legislation. As such, legal inconsistencies and conflicts among competing interest groups often arise. 
Table II.1. Environmental Treaties, Conventions, and Protocols

\begin{tabular}{|c|c|}
\hline $\begin{array}{l}\text { Item } \\
\text { Number }\end{array}$ & Name of Treaty, Convention, or Protocol \\
\hline 1 & $\begin{array}{l}\text { Convention establishing the Central American Commission on Environment and Development } \\
\text { (CCAD) }\end{array}$ \\
\hline 2 & Constituent Convention for Environmental Protection \\
\hline 3 & Central American Convention on Climate Change \\
\hline 4 & Tuxtla Gutierrez Convention II \\
\hline 5 & Vienna Convention for the Protection of the Ozone Layer \\
\hline 6 & Climate Change Framework Convention of the United Nations (UNFCCC) \\
\hline 7 & Convention Concerning Wetlands of International Importance \\
\hline 8 & Convention on Biological Diversity \\
\hline 9 & Convention on the International Trade of Species and Wild Fauna and Flora (CITES) \\
\hline 10 & Regional Convention on Climate Change \\
\hline 11 & United Nations Convention to Combat Desertification and Drought \\
\hline 12 & $\begin{array}{l}\text { Basel Convention on the Control of the Trans-border Movement of Hazardous Wastes and } \\
\text { Their Disposal }\end{array}$ \\
\hline 13 & London Convention on the Dumping of Wastes at Sea \\
\hline 14 & Stockholm Convention on Persistent Organic Pollutants \\
\hline 15 & $\begin{array}{l}\text { Convention for the Protection and Development of the Marine Environment in the Wider } \\
\text { Caribbean Region }\end{array}$ \\
\hline 16 & $\begin{array}{l}\text { Convention for the Preservation of the Biosphere regarding the Protection of Priority Central } \\
\text { American Wildlife Areas }\end{array}$ \\
\hline 17 & Convention for the Protection of the Cultural and Natural World \\
\hline 18 & Inter-American Convention for the Protection and Conservation of Sea Turtles \\
\hline 19 & International Convention for the Prevention of Pollution by Ships \\
\hline 20 & The Convention Establishing the Association of Caribbean States \\
\hline 21 & $\begin{array}{l}\text { Convention on the Prohibition of the Development, Production and Stockpiling of } \\
\text { Bacteriological Weapons (biological and toxic, and Regarding Their Destruction) }\end{array}$ \\
\hline 22 & Convention 169 on Indigenous and Tribal Peoples in Independent Countries \\
\hline 23 & $\begin{array}{l}\text { Regional Convention for the Management and Conservation of Natural Forest Ecosystems and } \\
\text { Forest Plantation Development (Central American Convention on Forests) }\end{array}$ \\
\hline 24 & Joint Central America/United States Declaration of Common Cause \\
\hline 25 & $\begin{array}{l}\text { The Trifinio Plan, the Treaty between the Republics of Guatemala, Honduras, and El Salvador } \\
\text { for a solution to Managing the Water Resources of the Upper Lempa }\end{array}$ \\
\hline 26 & The Declaration of Guadalajara \\
\hline 27 & The Declaration of Uruguay or The Presidential Reunion of Uruguay \\
\hline 28 & Joint Statement between the presidents of Honduras and Chile \\
\hline 29 & $\begin{array}{l}\text { Rome Declaration on the Relationship between the Rio Group and the European Economic } \\
\text { Community }\end{array}$ \\
\hline 30 & The International Convention on Tropical Timber \\
\hline
\end{tabular}




\begin{tabular}{|c|c|}
\hline 31 & $\begin{array}{l}\text { Funding Convention between the European Community and the Central American } \\
\text { Commission on Environment and Development (CCAD) }\end{array}$ \\
\hline 32 & $\begin{array}{l}\text { Lima Convention, signed by the Government of the Republic of Honduras and the Latin } \\
\text { American Energy Organization (OLADE) }\end{array}$ \\
\hline 33 & $\begin{array}{l}\text { Resolution of the Central American presidents in the context of the } 19^{\text {th }} \text { Summit, related to the } \\
\text { Mesoamerican Biological Corridor }\end{array}$ \\
\hline 34 & $\begin{array}{l}\text { Regional Project for the Establishment of a Program for the Consolidation of the } \\
\text { Mesoamerican Biological Corridor (MBC) }\end{array}$ \\
\hline 35 & World Conference on Sustainable Development (WSSD) Rio +10 \\
\hline 36 & World Renewable Energy Summit \\
\hline 37 & Constitutive Act of the Action Committee on the Protection of the Sea and Freshwater \\
\hline 38 & Convention on the Program for International Dolphin Conservation \\
\hline 39 & Regional Convention on the Trans-border Movement of Hazardous Wastes \\
\hline 40 & Central American Alliance for Sustainable Development (ALIDES) \\
\hline 41 & $\begin{array}{l}\text { Basic Convention supplementary to the Convention for Scientific and Technical Cooperation } \\
\text { between the Governments of Spain and Honduras on Nature Conservation, Forestry } \\
\text { Development and Derivative Industries }\end{array}$ \\
\hline 42 & $\begin{array}{l}\text { Convention for the Permanent Establishment of the Latin American Forestry Research and } \\
\text { Training Institute, under the auspice of the FAO }\end{array}$ \\
\hline 43 & The Montreal Protocol on Substances that Deplete the Ozone Layer \\
\hline 44 & Kyoto Protocol to the United Nations Convention on Climate Change \\
\hline 45 & Cartagena Protocol on Biosafety \\
\hline 46 & $\begin{array}{l}\text { Supplementary Protocol to the Inter-American Convention for the Protection and } \\
\text { Conservation of Sea Turtles }\end{array}$ \\
\hline 47 & $\begin{array}{l}\text { Protocol to the Convention Establishing the Central American Commission on Environment } \\
\text { and Development (CCAD) }\end{array}$ \\
\hline 48 & Protocol on Cooperation for Combating Oil Spills in the Wider Caribbean Region \\
\hline 49 & North American Free Trade Convention DR-CAFTA \\
\hline
\end{tabular}

Source: Unit of Management Planning and Evaluation (UPEG-SERNA).

The General Law on the Environment (Legislative Decree 104-93), the Law on Financial Balance and Welfare (2002), and the Law of Administrative Simplification (2002) form the backbone of the Honduran legal framework for the management of natural resources and the environment. In addition, the Municipalities Law (Decree 134-90) contains provisions related to environmental protection, income generation arising from the use of natural resources, and investment in protecting the municipal environment. Management of land, forestry, and water resources is governed by the country's Land Management Law, the Law of Protected Forest Areas and Wildlife (2007), and the Framework Law for Water and Sanitation (2003), respectively. However, other laws also contain provisions regarding water resource management, including the Law of Protected Forest Areas and Wildlife, the Framework Law for the Electricity Sub-Sector (1997), and the National Water Law (1927). This environmental legal framework, however, still has important gaps. For example, there is no specific legislation in force to manage air quality or biodiversity. In addition, although a number of regulations have been issued (Table II.2), 
the water sector still lacks regulations to govern its many uses (consumption, production, and so forth).

Table II.2. Binding Environmental Management Regulations

\begin{tabular}{|l|l|}
\hline Regulation Subject & \multicolumn{1}{c|}{ Current Regulatory Status } \\
\hline Control of chemicals and hazardous wastes & Not currently addressed \\
\hline Transport of chemicals, goods, and waste by the CA5 & Third (final) draft in review \\
\hline Control of atmospheric emissions by stationary sources & Preliminary draft in review (sponsored CIDA) \\
\hline Environmental audits & No existing regulation \\
\hline Registration of environmental service providers & Regulation in place \\
\hline System inquiry complaints & No existing regulation \\
\hline Regulatory downloads and reuse wastewater & Preliminary draft in review \\
\hline Solid waste & Regulation in place \\
\hline
\end{tabular}

Source: "General Structure for Regulatory Prioritization" (USAID/MIRA).

Other regulatory weaknesses include institutional and legal inconsistencies within the country's environmental regulatory framework. For example, under the Land Management Law, the Ministry of Justice is responsible for developing the country's National Land Management Plan. This same responsibility is designated to the Ministry of Natural Resources and Environment (SERNA) under the country's General Law on the Environment (Article 11, paragraph c). There has also been a lack of harmonization between existing environmental legislation and the ratification of new treaties and protocols.

In addition to the regulatory weaknesses noted - gaps, overlaps, and inconsistencies there is also a lack of environmental standards to ensure adequate environmental protection and oversight. Table II.3 provides a listing of the environmental standards currently in place. Given that these standards provide for the protection and oversight of only a few environmental areas, additional environmental standards are required, in particular, for wastewater discharges into water bodies and coastal areas, selection of solid waste disposal sites, hazardous waste management, housing development, air quality, fuel quality, mineral exploration, building in coastal areas, among others.

Table II.3 Environmental Standards

\begin{tabular}{|l|l|}
\hline $\begin{array}{l}\text { Technical Standards for Wastewater } \\
\text { Discharges into Sewerage Systems (Agreement } \\
\text { No. 058, 1996) }\end{array}$ & $\begin{array}{l}\text { Issued by the Ministry of Public Health. These standards } \\
\text { specify the maximum permissible limits of wastewater } \\
\text { that can be discharged into sewerage systems. }\end{array}$ \\
\hline $\begin{array}{l}\text { Technical-Administrative Standards for the } \\
\text { Management of Protected Areas and the } \\
\text { Management of Forest Wildlife (Resolution No. } \\
\text { 138-2, 1994) }\end{array}$ & $\begin{array}{l}\text { Issued by the Honduran Corporation of Forestry } \\
\text { Development. These standards specify authorization } \\
\text { procedures for the management of protected areas and } \\
\text { forest wildlife (e.g., zoos, development programs, } \\
\text { tourism, investigations, etc.) }\end{array}$ \\
\hline $\begin{array}{l}\text { Regulation for the Control of Gas and } \\
\text { Particulate Emissions from Mobile Sources } \\
(1997)\end{array}$ & $\begin{array}{l}\text { Issued by the Executive Branch. This regulation specifies } \\
\text { the maximum permissible levels of vehicle emissions. }\end{array}$ \\
\hline
\end{tabular}




\section{Environmental Policy Instruments}

The primary instrument for managing the environmental implications of projects and activities in Honduras is the Environmental Impact Assessment (EIA). As in many countries in Latin America, EIA is a process driven by the need for environmental approval and licensing. Under the General Law on the Environment (1993), an EIA is required for all projects and activities, regardless of their expected impacts. Subsequent regulations corresponding to the the National EIA System (1994) outline procedures for processing EIAs, citizen participation, and issuing an environmental license. However, given the regulation's ambiguity on the type of projects that require licenses, almost all economic activities require a license. The processing steps to obtain a license, outlined in the regulation, include (i) project proponent's request for an environmental license; (ii) project categorization and preparation of EIA terms of reference by SERNA's Office of Environmental Assessment and Control (DECA); (iii) project proponent's preparation of the EIA; (iv) DECA's evaluation of the EIA; (v) issuance of legal resolution by SERNA's Legal Services Unit and signature of compliance contract; and (vi) approval of environmental license by SERNA's General Secretariat.

Under the Law of Administrative Simplification (2002), SERNA was assigned the responsibility of defining the types of projects subject to EIAs as well as those projects, given their localized and predictable impacts that would instead require a diagnostic study, with a scope narrower than that of an EIA, prior to the issuance of an environmental permit. SERNA categorized three principal types of projects (Categories 1,2 , and 3) based on their expected environmental impacts. In addition, it classified those projects, which given their significant environmental impacts could not be executed under any circumstance, as Category 4 projects. Category 1 projects are those likely to have minimal or no adverse environmental impacts, and expected to improve the socioeconomic and environmental wellbeing of the community. Since these projects can be implemented without mitigation measures, project proponents are required to simply register their project with SERNA in the event any environmental control measure is required at a future time. Category 2 projects are likely to have moderate, but predictable environmental impacts that can be mitigated via standard measures. For these projects, proponents should present a qualitative environmental diagnostic that identifies the project's location and characteristics (Figure II.1). Category 3 projects are those projects likely to have significant adverse environmental impacts and therefore, require an EIA and environmental license in accordance with the steps established under the regulations for the National EIA system (Figure II.2). Since the legal reform of 2002, environmental licenses have been issued with a two-year validity. At the end of two years, project proponents are required to reapply for a license.

Table II.4 and Figure II.3 illustrate the growing demand for environmental licenses. However, SERNA lacks the administrative and human resources to respond to growing license requests in a timely manner, resulting in high costs and bottlenecks that restrict both public and private investment (Table II.4). Further, given that SERNA lacks the resources to monitor the implementation of environmental management plans to mitigate 


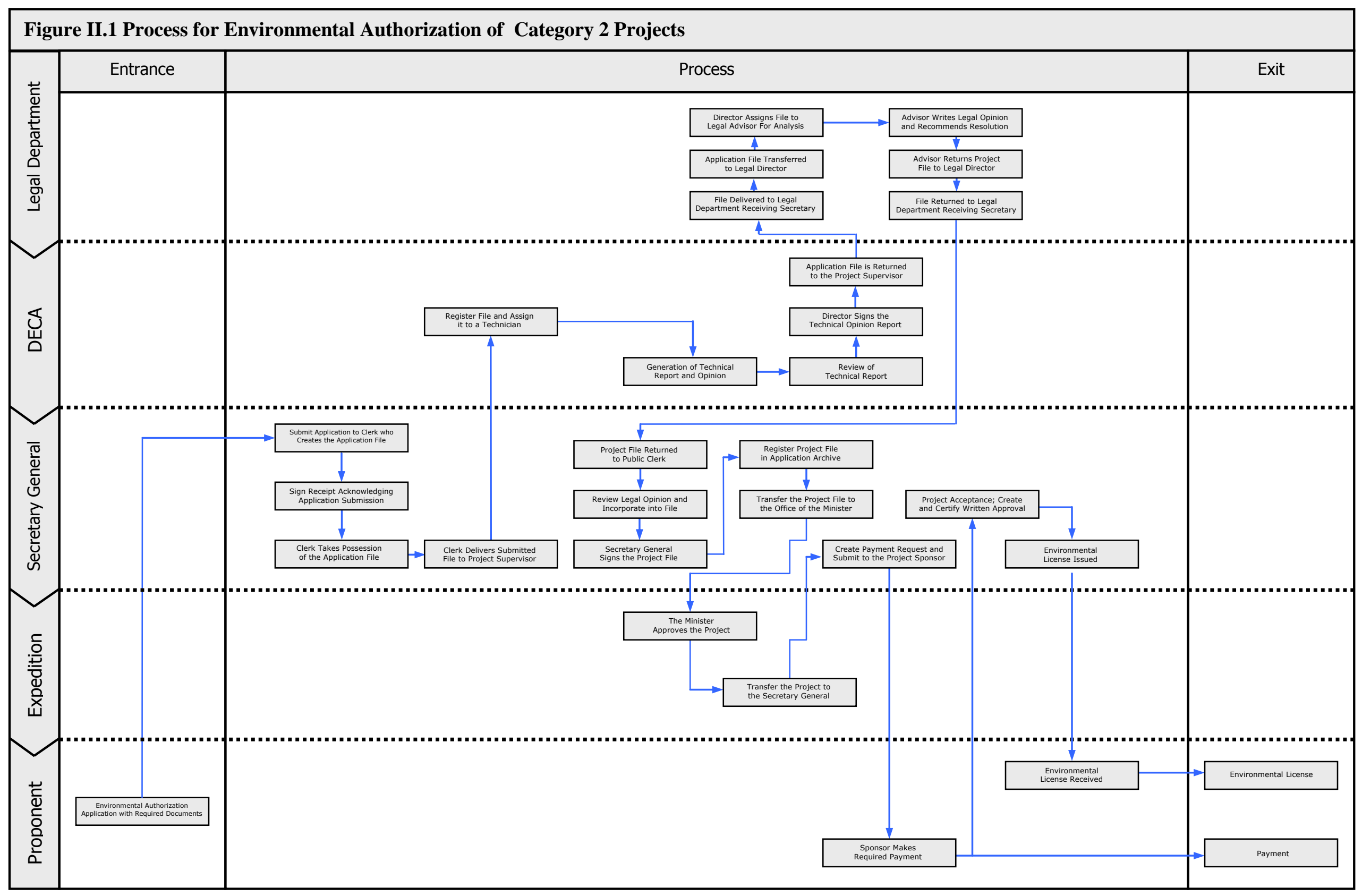




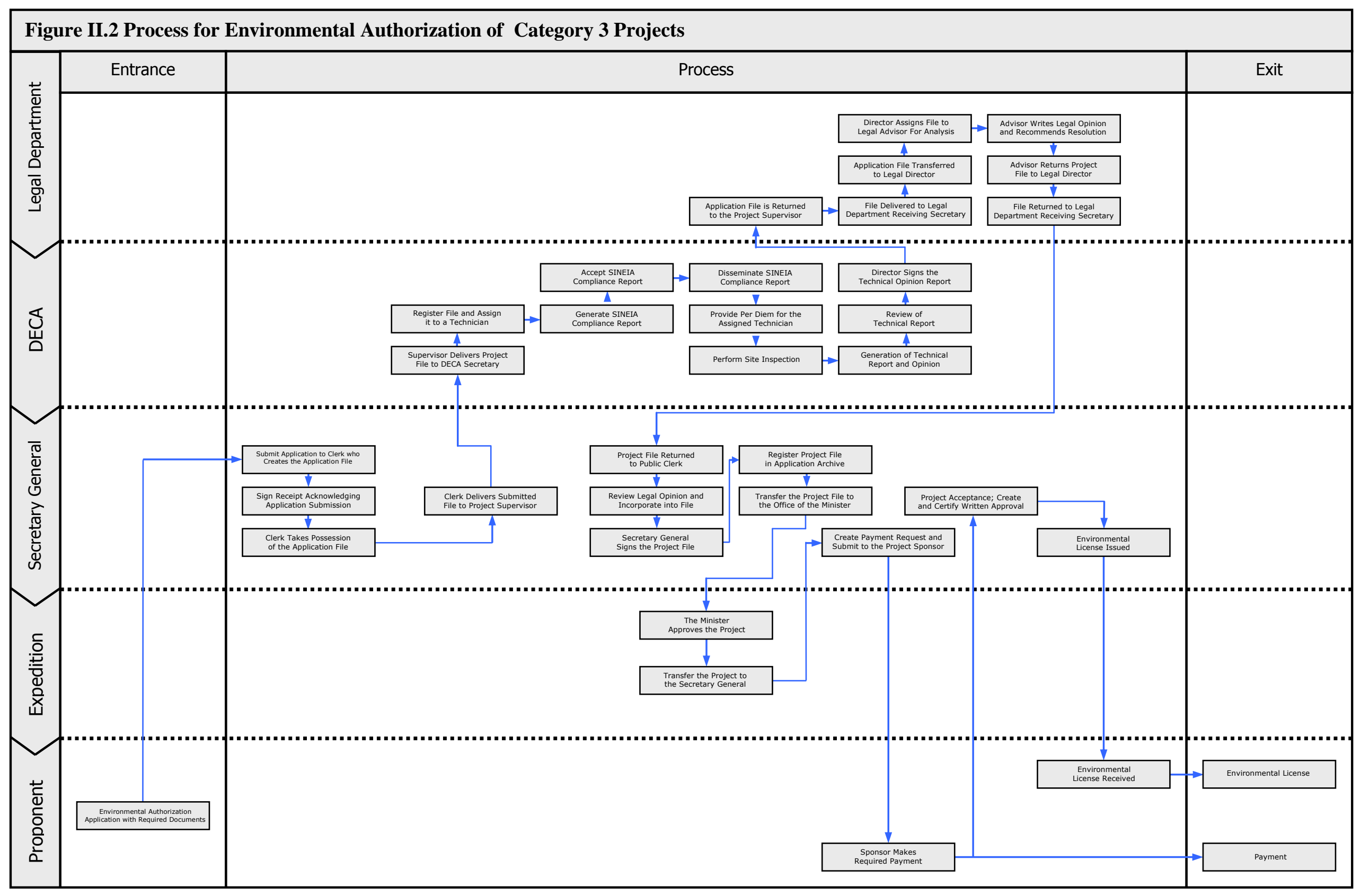


and manage environmental impacts, the effectiveness of the EIA instrument cannot be ensured.

Table II.4. New Licensing Applications by Year

\begin{tabular}{|c|c|c|}
\hline Year & License Applications & $\begin{array}{c}\text { Percentage Increase from } \\
\text { Previous Year }\end{array}$ \\
\hline 2002 & 349 & $57 \%$ \\
\hline 2003 & 548 & $12 \%$ \\
\hline 2004 & 616 & $20 \%$ \\
\hline 2005 & 742 & $16 \%$ \\
\hline 2006 & 863 & Capacity \\
\hline
\end{tabular}

Source: Analysis of the Demand for Services and Installed Capacity (UICN-SERNA 2007).

Figure II.3. Projected Demand for New Licensing Applications by Year

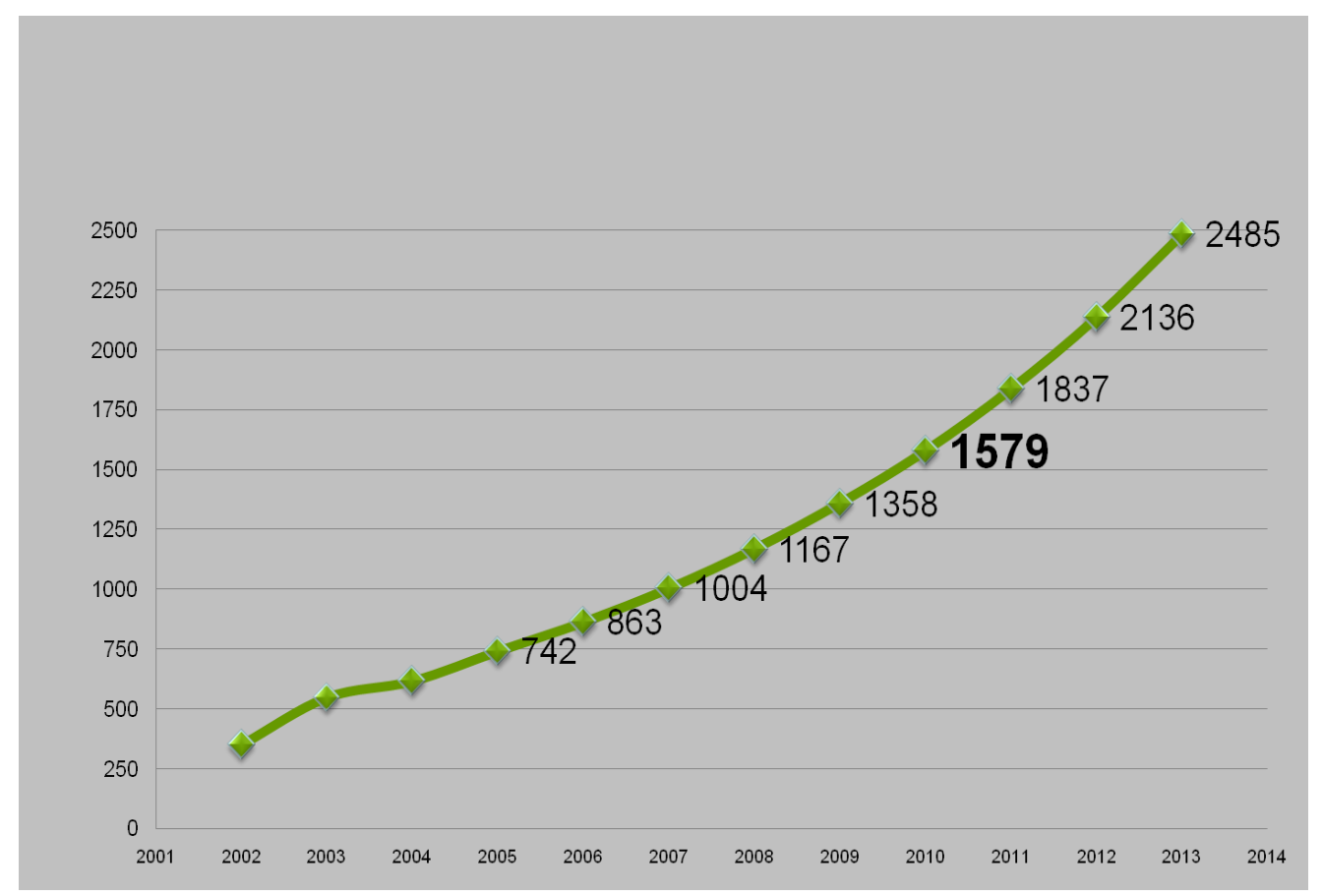

Source: Modernization Directorate, SERNA.

In the past few years, SERNA has made a significant effort to reduce the high backlog of environmental license requests, by introducing procedural improvements and hiring additional staff. For example, the present administration received a backlog of 800 license requests, which it has managed to reduce to approximately 500. In light of SERNA's budgetary constraints, however, these efforts have not been sustainable. Improving the efficiency and effectiveness of the environmental licensing process will require a new approach to environmental management. Two key characteristics of this approach should be (a) the delegation of some of SERNA's functions-including licensing of minor projects - to municipalities and ministerial environmental units (under the guidance and supervision of SERNA), and (b) using additional policy instruments. 
Although the regulatory environmental framework provides for other regulatory instruments, these are seldom exploited in Honduras (Table II.5). Of these, the administration of Natural Protected Areas has been most used in the country. Currently, there are 107 protected areas representing approximately 27 percent of the country's territory. To support the creation of additional regulatory instruments, both the Honduran Normalization Agency (OHN) and the Honduran Accreditation Agency (OHA) were recently created. Both agencies have clear mandates, but will require institutional support for these goals to be realized.

Table II.5. Applications for Services Managed by SERNA

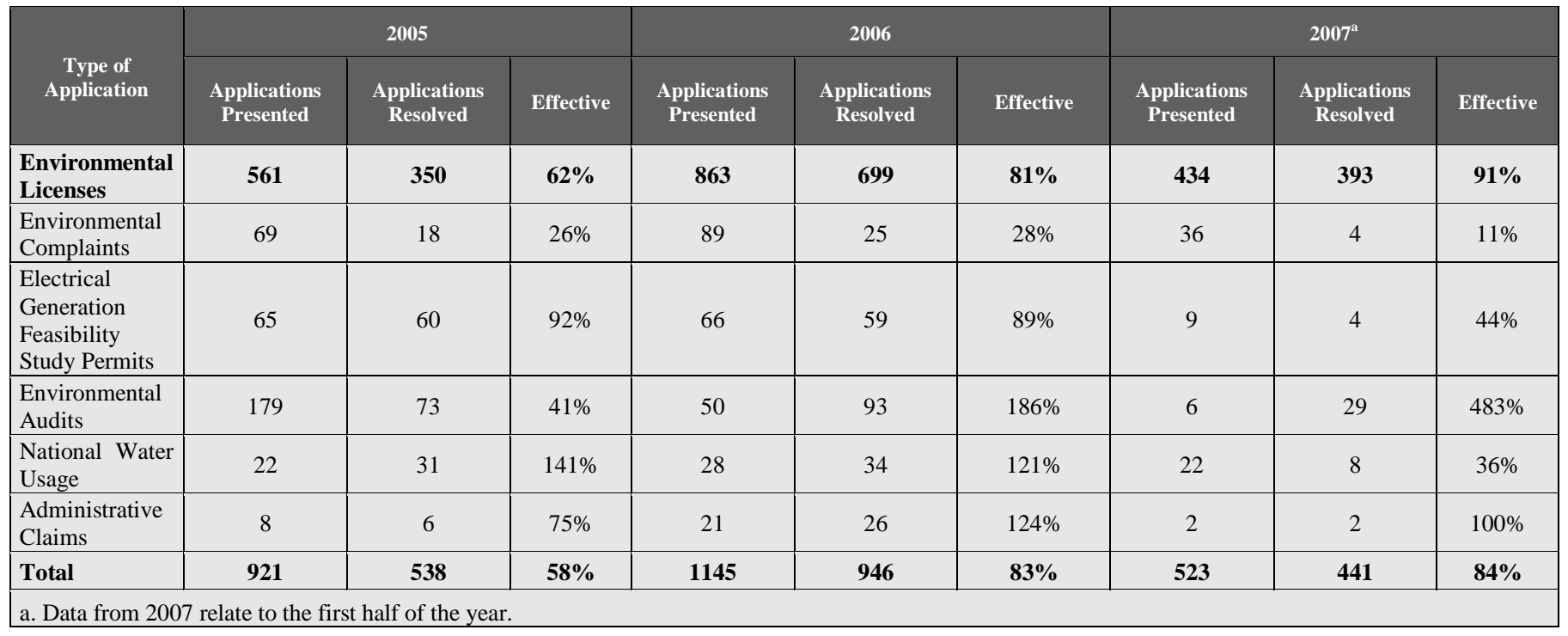

\section{Information}

The General Law on the Environment (Article 11, paragraph f) gives SERNA the responsibility to "develop and coordinate a national system of environmental information." In 1999 and 2000, SERNA began to develop an information system (SINIA). However, more recently, government priorities have shifted, and attention has been placed on information tools defined under the Land Management Law and Property Law, the National Information Planning System (SINIT), and the National Property Administration System (SINAP). Given SINIT's rapid development and the fact that many of its services overlap with SINIA, the development of SINIA has lagged.

Despite SINIA's limited advances, SERNA has adjusted the design of SINIA in response to standards agreed upon by Central American countries for the development of an Environmental Information System (SIAM), and in 2007 developed baselines of environmental indicators (Table II.6).

Although this baseline is comprehensive, it has significant information gaps, such as on particulate matter emissions from mobile and fixed sources, hazardous wastes, and the health impacts of pollution. Both the richness of natural resources and the severity of 
environmental degradation in Honduras make a strong argument for the role of environmental resources in reducing poverty, fighting hunger, and lowering child mortality. Policymakers who set environmental standards need to be aware of the likely consequences of environmental degradation on the economy, while economic policymakers must consider the environmental implications of current and projected patterns of consumption and production. Finally, while SINIA has focused on gathering basic information on environmental licensing processes and a selection of environmental indicators, this information should be extended and used to support environmental planning, prioritizing, decisionmaking, communication, and awareness-raising processes.

Table II.6. Structure of Environmental Indicators

\begin{tabular}{|c|c|c|}
\hline Area & \multicolumn{2}{|c|}{ Indicators } \\
\hline \multirow{18}{*}{ Water } & \multicolumn{2}{|l|}{ Water level } \\
\hline & \multicolumn{2}{|l|}{ Basins under management } \\
\hline & \multicolumn{2}{|l|}{ Water use by activity } \\
\hline & \multirow{7}{*}{ Continental Water Quality } & $\mathrm{PH}$ \\
\hline & & Total nitrogen \\
\hline & & Total phosphorus \\
\hline & & Biochemical oxygen demand \\
\hline & & Dissolved oxygen \\
\hline & & Solid in suspension \\
\hline & & Fecal coliform levels \\
\hline & \multicolumn{2}{|l|}{ Continental water critical index } \\
\hline & \multicolumn{2}{|c|}{ Percentage of variation in the demand for water contracts } \\
\hline & \multicolumn{2}{|c|}{ Average monthly demand for water contracts } \\
\hline & \multicolumn{2}{|c|}{ Variation of permits for feasibility studies processed } \\
\hline & \multicolumn{2}{|c|}{ Average of permits for feasibility studies processed } \\
\hline & \multirow{3}{*}{ Volume of treated wastewater } & Chemical demand for oxygen \\
\hline & & Total dissolved solids \\
\hline & & Fecal coliform levels \\
\hline \multirow{2}{*}{ Air } & \multicolumn{2}{|l|}{$\mathrm{CO}_{2}$ emissions from mobile sources } \\
\hline & \multicolumn{2}{|l|}{$\mathrm{SO}_{2}$ emissions from mobile sources } \\
\hline \multirow{2}{*}{ Domestic Waste } & \multicolumn{2}{|c|}{ Estimated domestic solid waste generation } \\
\hline & \multicolumn{2}{|c|}{ Final disposal of registered domestic solid waste } \\
\hline \multirow{4}{*}{ Energy Balance } & \multicolumn{2}{|c|}{ Generation of energy from renewable sources } \\
\hline & \multicolumn{2}{|l|}{ Fuel consumption by sector } \\
\hline & \multicolumn{2}{|l|}{ National energy balance } \\
\hline & \multicolumn{2}{|l|}{ Energy efficiency : Energy Intensity } \\
\hline \multirow{2}{*}{ Land and Soil } & \multicolumn{2}{|l|}{ Agricultural coverage } \\
\hline & \multicolumn{2}{|l|}{ Percentage of forested arable land } \\
\hline \multirow{3}{*}{ Political Settlements } & \multicolumn{2}{|c|}{ Percentage of municipalities with municipal environmental plans } \\
\hline & \multicolumn{2}{|c|}{ Percentage of municipalities with municipal land use plans } \\
\hline & Percentage of environmental impact a & its that include risk analyses \\
\hline Protected A reas & Surface area protected in order to mai & logical diversity \\
\hline 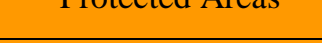 & Annual variation of protected surface & \\
\hline & Average processing of environmental & \\
\hline L icensing & Percentage variation in the processing & onmental permits \\
\hline Lictising & Average demand for environmental p & \\
\hline & Percentage variation in demand for en & ntal permits \\
\hline
\end{tabular}




\section{Public Participation}

Improving institutions is not only about improving policies, legal frameworks, and public agencies, but is also about building citizen engagement and voice. Voice and accountability are powerful tools for sustainable development. The Honduran Government has taken important steps to promote civic engagement in developing and monitoring public policies, particularly with respect to public investment. This public participation is regulated within the scope of the country's environmental legal framework, in which the General Law on Environment states "community involvement is essential to ensure the protection, conservation, and rational use of the natural wealth of the country and of the environment in general."

Regulations corresponding to the National Environmental Impact Assessment System (SINEIA) require that the public be notified of each Environmental Impact Assessment (EIA) process at its initial stages. This information should be publicized in national newspapers and through radio advertisements broadcast over both a national network and locally in the municipality where a project is planned. The SINEIA regulations also require that the EIA is available for public review and that the project proponent present the results of the EIA at workshops and/or town meetings.

Despite these achievements, the SINEA regulations do not provide mechanisms for public opposition to a proposed project, nor do they stipulate how public comments are taken into account before an environmental management plan is approved and an environmental license is granted. This regulatory gap has led to growing conflicts that stem from disagreements between project proponents and affected communities, most notably related to mining, forestry, infrastructure, and renewable energy projects.

Further, participatory mechanisms that would ensure the representation of those segments of the population affected by the adoption of an environmental law or regulation are lacking. For example, in practice SERNA only requires that project proponents publicize the initiation of an EIA in a single national newspaper. Further, although any citizen or group can request a meeting to learn more about a project, this public consultation process is rarely utilized. To date, SERNA has received very few requests for public meetings.

Recognizing the growing importance of the environment among the country's citizens, SERNA has also developed a Communications and Environmental Education Strategy. This strategy, however, has not reached its full implementation. In addition, environmental management in the private sector has begun to be perceived as an issue directly linked to competitiveness and opportunities for growth in the short and medium term, particularly under the framework of recent trade agreements ratified during the past two years. 


\section{Compliance}

Honduran legislation authorizes both SERNA's Office of Environmental Assessment and Control (DECA) and municipalities to develop instruments for the supervision and oversight of environmental projects and activities. However, SERNA has a staff of only 6 , located in Tegucigalpa, to provide oversight to the entire country, and is completely unable to respond to the requests for supervision and oversight services that it receives. Further, there are no standardized criteria for evaluating compliance, which means that compliance is judged at the discretion of responsible authorities, and there is little coordination among authorities legally responsible for addressing complaints and investigations of environmental crimes. In the absence of direct interventions aimed at ensuring compliance with environmental commitments, there is a risk of distorting the environmental licensing process. Moreover, lack of compliance will prevent effective environmental management.

The General Law on the Environment (Chapter II, article 16) establishes the Environmental Attorney General's Office to represent administrative and judicial interests of the State in environmental matters. The Environmental Attorney General is appointed by Congress and serves for five years. Moreover, the Attorney General relies on the Environmental Prosecutor's Office to conduct investigations of environmental crimes (Table II.7). There is evidence, however, of overlaps between the responsibilities delegated to both offices. This has been resolved through an agreement in which the Environmental Attorney General's Office assumes responsibility for the investigation of environmental crimes and the Environmental Prosecutor's Office assumes responsibility for working with prosecutors in the exercise of judicial actions that best represent the interests of the State.

\section{Table II.7. Institutional Responsibilities of the Environmental Attorney General's Office and Environmental Prosecutor's Office}

Environmental Attorney General

The Law of the Environment establishes the Environmental Attorney General, a subordinate of the Attorney General, who has the responsibility to represent the State's administrative and judicial interests in environmental matters.

All civil and criminal actions for environmental matters will be prosecuted directly by the Environment Counsel's office.
Environmental Prosecutor

Exercises all powers relating to the defense of the ecosystem, the environment, consumer and ethnic groups, national assets, and items of national heritage including archaeological, cultural, and other places of social and public interest. Acts on cases brought directly by the Attorney General, through administrative units, or through the actions of special officials designated for that role.

The Environmental Prosecutor's Office will work with prosecutors in the exercise of judicial actions to achieve the necessary unity of action and proper coordination to safeguard the interests of society.

The Environmental Prosecutor has the powers of an Executor General in the manner set forth in article 19 of the first rule of the Organic Law of the Attorney General to fulfill its duties at the national level with the mandatory assistance of the prosecutors of all courts and tribunals. All units of the State and individuals are obliged to comply with the requirements for the performance of their duties received from the Office. 
The Environmental Attorney General's Office relies on a staff of 30 professionals (25 with technical expertise and 5 administrative) that are divided into three regional offices in Tegucigalpa, San Pedro Sula, and La Paz. The Environmental Prosecutor's Office relies on nine regional offices located in Tegucigalpa, San Pedro Sula, La Ceiba, Santa Bárbara, Juticalpa, Catacamas, Choluteca, Comayagua, and the Bahía Islands. Each regional office has a staff of four officials (lawyers and technical specialists), with the exception of the Tegucigalpa office, which has a staff of 32.

In accordance with the General Law on the Environment (Article 128), any citizen may issue a complaint to the competent authority regarding any act or omission that constitutes a crime or administrative violation. In 2006, 89 claims were made. Legal action is being taken for 18 of these claims, but no decision has yet been made regarding these violations. Figure II.4 shows the number of citizen complaints made to date and also projects the trend in future complaints.

Figure II.4. Actual and Projected Citizen Complaints (2001-15)

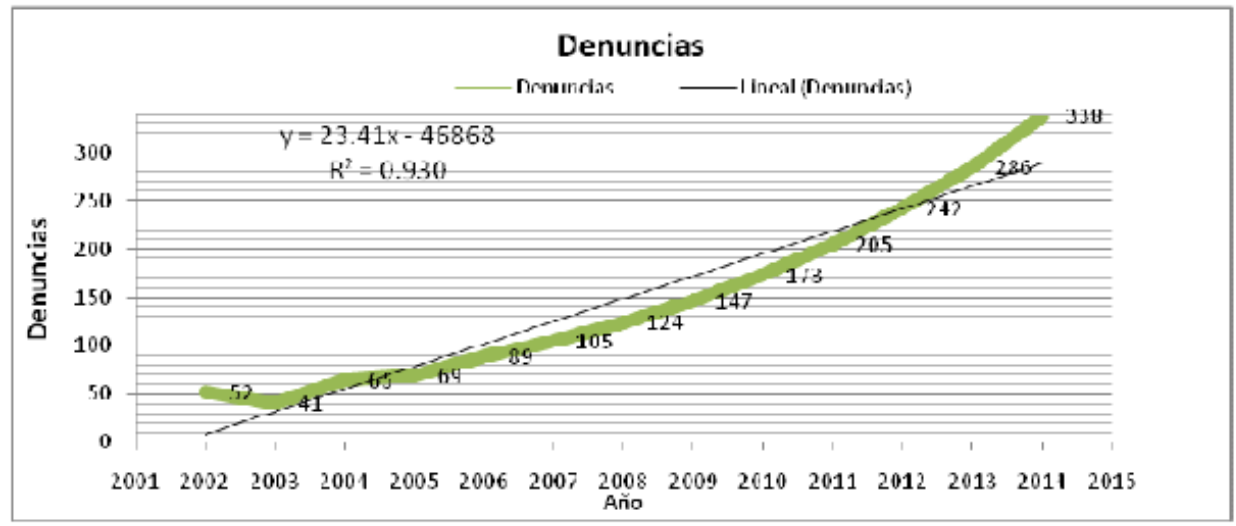

Source: Analysis of the Demand for Services and Installed Capacity (SERNA 2007).

Although one of the principles of the country's environmental policy is a preference for inducing environmentally sound behavior over sanctioning, the "crime and punishment" approach is the dominant component of the strategy of environmental compliance and enforcement in Honduras. The emphasis on administrative sanctions and criminal penalties makes it difficult to develop mechanisms (like notices of violations, warnings, and compliance agreements) to encourage a higher rate of compliance. International experience has shown that promotion should be an essential component of the compliance and enforcement strategy. These actions, when combined with credible sanctions and a track record of enforcement, may be more effective in fostering compliance than relying solely on deterrence.

\section{Organizational Analysis}

The principal organizations within the environmental sector that also have a regulatory role include the Ministry of Natural Resources and Environment (SERNA), the Ministry of Agriculture and Livestock, the Ministry of Public Health, the Ministry of Education, 
the Ministry of Tourism, the Ministry of Industry and Trade, the Honduran Forest Development Corporation, and the Honduran Institute of Tourism, the Honduran Coffee Institute, and the National Vocational Training Institute (INFOP).

\section{Ministry of Natural Resources and Environment (SERNA)}

SERNA's Functions: SERNA was created by Decree No. 218-1996 of 17 December 1996, which reformed the General Law of Public Administration in an effort to address the country's challenges within a global context and make public administration more efficient. Under this reform, approved by Congress under Decree No. 52-1997, the Ministry of Environment became the Ministry of Natural Resources and Environment.

Under Article 28 of Decree No. 218-96, SERNA is responsible for "the development, coordination, implementation, and evaluation of policies regarding the protection and use of water resources, new and renewable sources of energy, the generation and transmission of hydroelectric energy, mining activities, and the exploration and exploitation of hydrocarbons; the coordination and assessment of policies related to the environment, ecosystems, the national system of protected areas and national parks, and the protection of flora and fauna, as well as services supporting the investigation and control of pollution in all its forms." Although SERNA's mandated functions are oriented toward the formulation of policies, SERNA's actions in practice have been centered on the review and processing of Environmental Impact Assessments (EIAs).

The fact that environmental issues cut across many sectors adds an additional challenge to the Ministry, given that policy implementation requires a high degree of coordination among these sectors. Mechanisms are therefore needed that foster creation of a working team at the highest level that includes representation from all these sectors.

Functioning of the Ministry: Of SERNA's 586 staff, only 42 are dedicated to the evaluation of EIAs, and they are unable to meet the current demand for EIA reviews. The majority of this staff is located in the Environmental Assessment and Control Office, which is also responsible for attending to environmental complaints and processing environmental audits, among other functions (Table 11.5). This office of only 27 staff is responsible for approximately $85 \%$ of the total requests that SERNA receives. Further, of SERNA's total personnel, only 45 percent are permanent staff (Table II.8 and Figure II.5). Box II.1 provides additional details on the challenges to public service employment in Honduras. 
Table II.8. SERNA's Personnel, by Department

\begin{tabular}{|l|c|}
\hline Department & Number of Staff \\
\hline Coordination and Oversight & 11 \\
\hline General Secretary & 19 \\
\hline Environmental Management & 25 \\
\hline Environmental Assessment and Control & 27 \\
\hline Biodiversity Conservation & 49 \\
\hline Pollution Control and Study Center & 45 \\
\hline Energy & 32 \\
\hline Water Resources & 35 \\
\hline Climate Change & 1 \\
\hline International Cooperation & 4 \\
\hline Legal Services & 11 \\
\hline Administration & 119 \\
\hline Management Planning and Assessment & 10 \\
\hline Modernization & 3 \\
\hline National Environmental Information System & 7 \\
\hline Commerce and Environment & 1 \\
\hline Gender & 1 \\
\hline Transparency & 0 \\
\hline Audit & 8 \\
\hline Employees in Regional Offices (San Pedro \\
Sula, Comayagua, Ceiba, and Choluteca) & 178 \\
\hline \multicolumn{2}{|c|}{ Total } \\
\hline
\end{tabular}

Figure II.5. Organization of the Ministry of Natural Resources and Environment (SERNA)

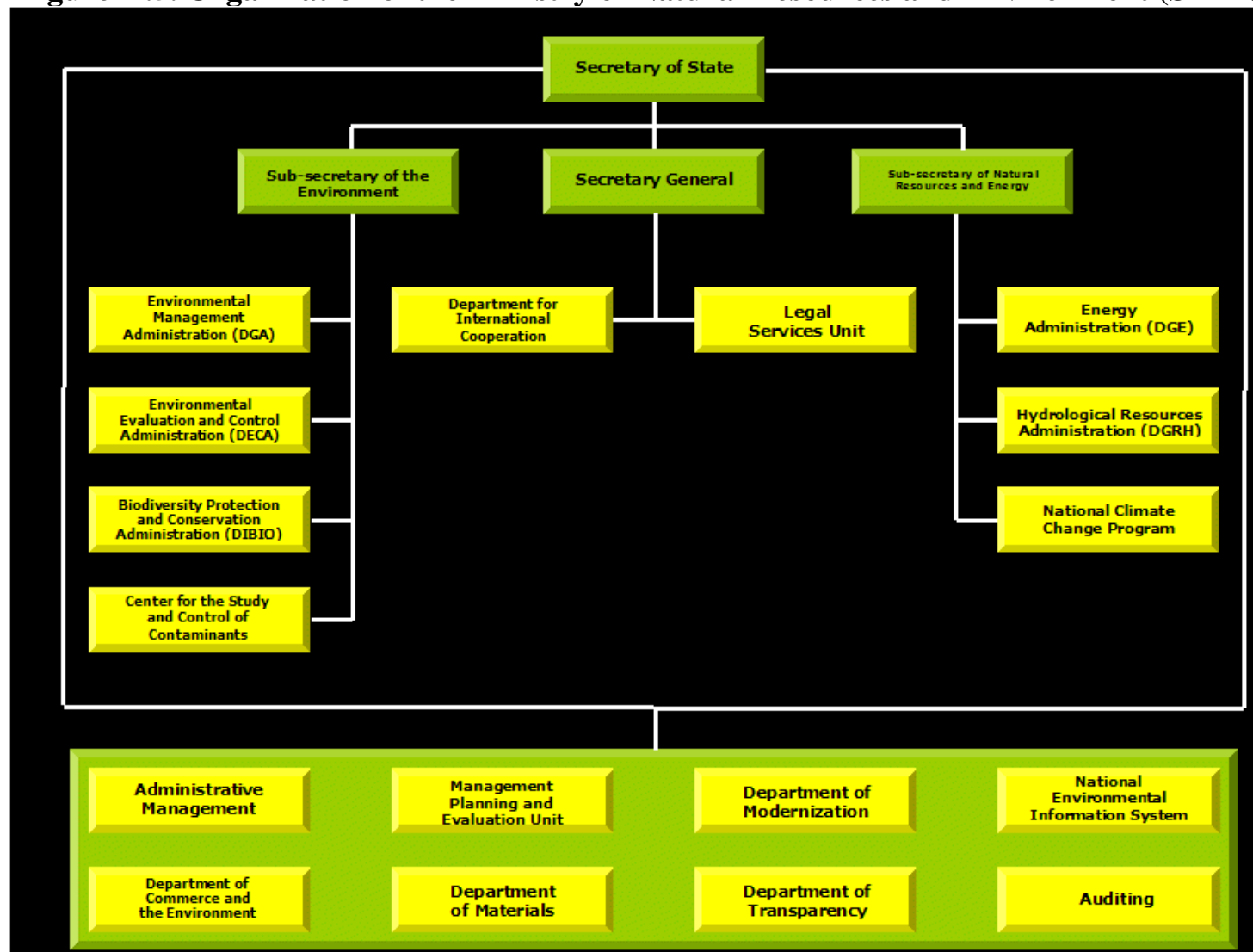




\section{Box II.1. Civil Service Reform}

While, the overall size of public sector employment in Honduras is not excessive compared to other Central American countries, there are serious staff imbalances across sectors. The consequence has been that many entities are clearly overstaffed in certain unneeded functions, and understaffed in other areas that limit the capacity to deliver adequate services (World Bank 2004). While civil service reform is a key aspect of the public sector reform process, from an environmental perspective it is important to ensure it is used to create a credible and competent cadre of environmental professionals. This would mean not only strengthening environment and natural resource-related agencies, but also building technical capacity within various ministries to understand the environmental problems faced by various sectors and to determine appropriate conditions for their operations.

Allocation of Financial and Human Resources: SERNA is one of the smallest ministries in Honduras, receiving only 1.4 percent of the central budgetary allocations (Figure II.6). However, of this budgetary allocation, 89.5 percent is allocated and transferred to other institutions, primarily the National Electricity Company. ${ }^{6}$ Thus, SERNA receives only 10.5 percent of the 1.4 percent budgetary allocation for its own operation. In addition, SERNA's budgetary allocations have been relatively constant over the past four years, increasing only 14 percent from 2004 to 2007 (Figure II.7).

SERNA's budget for issuing environmental licenses is $6,873,831.00$ lempira (L) and the cost of an environmental license is $22,137.50 \mathrm{~L}$. This budget can accommodate only 310 applications per year (equivalent to 30 percent of the yearly license applications). These budgetary constraints, coupled with human resource limitations, have lead to an unmet demand of 50 percent of requested environmental permits, 23 percent of requested feasibility studies, and 100 percent of requested compliance certifications. According to DECA's internal procedures, Category 2 projects should be processed in 5 to 6 weeks and EIAs for Category 3 projects should be reviewed within 30 days. However, given its resource limitations, SERNA is unable to comply with these procedures.

\footnotetext{
${ }^{6}$ Ninety-six percent of the transfers are earmarked toward the National Electricity Company.
} 
Figure II.6. Budgetary Allocations of Ministries of Natural Resources and Environment, Education, Health, and Infrastructure

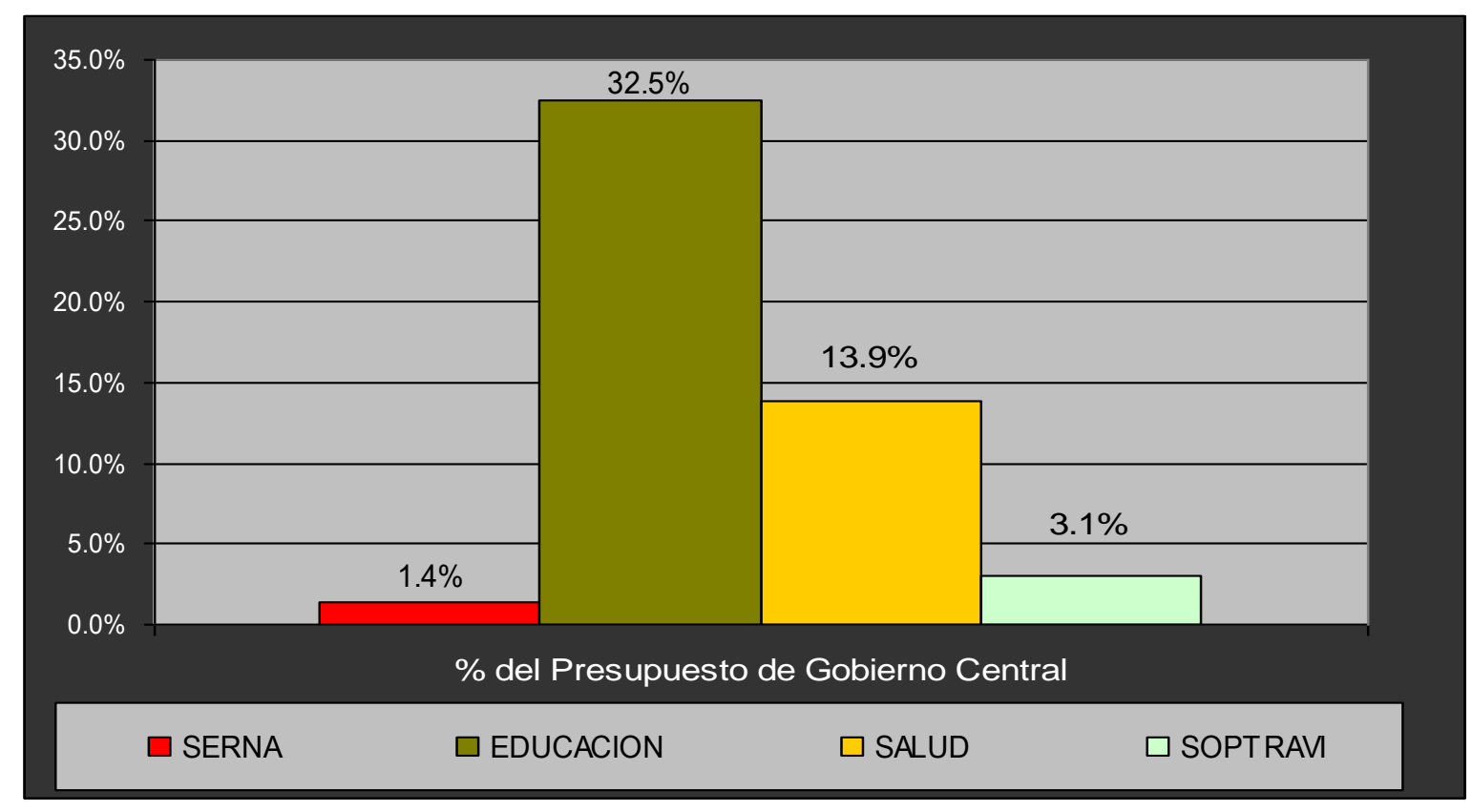

Figure II.7. Ministry of Natural Resources and Environment Budgetary Allocation (2004-07)

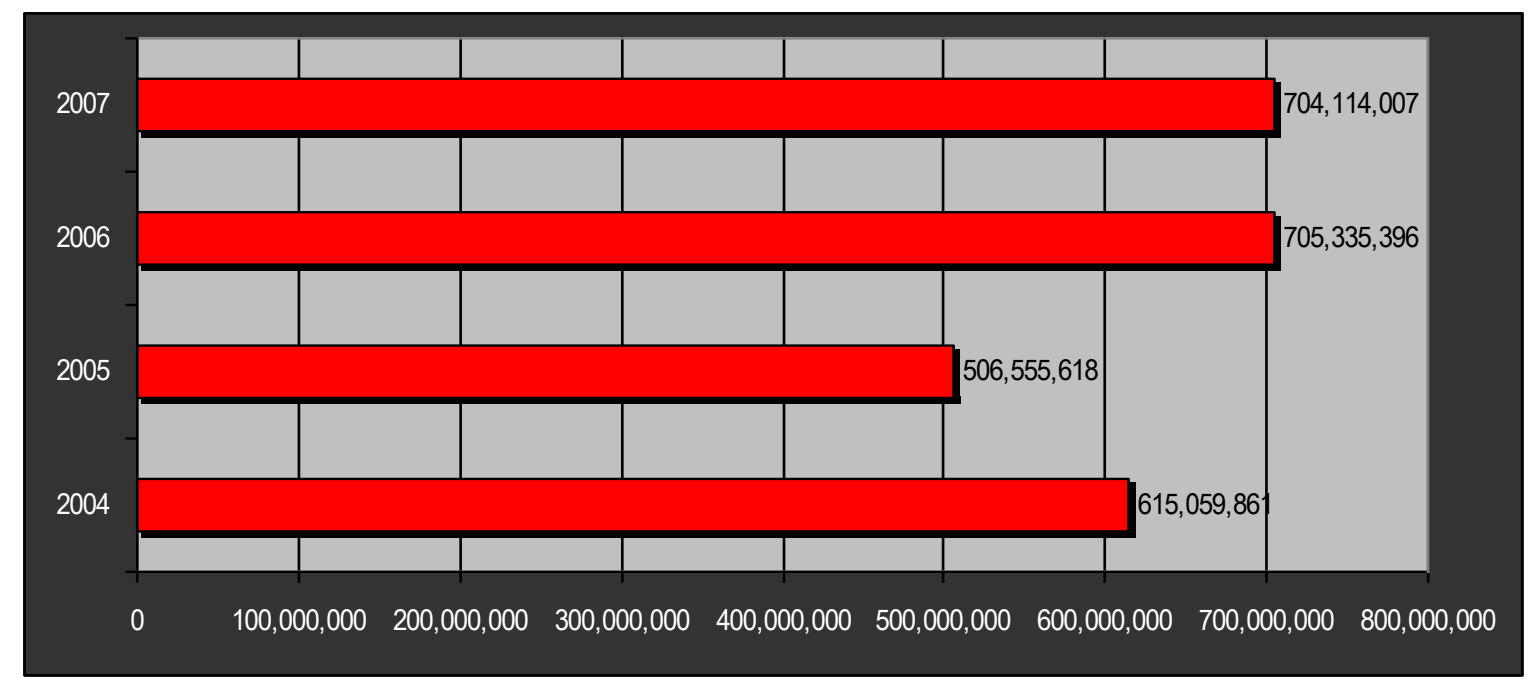

SERNA's Coordination with Other Public Organizations: An opportunity for improved decisionmaking. Given that the environment cuts across economic sectors and several institutions with environmental functions, cross-sectoral coordination that supports an improved decisionmaking process is essential. Cross-sectoral coordination bodies can help align the operations of different agencies. Article 10 of the Environment Law provides for the operation of a National Advisory Council for the Environment 
(COCONA), as an advisory body to the Secretary of SERNA. The Council is presided over by SERNA's Under-Secretary and includes (a) the Under-Secretary of Planning, Coordination, and Budget, (b) the Under-Secretary of Natural Resources, (c) the UnderSecretary of Public Education, (d) a representative from the Association of Municipalities, (e) a representative from the Institution of Higher Education, (f) a representative from the Federation of Non-governmental Environmental Organizations, (g) a representative from the Private Business Council, (h) a representative from workers' associations, and (i) a representative from farmers' associations. Although the COCONA has been legally formed, it has held only one meeting. This Council should be activated in order to improve cross-sectoral coordination among the different government agencies with environmental responsibilities and to strengthen decisionmaking.

Article 14 of the Environment Law creates the Technical Advisory Committee (the technical and scientific expertise comprising representatives from public and private sectors). However, the Committee has not been convened since the adoption of the law in 1993.

An opportunity to improve the effectiveness and efficiency of environmental management. The General Law on the Environment creates legal spaces to develop decentralization processes and transfer environmental responsibilities from the national to the local level. Despite this opportunity to improve the effectiveness and efficiency of environmental management, progress is only now being made. However, given the fact that the demand for services (for example, environmental permits, authorizations for feasibility studies for renewable energy projects, applications for the use of national waters, and monitoring and oversight) is greatest in only a few regions of the country, there is an opportunity to develop a focused and progressive decentralization process that initially targets specific municipalities. Many of the municipalities in these regions have a strong installed capacity (for example, Tegucigalpa, San Pedro Sula, Puerto Cortes, Choloma, Tela, La Ceiba, Tocoa, Juticapla, Choluteca, and Santa Rosa de Copan). This decentralization process, however, must be accompanied by technical support to strengthen SERNA's regulatory role, and to train and certify municipalities.

\section{Institutional and Organizational Strengths and Weaknesses}

Honduras faces tremendous challenges in terms of development, economic growth, and social development. Many of these challenges are directly related to the nation's capacity to find rational and sustainable ways to exploit the country's natural resources. As such, it is important to recognize the key strengths and weaknesses of environmental management in Honduras.

The country's strengths in meeting these challenges include:

- The country has an environmental policy that, despite its limitations, provides principles, policy guidelines, and instruments that define a vision for the country regarding its natural resources and the environment. 
- A General Law on the Environment, which has been adjusted over time in a process of modernization and is continuously improving.

- The country has modern environmental legislation in terms of land use (Law of Land Management, 2003), water (Water Act (under discussion), Framework Act for the Water and Sanitation Sector, 2003), development, and forest conservation (Forestry Act for Protected Areas and Wildlife 2007).

- Legislation has created Honduran policy instruments that are essential for the management of the environment: The National Environmental Information System (SINIA) and the National System of Evaluation of Environmental Impact.

- The State has demonstrated a commitment to citizen participation, having initiated important processes including decentralizing resource allocations for the implementation of the Poverty Reduction Strategy (PRS).

- Solid experience in the field of environmental licensing.

- A private sector that is aware of the relationship between sound environmental practices and market competitiveness.

- Well-organized environmental nongovernmental organizations.

- A strong government commitment to comply with trade agreements, and thereby a mandate to implement environmental commitments included under their framework.

- A suitable institutional framework in terms of design.

In contrast, the following are the greatest weaknesses:

- A legal framework with apparent inconsistencies in terms of internal legislation and correlation with international treaties and conventions ratified by the State.

- Gaps in terms of formalizing Environmental Technical Regulations and Standards to promote conservation and environmental protection, especially those associated with air quality and biodiversity.

- An undeveloped National Environmental Information System (SINIA), which lacks financial resources and a comprehensive action plan for the short and medium term.

- Despite the spaces provided for citizen participation, there are no regulations that specify particular forms of participation or conflict resolution mechanisms.

- A preventive environmental management system based almost exclusively on the use of the Environmental Impact Assessments as a regulatory tool.

- Significant financial gaps between the demand for services provided by SERNA and the allocation of budgetary resources assigned by the State.

- A nascent decentralization process that is restricted by legal provisions (SINEIA regulation).

- Inability to provide environmental oversight of Category 2 and 3 projects and ensure compliance with agreed mitigation measures, given SERNA's limited resources.

- A system that attends to environmental complaints, investigations, and trials that is constrained financially, technically, and logistically.

- No provision for interagency coordination that allows for the integration of environmental considerations into sectoral policies and plans or agreements between the government and civil society. 


\section{Recommendations}

Although Chapter VI provides comprehensive recommendations to improve the Honduran environmental institutional framework, some of these key recommendations are summarized below.

(a) Activating the National Advisory Council for the Environment (COCONA), to serve as an advisory board to the Ministry for policy and regulation. The Council should, at a minimum, have the responsibilities to:

- Provide recommendations on the formulation and design of sectoral policies and norms.

- Recommend actions that support compliance with the legal framework.

- Present initiatives that support the development of new norms.

- Promote programs on pollution prevention, environmental education and information, and dissemination.

- Act as an information source in order to support transparency.

The Council should be expanded to comprise all stakeholders that have environmental responsibilities, including representatives of the public and private sectors, civil society, NGO's, academia, and indigenous groups. To ensure that the Council is effective, it should meet biannually and provide biannual reports on its actions. Once the Council has been formed, it is recommended that SERNA seek support from UN-system or bilateral donors in overseeing the Council's recommendations.

(b) Decentralizing responsibilities. SERNA has multiple responsibilities but few resources to fulfill them, which in turn limits the coverage and capacity of the country's environmental management. As such, the report recommends developing a strategy to increase the efficiency and effectiveness of environmental management via the selective decentralization of environmental functions. Only a few municipalities with strong installed capacity would initially be eligible. This strategy would begin with an initial phase of decentralizing the receipt and management of environmental assessment applications (only Category 1 and 2 projects) and information requests, and later be extended to include environmental oversight and analysis functions.

(c) Addressig Regulatory Gaps. Additional environmental standards are required to ensure adequate environmental protection and oversight, particularly in the areas of air and water quality and solid and hazardous waste management. Without these standards, the criteria utilized in assessing environmental impacts and in the oversight of environmental management plans is applied at the project proponent's or reviewer's own discretion. Further, their absence often leads to delays in renewing environmental licenses for projects with minimal impacts, such as a restaurant in a commercial zone, and projects that require greater oversight given their adverse impacts can be unattended for long periods of time. 
(d) Promoting Compliance. One of greatest challenges to the sector is compliance with environmental laws, regulations, and standards. Compliance has centered on the use of environmental assessments. A definition of what constitutes environmental damage and how to estimate it are lacking, making it difficult to apply appropriate sanctions. However, the system is designed to sanction or prohibit actions that the country does not have the capacity to monitor. To confront these challenges, the report recommends developing incentives to promote compliance accompanied by credible sanctions that are based on clear and cost-effective standards and enforced by well-staffed agencies. 


\section{Environmental Health in Honduras}

\section{Background}

Environmental health costs represent a significant burden on Honduras's economy. While progress is being made on interventions to address environmental risks, much more attention and resources need to be invested in water supply coverage, improved sanitation coverage, and proper waste disposal. Indoor air quality, especially in rural areas where biomass is used for cooking, and outdoor air quality, especially in urban areas such as Tegucigalpa, are growing and important concerns. These environmental health risks are especially important for the most vulnerable subgroups of Honduras's population, including children under 5 years of age, women, the elderly, and the poor.

As the evidence shows, the environmental health implications of poor water supply and sanitation and of indoor and urban air pollution dramatically impact Honduras's ability to achieve targets for reducing child mortality, improving maternal health, combating diseases, and other Millennium Development Goals (MDGs). Overall, the analysis shows that Honduras's economic costs associated with lack of water and sanitation, and indoor and urban air pollution, amount to nearly 4 billion lempira (L) (US $\$ 0.2$ billion), or 2.2 percent of the country's gross domestic product (GDP) (see Table III.1). This is comparable in range to other such valuation studies on environmental health carried out in the Latin American region (see Figure III.1).
Figure III.1. Costs of Environmental Degradation (as percent of GDP)

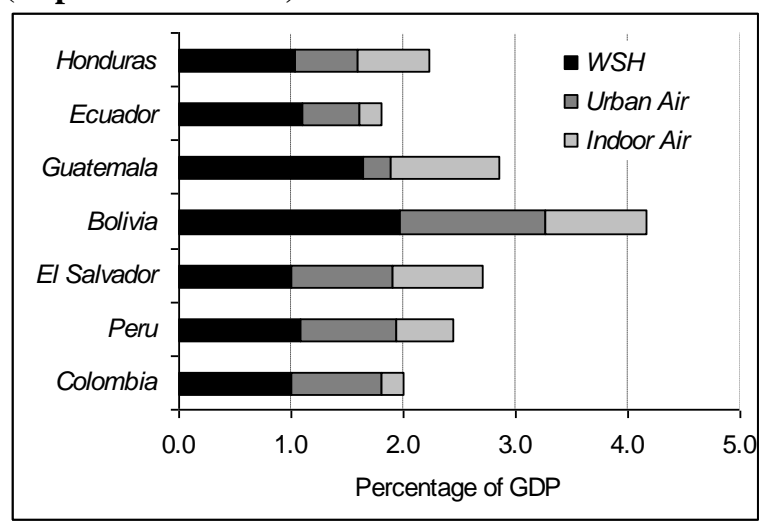

Table III.1. Aggregate Environmental Health Costs for Honduras

\begin{tabular}{lccc}
\hline & Lempira (millions) & $\begin{array}{c}\text { US\$ } \\
\text { (millions) }\end{array}$ & $\begin{array}{c}\text { Percent } \\
\text { of GDP }\end{array}$ \\
\hline Lack of water and sanitation & $1,830(1,420-2,240)$ & 97.3 & 1.03 \\
\hline Indoor air pollution & $1,125(770-1,480)$ & 59.8 & 0.64 \\
Urban air pollution & $970(280-1,660)$ & 51.6 & 0.56 \\
Total & $\mathbf{3 , 9 2 5}$ & $\mathbf{2 0 8 . 7}$ & $\mathbf{2 . 2 2}$ \\
\hline
\end{tabular}

The costs of these environmental problems have been estimated in this report to help policymakers in Honduras appreciate the magnitude of these issues and better integrate environmental health considerations into economic development decisionmaking. These costs include not only the medical costs of treatment and lost productivity due to sickness and caregiving, but also provide an estimate of the value of pain and suffering from premature death and disease. This analysis covers only a limited number of diseases attributed to the three environmental risk factors in question-inadequate water and sanitation, indoor air pollution, and urban air pollution - and therefore underestimates the economic burden these environmental risk factors place on Honduras. 


\section{Inadequate Water and Sanitation}

Water pollution is a continuing concern in Honduras -from both municipal discharges as well as from industrial effluents. About $140,000 \mathrm{~m}^{3}$ of untreated sewerage water is annually discharged into streams and rivers through sewerage systems in the country ${ }^{7}$. Water pollution is conspicuous in water systems around urban areas -microbiological pollution levels are high in the Choluteca River around Tegucigalpa and Choluteca. In addition, most industrial water effluents receive no treatment at all (for example, in Tegucigalpa, the effluents of 9 out of 10 industries are released directly into the sewer system or into the Choluteca River).

In Honduras, 12 percent of the total population lacks access to an improved water source and around 25 percent lack access to sanitation. Honduras's national coverage for potable water increased from 73 percent to 82 percent over 1990-2004, while sanitation coverage increased from 66 percent to 77 percent. However, large disparities in coverage rates are observed across rural and urban areas, and even across large and smaller cities (Bussolo and Medvedev 2007). The two most common methods of disinfection are water chlorination and boiling water-about 40 percent of households disinfect their drinking water in this manner (ENDESA 2005-06).

Health impacts: Data from the Encuesta Nacional de Demografia y Salud 2005-06 (ENDESA 2005-06), and World Health Organization (WHO) estimates, indicate that 12.6 to 21 percent of child mortality in Honduras is due to intestinal diseases. This analysis has looked at health data relating to diarrheal illness, and at hepatitis, typhoid, and paratyphoid cases in Honduras. Diarrheal prevalence (during the preceding two weeks) was 17.2 percent in rural areas and 13.3 percent in urban areas among children under 5 years of age (ENDESA 2005-06). Household survey data in Honduras do not provide information on diarrheal illness in the population above 5 years of age. International evidence indicates that diarrheal incidence in children under age 5 is about five times higher than the incidence in the population over age 5 (Larsen 2004a, 2004b).

WHO estimates that 90 percent of diarrheal illness is attributable to inadequate water, sanitation, and hygiene. Using this figure, there are an estimated 1,050 premature deaths, and about 3 million additional cases of diarrhea in children under 5 attributed to poor water sanitation and hygiene (see Table III.2). Although the overall rural population share in Honduras is about 55 percent, the share of children is substantially higher than in urban areas. This explains why diarrheal child mortality is 15 percent higher in rural areas than in urban areas, and why the number of diarrheal cases is twice as high in rural as in urban areas.

\footnotetext{
${ }^{7}$ http://www.jica.go.jp/english/global/env/profiles/pdf/04.pdf
} 
Table III.2. Estimated Annual Health Effects (Diarrhea) from Water, Sanitation, and Hygiene

\begin{tabular}{|l|c|c|c|}
\hline & \multicolumn{2}{|c|}{ Cases } & \multirow{2}{*}{ Total } \\
\hline Children (under age 5)—increased mortality & Urban & Rural & 1,050 \\
\hline Children (under age 5)—increased morbidity & 330 & 720 & $3,050,000$ \\
\hline Population (over age 5)—increased morbidity & $1,050,000$ & $2,000,000$ & 3,000 \\
\hline
\end{tabular}

Economic costs: Inadequate access to water and sanitation leads to premature deaths and disease, which in turn impose costs on the Honduran economy. These costs include the expenses incurred to treat illness from diseases attributed to poor water and sanitation, doctor fees, laboratory tests, drugs, and bed charges when hospitalization is needed. Other costs include lost productivity when adults fall sick and stay home from work, or when primary caregivers have to take care of sick children (and potentially lose wages). Furthermore, the pain and suffering from premature death and illness can also be valued by calculating the burden of disease in disability adjusted life years (DALYs), and costing these DALYs at GDP per capita.

The annual costs of diarrheal mortality and morbidity attributed to inadequate water, sanitation, and hygiene are estimated at 480 million $\mathrm{L}$ in urban areas and 1,105 million $\mathrm{L}$ in rural areas. The cost of diarrheal child mortality-based on the Human Capital Approach $(\mathrm{HCA})^{8}$ - is estimated at 775 million L. The cost of morbidity-which includes the cost of illness (medical treatment, medicines, and value of lost time) - is estimated at 810 million L. About 70 percent of these costs are associated with the value of time lost to illness (including caregiving), and 30 percent are from cost of treatment and medicines.

Hepatitis A, Typhoid, and Paratyphoid: There were 3,088 recorded cases of hepatitis A in Honduras in 2004 (TRANS 2005). The number of typhoid/paratyphoid cases is not available but is assumed to be at the same level as hepatitis A. Annual costs of these illnesses are estimated at 18 million L. Over half (10 million L) of these costs are from hospitalization, while about 40 percent ( 8 million L) is associated with time losses for sick individuals and their caregivers.

Avertive Expenditures: People often take averting measures to avoid perceived health risks. For example, if people perceive a risk of illness from their local water supply sources, some of them are likely to purchase bottled water, while others may boil their water (nearly 19 percent of urban households and 23 percent of rural households in Honduras), or chlorinate their water (nearly 21 percent of urban and 23 percent of rural households). This analysis estimates the total household costs relating to avertive expenditures to range from 52 million $\mathrm{L}$ to 239 million $\mathrm{L}$ per year-representing 8 percent of the total estimated annual costs associated with inadequate water supply, sanitation, and hygiene.

\footnotetext{
${ }^{8}$ According to the HCA, the social cost of mortality is the discounted future income of an individual at the time of death. If the risk of death, or mortality risk, is evenly distributed across income groups, average expected future income is applied to calculate the social cost of mortality.
} 
In the final analysis, the estimated annual cost associated with inadequate water supply, sanitation, and hygiene ranges from 1,418 L to 2,238 million L per year, with a mean of 1,828 million L-equivalent to about 1 percent of GDP in 2006. These costs include those relating to mortality in children, morbidity in children and adults, and avertive expenditures (bottled water consumption, water chlorination, and water boiling). The estimated costs of under-5 child diarrheal mortality are about half of the costs of morbidity in children and adults (Figure III.2). Urban costs account for 34 percent, while rural costs represent 66 percent of the total costs associated with inadequate water supply, sanitation, and hygiene.

\section{Water, Sanitation, and Hygiene Interventions}

Interventions relating to improving the quality and quantity of water supply, improving access to improved sanitation, and programs encouraging better hygiene practices (including handwashing) have potential health benefits. Based on studies from several countries, estimates of the benefits associated with different interventions to reduce damage arising from unsafe water and sanitation have been developed. These international studies estimate the percentage reductions in the incidence of diarrheal morbidity and mortality following interventions to improve the infrastructure that provides drinking water or basic sanitation, or interventions that improve personal hygiene. The results are applied to Honduran health data and to Honduran estimates of the costs of providing improvements in the areas described above.

The aim of the infrastructure interventions is to improve water supply and sanitation, largely in rural areas. Two potential programs are investigated: one that provides 1.9 million people with improved sanitation, and one that provides 1.3 million people with an improved water supply. ${ }^{9}$ Local data from Honduras indicate that annualized per capita costs amount to $75 \mathrm{~L}$ for improved sanitation and $132 \mathrm{~L}$ for improved water supply. The benefits are derived from a range of studies and are calculated separately for different categories of individuals in rural Honduras. The morbidity costs, based on the costs of treatment and value of lost time, are $170 \mathrm{~L}$ per case of diarrhea. The mortality costs are calculated based on the Human Capital Approach, which represents the lower bounds of these estimates. Finally, the programs generate savings in time,

Figure III.2. Annual Costs by Category (Million L)

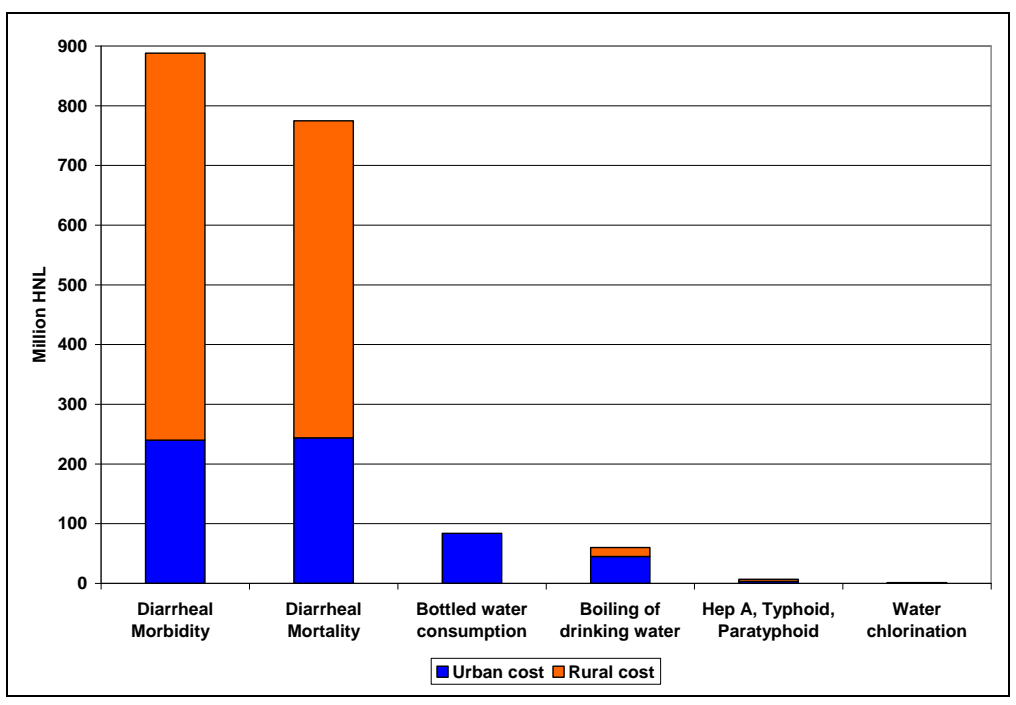

\footnotetext{
${ }^{9}$ This is the population in rural areas that lacks improved sanitation and water supply according to ENDESA 2005-06.
} 
which is an important ingredient in the calculations. It is based on data for households more than a 15-minute walk from a water source (approximately 35,000 households are in this category). Time saved is valued at 75 percent of the average rural wage $(180 \mathrm{~L}$ per day, or $22 \mathrm{~L}$ per hour).

The data reveal that programs to improve sanitation in rural areas have a benefit-cost ratio greater than 1.0 when the time savings of improved water are excluded. However, the ratio increases to over 5.0 when time savings are taken into account (see Table III.3). For the water supply program, the benefit-cost ratio is greater than 1 only if time benefits are included. For water supply/sanitation programs in urban areas, the costs are higher and the benefits lower due to lower diarrheal mortality among children under 5 and lower diarrheal prevalence. Thus the benefit-cost ratio is above 1 only for the sanitation program when time saving is included. Marginal costs would exceed marginal benefits (health damage reduction) only for sanitation programs in rural areas.

Table III.3. Benefits of Reductions in Diarrheal Morbidity and Mortality in Rural Honduras

\begin{tabular}{|l|c|c|}
\hline & $\begin{array}{c}\text { Improved } \\
\text { Sanitation } \\
\text { Facilities }\end{array}$ & $\begin{array}{c}\text { Improved } \\
\text { Water } \\
\text { Supply }\end{array}$ \\
\hline Population (million) Receiving Improved Sanitation & 1.9 & \\
\hline Population (million) Receiving Improved Water Supply & & 1.3 \\
\hline $\begin{array}{l}\text { Percent reduction in diarrheal illness per person (from Fewtrell and } \\
\text { Colford 2004) }\end{array}$ & $32 \%$ & $25 \%$ \\
\hline Diarrheal Cases (million) Averted per Year & 0.6 & 0.4 \\
\hline Deaths in Children Averted per Year & 120 & 80 \\
\hline Annual Health Benefits of Improved Services (Million L) & 190 & 130 \\
\hline Annual Value of Time Savings from Improved Services (Million L) & 650 & 105 \\
\hline Annualized Cost of Service Provision (Million L) & 145 & 165 \\
\hline & & \\
\hline Benefit-Cost Ratio (Health Benefits Only) & 1.3 & 0.8 \\
\hline $\begin{array}{l}\text { Marginal cost (million L per percent of Water Supply Sanitation and } \\
\text { Hygiene health cost reduction) }\end{array}$ & 14 & 23 \\
\hline Benefit-Cost Ratio (Health Benefits and Time Savings) & 5.5 & 1.4 \\
\hline
\end{tabular}

\section{Summary Assessment of Interventions Relating to Water, Sanitation, and Hygiene}

Apart from sanitation and water supply interventions, various forms of disinfectionboiling water and chlorination-are also examined as possible interventions, as are hygiene programs (handwashing). For Honduras, the analysis presents these interventions in terms of their contribution to reduced environmental damage and costs per 1 percent of health damage reduction (marginal cost). Figure III.3 shows the percent of reduction of environmental damage on the horizontal axis and the marginal cost as explained above on the vertical axis.

Drinking water disinfection (that is, household drinking water chlorination and boiling of drinking water) has the lowest marginal costs, but only rural interventions make a significant reduction in environmental damage. This is followed by rural hand-washing by mothers or caretakers of young children, which yields a higher reduction in damage. Next is rural sanitation programs and urban hand-washing. The latter two interventions 
(hygiene and rural sanitation improvement) reduce damages the most. Safe water supply in rural areas is estimated to have higher marginal costs than benefits. The benefits of hand-washing among adults and safe water supply and sanitation programs in urban areas are not presented in Figure III.3.

These interventions were estimated to have significantly higher costs than benefits and to have a corresponding benefit-cost ratio lower than 1. All interventions that have marginal costs lower than marginal benefits could reduce total health costs from inadequate water supply, sanitation, and hygiene for about 40 percent. The benefit-cost ratios for handwashing and drinking water disinfection are based on behavioral change being sustained for two years. The ratios would be higher if, as a result of promotion programs, households sustain improved behavior for longer than two years. This figure does not consider the possible interaction effects between different interventions (that is, how the impacts of a first intervention affect those of a second intervention), because data constraints preclude a sound analysis of such effects.

Figure III.3. Marginal Costs/Marginal Benefits Relating to Interventions for WSH in Honduras

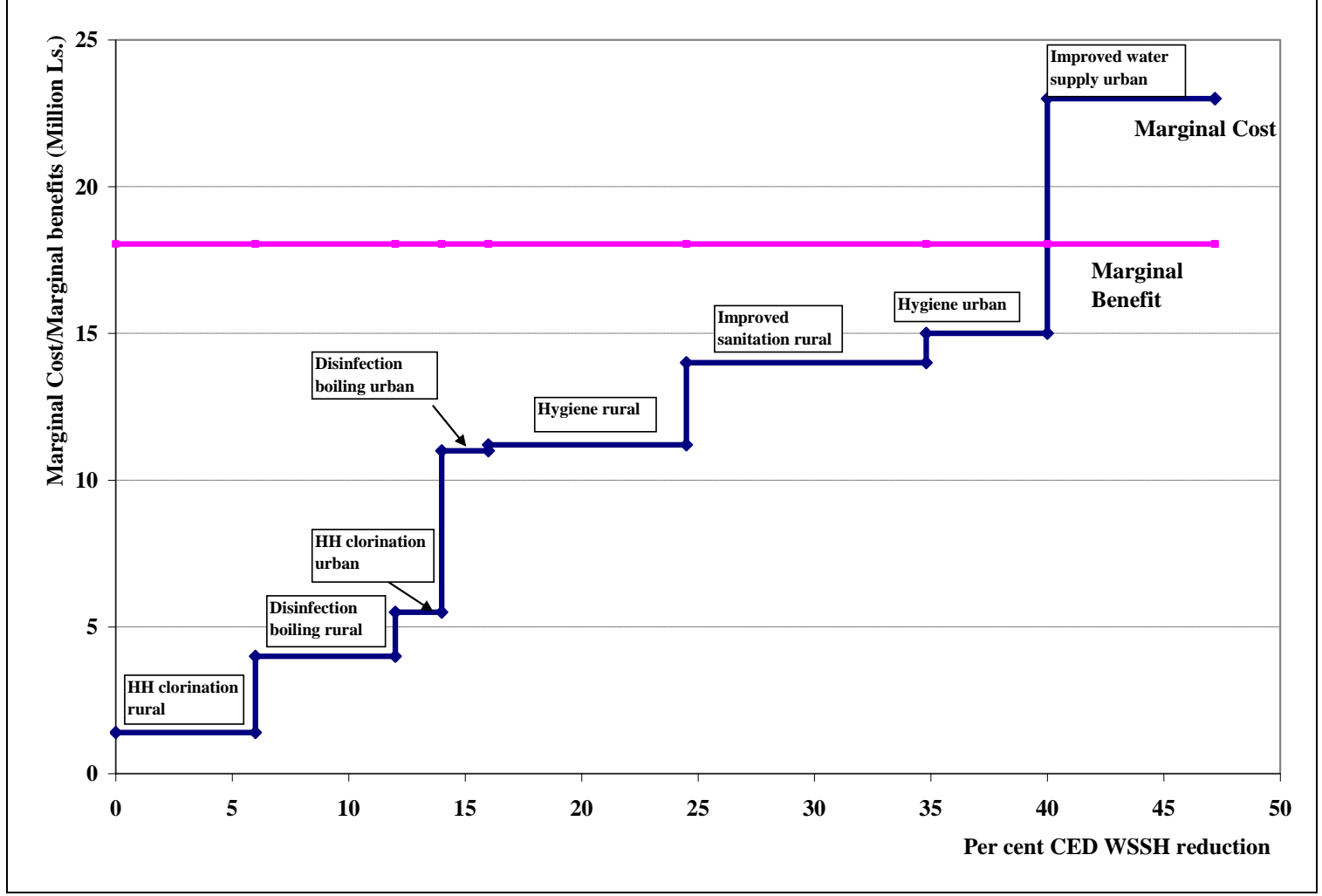

\section{Recommendations for Actions on Water, Sanitation, and Hygiene}

From the analysis presented here, it is clear that most measures to improve the water supply and sanitation facilities in rural areas yield benefits in excess of costs under most assumptions. The programs are also justified because the benefits are concentrated primarily among the poor. These measures include drinking water disinfection, 
handwashing, improved rural water supply, and safe rural sanitation. The highest priority should be given to the drinking water disinfection and handwashing programs.

\section{Rural Energy and Indoor Air Pollution}

About 2.4 billion people worldwide burn biomass (wood, crop residues, charcoal, and dung) for cooking and heating. The smoke created from burning these fuels turns the kitchens of the world's poorest countries into death traps. Indoor air pollution from the burning of solid fuels kills over 1.6 million people, predominantly women and children, each year. Smoke in the home is one of the world's leading child killers, claiming the lives of nearly 1 million children each year (ITDG 2004). In Honduras, especially in the rural areas, indoor air pollution remains an important concern.

Rural energy use: The vast majority of Honduran households use biomass for cooking, especially firewood and agricultural residues. Household surveys show that around 20 percent of urban and 86 percent of rural households used fuelwood for cooking in 2005 (ENDESA 2005-06). Nationally, over half the households use fuelwood for cooking, while liquefied petroleum gas (LPG) and electricity are each used by 20 percent of households. About a third of urban households and less than 10 percent of rural households use cleaner fuels such as LPG (ENDESA 2005-06).

Health effects: Acute respiratory infections (ARIs), and chronic obstructive pulmonary disease (COPD) are the most common diseases associated with indoor air pollution in Honduras. ARIs affect mainly women and children in rural areas, where over 8 out of 10 households burn fuelwood in inefficient stoves in poorly ventilated areas. Mortality in children under 5 from ARIs is 17 percent of total estimated child mortality in Honduras (ENDESA 2005-06). Data on COPD mortality and especially morbidity incidence are not readily available for Honduras; therefore regional estimates from WHO (2001) and Shibuya and others (2001) for the AMRO B region are used instead. ${ }^{10}$

Every year, an estimated 365 to 480 children under age 5 die from ARIs in rural areas, and an additional 55 to 90 children die in urban areas (see Table III.4). Among children under age 5, more than half a million annual cases of acute respiratory infections in rural areas, and more than 100,000 cases in urban areas, can be linked to indoor air pollution. Among females over age 30, there are annually 250,000 cases in rural areas and nearly 30,000 cases in urban areas of indoor-air-pollution-related ARI morbidity. Indoor air pollution also causes COPD in females over 30 years of age-up to 300 women die annually from COPD in urban and rural areas, and about 25,000 new cases of COPD annually can be attributed to indoor air pollution.

\footnotetext{
${ }^{10}$ Honduras belongs to the AMRO B region of WHO, which is one of three WHO regions in the Americas.
} 
Table III.4. Estimated Annual Health Effects of Indoor Air Pollution (Rural and Urban)

\begin{tabular}{|l|c|c|c|c|}
\hline & \multicolumn{2}{|c|}{$\begin{array}{c}\text { Estimated Annual } \\
\text { Rural Cases }\end{array}$} & $\begin{array}{c}\text { Estimated Annual } \\
\text { Urban Cases }\end{array}$ \\
\hline & "Low" & "High" & "Low" & "High" \\
\hline Acute Respiratory Illness (ARI): & & & & \\
\hline Children (under age 5)—increased mortality & 365 & 480 & 55 & 90 \\
\hline Children (under age 5)—increased morbidity & 535,000 & 729,000 & 95,000 & 158,000 \\
\hline Females (age 30 and older)-increased morbidity & 183,000 & 250,000 & 19,500 & 32,500 \\
\hline Chronic obstructive pulmonary disease (COPD): & & & & \\
\hline Adult females-increased mortality & 145 & 210 & 50 & 100 \\
\hline Adult females-increased morbidity & 1,050 & 1,550 & 415 & 865 \\
\hline
\end{tabular}

Economic costs: The mean estimated annual costs of health impacts from indoor air pollution in Honduras associated with the use of traditional fuels (mainly fuelwood) ranges from 770 million $\mathrm{L}$ to 1,475 million $\mathrm{L}$, with a mean of 1,120 million $\mathrm{L}$, equivalent to about 0.6 percent of the country's GDP in 2006. COPD mortality in adult females accounts for 35 percent of the cost, while respiratory child mortality represents 32 percent (see Figure III.4). ARIs in children represent 23 percent of the cost, while COPD and ARI morbidity in adult females represents 11 percent of the cost. The rural population bears 78 percent of the total cost of indoor air pollution.

\section{Indoor Air Pollution Interventions}

A wide range of interventions are available to reduce indoor air pollution and associated health effects. These interventions can be classified according to the level at which they are effective: (a) interventions on the source of pollution-including moving from traditional stoves to improved stoves, and switching to cleaner fuels such as LPG; (b) interventions to the living environment-such as

Figure III.4. Annual Costs of Indoor Air Pollution (million L)

chimneys and smoke hoods (with flues); and (c) interventions to user behavior-such as keeping young children away from smoke. For purposes of this economic analysis for indoor air quality in Honduras, only those interventions relating to the source of pollution have been considered, that is, moving from unimproved to improved stoves, and switching to cleaner fuels.

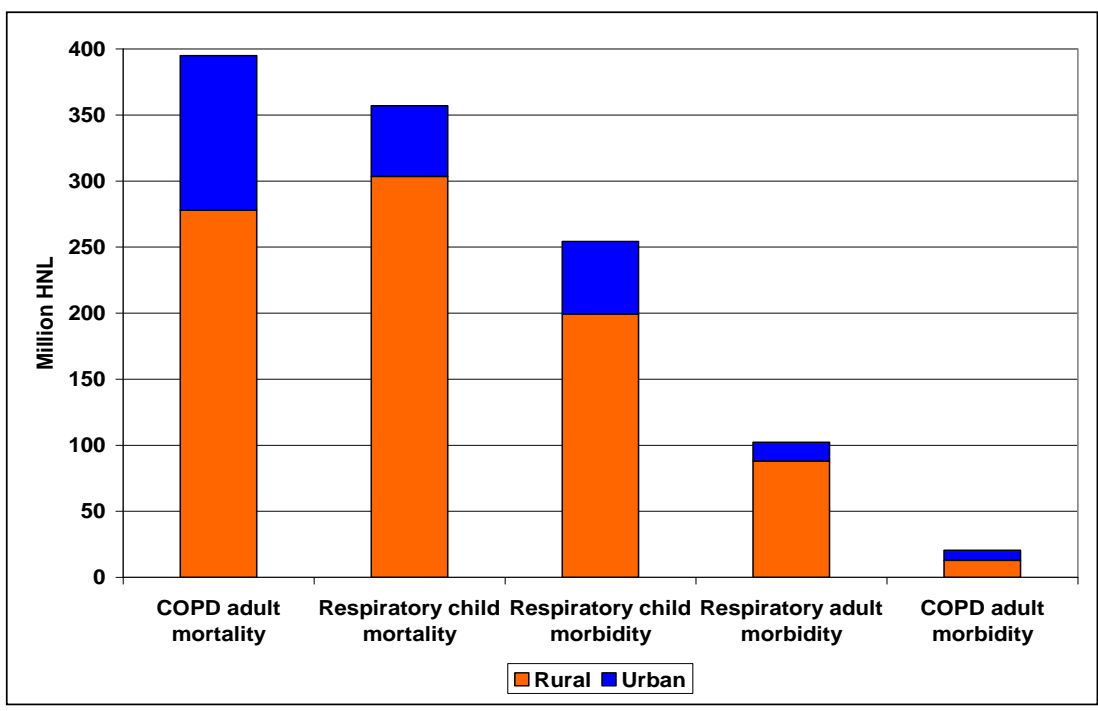


There are a few improved cookstove programs being undertaken in Honduras. For example, Trees, Water, \& People (TWP), the Honduran Association for Development (AHDESA), and the Aprovecho Research Center are undertaking the "Micro-Enterprise Stove Project" to introduce safer and more environmentally friendly cookstoves for the people of Honduras. These Justa stoves save an average of 50 to 70 percent on firewood compared to traditional stoves. The Justa also removes about 90 percent of toxic smoke from the kitchen. Only clean fuel like LPG or electricity would enable eliminating close to 100 percent of the health risks from indoor air pollution (IAP). However, the price of commercial fuel is high and getting higher in Honduras, with the cost of LPG reaching $199 \mathrm{~L}$ for a 25 -pound bottle.

Four scenarios considered for Honduras represent four stylized situations commonly found in most developing countries (see Table III.5). These stylized situations represent reasonably well the pollution loads from solid fuel use. However, actual pollution exposure can vary substantially in each scenario, and depend on additional factors such as household ventilation practices, housing characteristics, and household behavior.

Table III.6. Benefits and Costs of Rural Indoor Air Pollution Control in Rural Honduras

\begin{tabular}{|l|c|c|c|c|}
\hline & $\begin{array}{c}\text { Improved Stove } \\
\text { from } \\
\text { Unimproved } \\
\text { Stove }\end{array}$ & $\begin{array}{c}\text { LPG } \\
\text { from } \\
\text { Improved } \\
\text { Stove }\end{array}$ & $\begin{array}{c}\text { LPG from } \\
\text { Mix of } \\
\text { Unimproved } \\
\text { Stove and } \\
\text { LPG }\end{array}$ & $\begin{array}{c}\text { LPG from } \\
\text { Improved } \\
\text { Stove and } \\
\text { LPG }\end{array}$ \\
\hline Population receiving intervention (million) & 1.6 & 1.6 & 0.02 & 0.02 \\
\hline ARI cases averted per year (thousand) & 270 & 280 & 32 & 18 \\
\hline ARI deaths in children averted per year & 132 & 135 & 15 & 10 \\
\hline COPD cases averted per year & 330 & 350 & 40 & 20 \\
\hline COPD deaths averted per year & 55 & 60 & 6 & 3 \\
\hline Annual health benefits (million L) & 280 & 290 & 35 & 20 \\
\hline Annual time and fuelwood saving (million L) & 280 & 570 & 50 & 30 \\
\hline Program cost (million L) & 40 & 40 & 5 & 5 \\
\hline Annualized stove cost, (million L) & 45 & 100 & & \\
\hline Annual cost of LPG (million L) & 0 & 1000 & 60 & \\
\hline Benefit-cost ratio (health benefits only) & 3.3 & 0.3 & 0.5 & 60 \\
\hline $\begin{array}{l}\text { Marginal cost (million L per 1\% of indoor air } \\
\text { pollution health cost reduction) }\end{array}$ & 4 & 44 & 21 & 0.3 \\
\hline Benefit-cost ratio (total benefits) & 6.6 & 0.8 & & 39 \\
\hline
\end{tabular}

Substitution from unimproved and improved stoves in individual households is found to have substantially higher benefits than costs (Table III.6). The benefit-cost ratio is estimated at 3.3 for substitution from unimproved stoves to improved stoves, and 6.6 for substitution from improved stoves to unimproved stoves when time benefits are included. The benefit-cost ratio is higher than 1 if the household is already using 50 percent of LPG to cook at an unimproved stove. The reasons for the high benefit-cost ratios are substantial health and time gains accompanied by lower improved stove cost. However, for households with improved stoves, the health benefits alone are not large enough to 
outweigh the cost of switching to LPG. While promotion of improved stoves is a very attractive intervention, the merits of promoting LPG in individual rural households are uncertain. LPG prices would have to be reduced dramatically for the estimated benefits to exceed costs. Moreover, the benefits include both health improvements and time saving from reduced fuelwood collection. Time savings are valued at 75 percent of rural wages. Therefore, it seems that LPG will have a chance of success only in better-off households.

\section{Summary Assessment of Interventions to Address Indoor Air Pollution}

The various interventions are summarized in terms of their contribution to reduced environmental damage and costs per 1 percent of health damage reduction (marginal cost), as was done for the water and sanitation programs (Figure III.5). Marginal cost reflects only program cost and private household cost, without taking into account time and fuelwood savings. Household substitution from unimproved to improved stoves has the largest reduction in damage in rural areas. This is followed by households switching to LPG alone from a mix of unimproved stoves and LPG in urban and rural areas. The last two interventions contribute a smaller amount of reduction in environmental damage; their marginal costs slightly exceed marginal benefits. In total, the former four interventions reduce the cost of health effects by about 37 percent per year. This reflects a substitution to improved stoves in 42 percent of rural households, and 7 percent of urban households, switching to LPG alone from a mix of unimproved stoves, and LPG in 5 percent of rural and 5 percent of urban households.

Figure III.5. Marginal Costs/Marginal Benefits Relating to Interventions for Indoor Air Pollution in Honduras

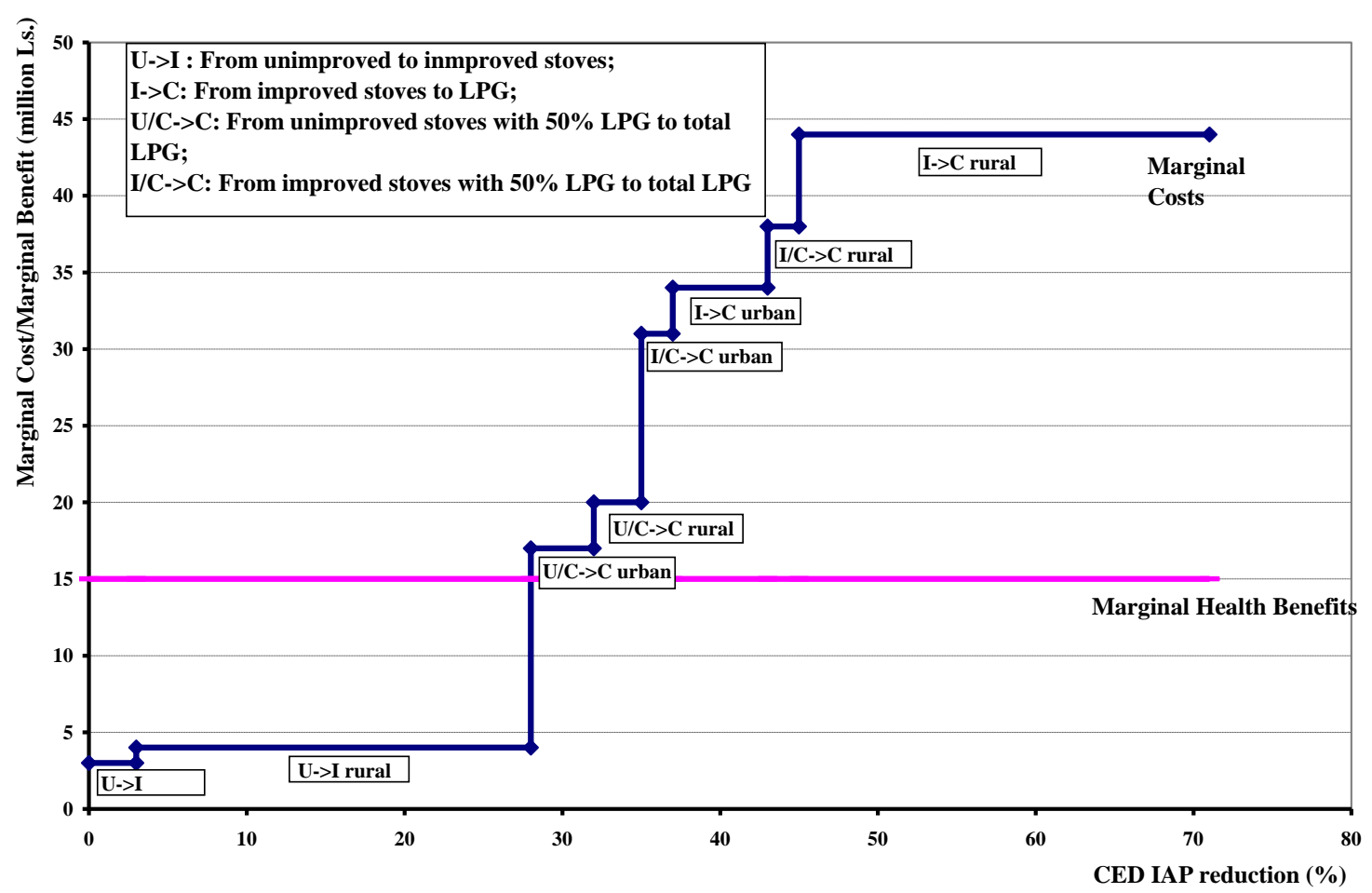




\section{Recommendations for Actions on Indoor Air Pollution}

The analysis presented here supports the unqualified recommendation to shift households that have unimproved stoves to improved stoves. The results of other interventions, such as from unimproved stoves to LPG or from improved stoves to LPG, depend on the costs and benefits used. Hence, a more detailed analysis needs to be carried out for such changes, looking at specific cases and taking into account other benefits.

\section{Urban Air Pollution}

Air quality: Urban (outdoor) air pollution is emerging as a major problem in Honduras's urban centers, particularly in Tegucigalpa. Particulate matter concentrations (measured as total suspended particles [TSPs] and particles smaller than 10 microns in size $\left[\mathrm{PM}_{10}\right]$ ), exceeding WHO air quality guidelines are the major air quality problem identified in Tegucigalpa by Honduras's Center of Pollution Studies (CESSCO). According to CESSCO, these concentrations are mainly related to traffic, but can also be associated to re-suspended particles and unpaved roads.

Air quality monitoring data is scarce in Honduras, with only seven air quality monitoring stations in Tegucigalpa, two of which measure $\mathrm{PM}_{10}$ (Figure III.6). Measurements at the highest traffic site are 150 micrograms per cubic meter as an annual average. Various studies and the data coming from the monitoring stations show that Tegucigalpa's air pollution, particularly the concentration of particulate matter in 2001, were three times higher than the recommended limit set by WHO. In the absence of monitoring stations in other cities (San Pedro Sula, La Ceiba, Choloma, and El Progreso) annual average $\mathrm{PM}_{10}$ levels were assigned based on World Bank modeling of $\mathrm{PM}_{10}$ concentrations. ${ }^{11}$ The poor availability of air quality monitoring data contributes to the high level of Figure III.6. Monitoring Stations in Tegucigalpa

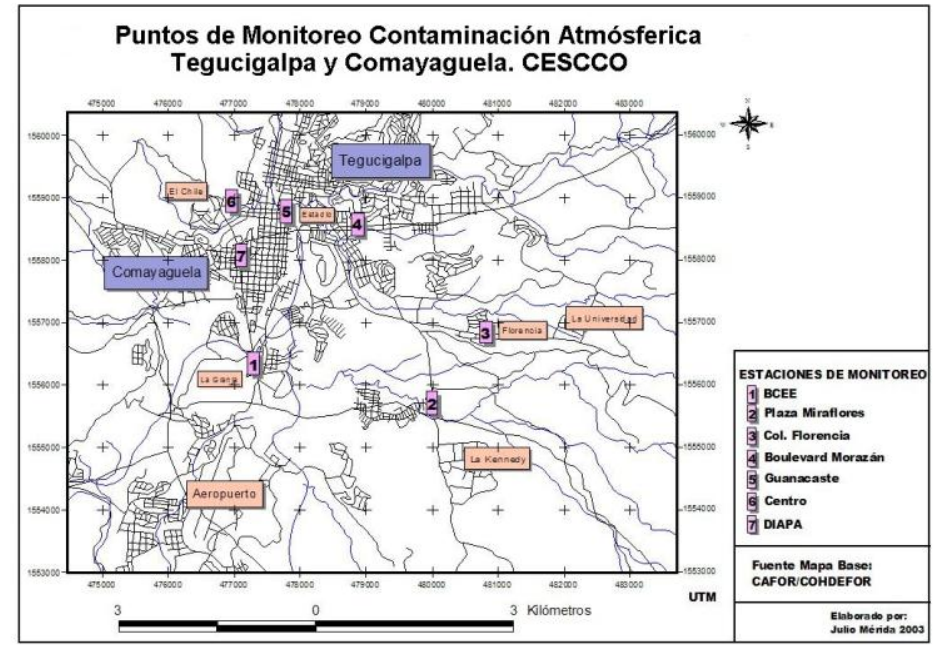

Source: http://www.cescco.gob.hn/Contenido/CalAire/2003.htm. uncertainty in the following analysis.

Additional measurements for nitrogen dioxide $\left(\mathrm{NO}_{2}\right)$ and ozone $\left(\mathrm{O}_{3}\right)$ as a result of monitoring campaigns using passive monitors find that $\mathrm{NO}_{2}$ concentrations exceed the annual WHO standard in high-traffic roads, while ozone concentrations also exceed these standards, but to a lesser extent. Importantly, Honduras has not set official air quality standards.

\footnotetext{
${ }^{11}$ www.worldbank.org/nipr/Atrium/mapping.html.url.
} 
Emissions monitoring: Integrated emission inventories do not exist for cities in Honduras. Based on available information, CESSCO has estimated that motorized transport contributes to 70 to 80 percent of the total emissions in Tegucigalpa and San Pedro Sula. According to the same source, industrial emissions appear to contribute to air pollution, but to a lesser extent, because there has not been significant industrial development of high-air-quality emitters. Forest fires are a periodic source of concern during the dry season. The burning of sugarcane during zafra (the sugarcane harvesting period) and heavy fuel oil combustion in sugar refineries are local sources of poor air quality, as are extended unpaved areas in periphery urban neighborhoods.

Vehicle growth: Air pollution from vehicles is generally due to poor fuel quality, poorly maintained vehicles, inadequate transport-related infrastructure, and lack of proper land use and transport planning. According to the General Directorate of Transport, there are around 200,000 motorized vehicles in Tegucigalpa and that number could double in the next five years. Travel distances are extending due to unplanned urban expansion. A combination of all these factors is causing air quality to deteriorate in Honduras's cities.

Health Impacts: The most significant health impact of outdoor air pollution has been associated with particulate matter and, to a lesser extent, with ground-level ozone. Particles smaller than 10 microns in size $\left(\mathrm{PM}_{10}\right)$, and especially those smaller than 2.5 microns $\left(\mathrm{PM}_{2.5}\right)$, penetrate deep into human lungs and cause health impacts such as acute respiratory infection (both upper and lower respiratory tract infections), chronic obstructive pulmonary disease (especially bronchitis), asthma attacks, cardiovascular disease, and lung cancer. Certain population subgroups, such as the elderly, children, and individuals with existing respiratory or cardiovascular diseases, are at increased risk from exposure to particulate matter.

In Honduras, the accuracy of health data is a concern - with high uncertainty in the quality of data on mortality causes. Underreporting also contributes to the problem, with only about 50 percent of total deaths being registered with corresponding mortality causes (http://www.paho.org/English/DD/AIS/cp_340.htm ). The combination of poor air quality monitoring, the absence of integrated emissions inventories, and the underreporting of related health problems all contribute to the high level of uncertainty in the analysis of health costs relating to urban air pollution in Honduras, and point to the need to strengthen these pollution monitoring and health information systems.

Given these caveats, the estimated annual health effects of ambient particulate outdoor air pollution in Honduras are presented in Table III.7. There are an estimated 504 premature deaths and 708 new cases of chronic bronchitis in Honduras every year. Annual hospitalizations due to pollution are estimated at 1,800, and emergency room visits/outpatient hospitalizations are estimated at 35,000 per year. Cases of less severe health impacts are also presented in Table III.7. 
Table III.7. Estimated Annual Health Effects of Urban Outdoor Air Pollution

\begin{tabular}{|l|c|}
\hline Health End-points & Total Cases \\
\hline Premature mortality & 504 \\
\hline Chronic bronchitis & 708 \\
\hline Hospital admissions & 1,800 \\
\hline Emergency room visits/Outpatient hospital visits & 35,310 \\
\hline Restricted activity days & $5,349,800$ \\
\hline Lower respiratory illness in children & 96,262 \\
\hline Respiratory symptoms & $17,026,320$ \\
\hline
\end{tabular}

Economic costs: Increasing air pollution in Honduras's urban areas, especially in Tegucigalpa, is imposing a negative economic impact from premature deaths, illness, medical costs, and lost productivity. Costs of health impacts from particulate matter have been assessed, and health conditions such as premature mortality, hospital admissions, restricted activity days, and emergency visits have been considered. In the absence of proper data on treatment costs, informed estimates have been provided by medical experts in Tegucigalpa.

The mean estimated annual cost of particulate matter urban air pollution in Hondurasbased on particulate matter exposure only-is estimated at about 972 million L or about 0.7 percent of the country's GDP in 2006. Of this cost, about 80 percent is associated with mortality, and 20 percent with morbidity (Figure III.4).

\section{Summary Assessment of Actions on Urban Air Pollution}

Health effects of air pollution are a function of ambient air quality. Estimating the benefits of urban air pollution control therefore requires: (a) an emissions inventory, (b) a relationship between the inventory and ambient air quality, and (c) an estimate of emissions reductions from individual pollution control measures. Each of these three dimensions is complex, and estimates of benefits and costs of control options need therefore to be accompanied by a careful sensitivity analysis of key parameters of the estimates. In Honduras, however, no emissions inventory has been carried out, making these related economic analyses difficult.

Interventions to control primary and secondary particulate emissions from mobile sources can be broadly classified into (a) market-based instruments, such as fuel pricing and taxation, vehicle taxation, and emission taxes; (b) vehicle technology standards and regulations including in-fleet technology retrofitting and inspection and maintenance programs; (c) fuel quality improvements and fuel use regulations, such as low-sulfur diesel and conversion to compressed natural gas; and (d) traffic management and urban planning, including public transportation policies (Larsen 2005).

In cities such as Lima, the following control options are being considered (World Bank 2006):

- Low-sulfur diesel

- Encouraging use of gasoline cars at the expense of diesel cars through tax incentives 
- Conversion of gasoline/diesel cars to natural gas

- Conversion to ethanol or biofuel

- A new public transport system

- Tax incentives to scrap older high-use cars (such as taxis)

- Inspection and maintenance programs

- Retrofitting catalytic converters on cars and/or retrofitting particle control technology for diesel vehicles

- Banning imports of used cars for taxi use

- Banning use of diesel cars and/or two-stroke engines as taxis

- Various city planning interventions, such as "green traffic light waves" and bike lanes

- Measures regarding emissions from industry sources.

Several of these measures may be potential options for the Government of Honduras to consider in light of worsening air quality in its cities. For example, in Honduras, the average age of light-duty vehicles exceeds 10 years, and these are not subject to any emission standard or specification. Furthermore, a large proportion of the car fleet is not equipped with catalytic converters. Frequently, those devices are removed from vehicles originally equipped with them due to the misconception that they increase fuel consumption and reduce engine power. There is also no formal inspection and maintenance program in place. Both gasoline and diesel are high-sulfur fuels.

Air pollution from older vehicles using diesel is also threatening air quality. Both in Tegucigalpa and San Pedro Sula, the bus fleets include diesel buses older than 20 years. In San Pedro Sula, rapiditos, or medium-size buses, compete for passengers, contributing to traffic congestion, accidents, and additional air pollution.

\section{Recommendations for Actions on Urban Air Pollution}

Rapidly increasing urban populations and accompanying vehicle growth, coupled with inadequate regulations and monitoring, will impact the air quality in cities such as Tegucigalpa unless appropriate actions are taken. Recognizing some of these issues, the Government of Honduras is in the process of preparing a comprehensive air quality management plan.

As part of improving the Honduran air quality management system, a detailed and integrated emissions inventory for Tegucigalpa and San Pedro Sula should be developed. A health and air quality indicator system should be established, and establishing and implementing an Alert Plan to manage high air pollution levels related to forest fires in Tegucigalpa and urban air pollution episodes should be made a priority.

Additional measures are needed in terms of improving the regulatory framework for air quality management in Honduras. These include: 
- Updating, implementing, and enforcing the Rule for Smoke and Gas Emissions for Motorized Vehicles for new and existing vehicles, and accompanying verification and enforcement procedures.

- Establishing and implementing air quality standards (exploring the possibility of adopting the WHO intermediate air quality guidelines).

- Adopting low-sulfur specification standards, in conjunction with the Central American Commission for Environment and Development.

- Designing and implementing regulations for industrial emissions. 


\section{Infrastructure and the Environment-Toward Sustainability and Efficiency}

\section{Background}

Infrastructure, along with supportive economic and financial policies, has long been recognized as a key element of a supportive environment for economic growth. Access to a range of infrastructure services and their cost and quality - such as water and energy supply, telecommunications, and transportation services provided by roads, ports, and airports - significantly affect an economy's competitiveness, facilitate trade, and raise output levels. Existing estimates suggest that a 10 percent increase in infrastructure stocks would have increased output levels in Latin America by around 1.5 percent-with dramatic implications for poverty, since a 1 percentage point increase in per capita income is estimated to reduce the share of people living in poverty by half a percentage point. ${ }^{12}$ Other estimates suggest that inadequate investment in infrastructure in Latin America during the 1990s reduced long-term growth by 1 to 3 percentage points. ${ }^{13}$ Inadequate access to infrastructure services such as water, sanitation, and clean fuels, also has significant public health costs, especially among the rural population.

Another study finds that one-fifth of the difference in output growth between East Asian and Latin American countries is attributed to the differences in infrastructure endowments in these two regions (Calderon and Servén 2003). Furthermore, empirical studies of countries at different stages of development reveal that infrastructure spending makes the highest contribution to growth in low-income countries or low-income regions in richer countries (Estache 2004). According to some estimates, with better infrastructure, economic growth in Honduras could be up to 4 percent higher than it is now (Calderon and Servén 2003).

Improving access to infrastructure services has been a high government priority in recent years, with Honduras achieving national coverage of around 80 percent for potable water, and about 70 percent for sanitation and electricity by 2004 . Important progress has also been made in strengthening the road sector, particularly through improved maintenance. Infrastructure is especially needed in the countryside. There is growing evidence that infrastructure is one of the key determining factors for the economic growth of rural areas. ${ }^{14}$ However, infrastructure, like poverty, is unequally distributed between urban and rural areas in Honduras. Lack of access to basic infrastructure services constrains the potential for economic and social development and perpetuates health inequalities, isolation and poverty in the rural population.

Poor infrastructure services in Honduras translate into significant public health cost, especially among the rural population. Lack of access of clean water and poor sanitation

\footnotetext{
${ }^{12}$ Estache and others (2002) as cited in Briceño-Garmendia and others (2004).

${ }^{13}$ Easterly and Servén (2003) as cited in Briceño-Garmendia and others (2004).

${ }^{14}$ The Bank's Pro-Poor Growth Study (2005), analyzing the experiences of 14 countries over the past decade, demonstrates that insufficient access of poorer households to infrastructure services (particularly electricity and roads) has constrained the ability of rural households to tap into their countries' higher overall growth rates, particularly in nonagricultural sectors.
} 
is resulting in several waterborne diseases - about 1,000 Honduran children under five years are dying prematurely from diarrheal diseases. Also, inadequate access to cleaner fuels, especially in rural areas, means higher exposures to indoor air pollution from use of biomass and consequent respiratory infections-about 500 children under five and an additional 300 women are dying prematurely from exposure to indoor air pollution. Translated into economic terms, health costs in Honduras associated with poor water, sanitation and inadequate access to clean fuels amount to nearly 1.7 percent of the country's GDP. These deaths and illnesses can potentially be averted through appropriate investments in infrastructure services.

In a spatial context, the access to infrastructure services in Honduras varies widely between urban and rural areas. While the urban-rural gap in access to services is significant for all sectors, it is particularly striking for electricity, with only 38 percent access in rural areas compared to 95 percent access for the urban population. Access to electricity is particularly low among poorest rural households, and it is lower in rural areas of Honduras than in most other countries in the region. In addition, available information from surveys and sector studies points to quality and sustainability issues, particularly in past investments in water, sanitation, and roads. The absence or low quality of these infrastructure services in rural areas seriously limits access to markets, schools, and clinics, and constrains prospects for improving productivity.

Finding the resources to finance new infrastructure investment in Honduras has not been easy. Fiscal constraints continue to hamper public commitments while private sector participation in infrastructure has been spotty. To date, relatively small electricity generation plants have been financed with private capital as well as a few water concessions in secondary cities. However, key investments such as large energy supply, port development and network service-roads, fixed line telephony, and power transmission and distribution-remain the responsibility of public or government-owned agencies. As Honduras considers the use of private sector financing for major assets, such as hydro-electric facilities and highways, and moves to close the investment gap in other sectors, such as wastewater collection and treatment, a sustainable framework for environmental protection becomes particularly important.

\section{Infrastructure and the Environment}

In Honduras, as in many developing countries, natural capital is a very important determinant of well-being. ${ }^{15}$ While declining as a share of total economic production, agriculture, forestry, and fishing still accounted for one-quarter of gross domestic product (GDP) and one-half of exports between 2000 and 2006. Natural capital accounts for 26 percent of the country's total wealth, more than twice the overall rate for Latin America and the Caribbean. To preserve the country's natural capital in the face of growing pressures from expansion of large-scale infrastructure projects, particularly in the

\footnotetext{
${ }^{15}$ Capital can be defined as: "a stock that yields a flow of valuable goods or services into the future." Natural capital is thus the stock of natural ecosystems that yields a flow of valuable ecosystem goods or services into the future.
} 
hydropower and transport sectors, environmental considerations need to be effectively mainstreamed in infrastructure development strategies in Honduras.

The links between infrastructure and the environment run in both directions: the impact of infrastructure on the environment, and the effect of environmental regulations and uncertainty about these risks on infrastructure investments. The impact of infrastructure on the environment can potentially have positive and negative outcomes. However, mainstreaming environmental considerations in the early stages of planning and design of infrastructure projects can help reduce or completely avoid some of the adverse environmental impacts. On the flip side, appropriate and well-targeted investments in infrastructure services relating to water, sanitation and energy have the potential to generate significant public health benefits, especially for the rural population (see chapter III).

Because of the large-scale civil works that they often involve, infrastructure projects can significantly affect the environment. The environmental and social consequences of building dams have become widely recognized. In addition to population displacement, energy and hydropower projects may impact the environment through flooding of natural habitats near reservoirs, deterioration of water quality, and modification of the hydrological regime. For example, reservoir operation may reduce water flow in downstream areas or lead to seasonal desiccation of rivers. Water and sanitation projects, in the absence of mitigation measures, typically have such environmental effects as pollution of water supply sources; deterioration of wetlands; loss of connectivity between rivers, wetlands, and riparian zones; invasion of aquatic weeds, and disease vectors. Construction of ports frequently leads to the deterioration of water quality; dredging disturbs riparian habitats and damages aquatic life; and the hydrological regime may also be affected. Road and telecommunications projects (building access corridors) directly affect the environment through fragmentation of habitats, but the induced effects from follow-on development when roads are built or upgraded are much higher. Other projects, such as building reservoirs and hydropower plants, may also have indirect environmental effects by giving impetus to further development, such as irrigation and roads.

Infrastructure development often destroys natural habitats, causing displacement and loss of wildlife and biodiversity, and alteration of fish populations and other aquatic life. Many economically valuable ecosystems services can also be lost in the course of infrastructure development, such as flood protection provided by wetlands and forests, protection against landslides, and clean drinking water services generated by wetlands, moorlands, and mountain lakes. The costs of replacing the lost ecosystems services can be massive. Protection and restoration of wetlands, mangroves, and forest buffer zones is a critical component of the strategy to reduce vulnerability to natural disasters, especially relevant in Honduras.

On the flip side, environmental regulations have the potential to impact infrastructure investments. The quality of environmental regulations has particular implications for economic competitiveness and the terms of infrastructure concessions. Infrastructure investors require high premiums for regulatory uncertainty, including uncertainty with 
respect to environmental regulations and environmental liability. Thus, depending on the country and subsector, it is estimated that regulatory risks can add 2 to 6 percentage points to the cost of capital (Guasch 2004), and this translates into significantly higher tariffs or lower sale prices for concessions. ${ }^{16}$ Furthermore, environmental licensing requirements create additional administrative burden and delays, affecting the overall investment climate.

Infrastructure projects do not necessarily have to produce negative environmental consequences. Mainstreaming environmental considerations in project design at an early stage can significantly reduce infrastructure's environmental footprint. This can be achieved through avoiding critical natural habitats in infrastructure siting, minimizing damage to other (noncritical) natural habitats, and through such mitigation measures as careful engineering design and ecological compensation programs (Box IV.1).

\section{Box IV.1. Ecological Compensation Program in Yacyretá's Hydroelectric Project II}

A joint venture between Argentina and Paraguay, the Yacyretá hydroelectric facility is one of the largest dams in Latin America. The site-which some experts later considered a poor choice because of the large flooded area and high population displacement that were required - was selected over two decades ago and was established by the Yacyretá Binational Treaty. A recent World Bank-supported project, Yacyretá II, which financed the civil works needed to complete the facility, established a successful mechanism for mitigating some of the project's adverse environmental effects.

Once the dam is operational, around 240 kilometers of riparian habitat along the branches of the river and some 107,600 hectares of terrestrial habitat, including forested savanna and wetlands, will be lost. Flooding of the area will mean permanent loss of habitats for some endangered terrestrial species and trees, including the arary (Calophyllum brasiliense) forests. The dam also precludes fish migrations and will deplete upstream populations. Some 22 kilometers of a downstream tributary of the Paraná River will become dry part of the season with severe impacts on the ecosystems and fish populations. Modification of the hydrological regime, without mitigation measures, would turn part of the river into a lake and substantially reduce peak flows in downstream areas.

Despite the advanced stage of the construction works and the severity of the dam's environmental impacts, a conservation program consisting of a system of new protected areas and a hydrological compensation program will significantly reduce the damage. A network of nine protected areas in Argentina and three in Paraguay covering 161,000 hectares will surpass the size of the flooded area. The area will include a restricted-use zone and a buffer zone for community use, co-managed by a public entity and an NGO. The hydrological compensation program will include a separate spillway and water releases to maintain seasonal stream flow variation downstream, water quality monitoring to ensure the new lake at the dam site does not turn into a noxious environment, and such measures as a fish elevator and ex situ conservation will be designed to protect several endangered species. Inclusion of the expenses related to the conservation programs in the fixed costs of operating the dam for the entire lifetime of the project have helped overcome the main challenge in conservation: securing ongoing, sufficient funding.

Source: Quintero (2007).

Another link between infrastructure and the environment has to do with the vulnerability of infrastructure to extreme weather events. Infrastructure in Honduras is highly vulnerable to natural disasters - a phenomenon that is likely to keep rising with the

\footnotetext{
${ }^{16}$ For example, the regulator grants the concessionaire of water service provision in Buenos Aires a 3.5 percent increase in tariffs for each 1 percentage point increase in the cost of capital.
} 
increasing intensity and frequency of extreme weather events predicted to occur with climate change. The losses to the infrastructure sector from Hurricane Mitch have been estimated at US\$344 million in direct costs and US\$322 million in indirect costs (CEPAL 1999). Losses happen not only because of the loss of physical structures but also because of such indirect impacts as the disturbance of the day-to-day life, the loss of passability of roads, and disruption of trade and economy. The greatest damage from Hurricane Mitch was to the road system with 78.9 percent of total damage, followed by water and sanitation with 8.7 percent of the total costs, and the energy sector with 7.3 percent.

Physical rehabilitation after disasters is a necessary policy response, but strengthening sector management and disaster mitigation in all the subsectors before the disaster occurs-which receives less attention in Honduras - is crucial to diminishing the losses in infrastructure. Recent studies estimate that a 1 percent increase in initial costs could reduce the cost of replacing the infrastructure after natural disasters by 50 percent (Pollner 1999). Another study estimates the annual exposure of the national capital stock in Honduran infrastructure at US\$82 million (IIASA; Freeman and others 2000).

The challenge for the Government of Honduras is to meet its ambitious infrastructure development targets in an environmentally sustainable way, while improving economic competitiveness through greater efficiency of the environmental management process. For efficiency, environmental management will need to use policy instruments commensurate with the magnitude of expected environmental impacts. From a public health perspective, this also means providing accompanying interventions in hygiene promotion and water disinfection (e.g., chlorination of water, handwashing) and behavior change (e.g. better ventilation can help reduce exposures to smoke) (see chapter III). Another challenge is to enhance institutional capacity of central government agencies and at the municipal level in order to mainstream sustainability considerations in sectoral planning and individual projects. In order to be effective, environmental regulation needs to be accompanied by credible enforcement mechanisms and incentives. Broader sectoral policies-subsidy provision and tariff-setting mechanisms-have important environmental and social implications that also need to be considered as part of an overall assessment of the tariff policy for infrastructure services.

\section{Planned Expansion in Key Infrastructure Sectors}

Several key infrastructure sectors are undergoing reforms that are likely to raise private and public investment levels. The planned expansion of key infrastructure sectors in Honduras can have significant environmental implications. At the same time, risks associated with environmental regulation and delays experienced by developers because of the environmental licensing process adversely affect the investment climate and may prove to be an obstacle in the reform process. Large economic and social benefits can be realized from improving the effectiveness and efficiency of the environmental licensing process and enhancing capacity to conduct environmental assessment at the central and local levels. It is particularly true in the power, roads, and water and sanitation sectors. 


\section{Power Subsector}

The power sector in Honduras does not have sufficient capacity to meet rising demand. Following a severe financial crisis in the electricity sector in the early 1990s, the hydrodominated generation system was converted to a thermal-dominated system through a series of market reforms in the sector. As a result, Honduras now depends on imported fuels for about 70 percent of its power generation (World Bank 2007a). With expected growth in demand, the National Electricity Company (ENEE) projects a rising demandsupply gap and the risk of another energy crisis (Figure IV.1). To reduce the gap in the longer term, ENEE plans to install 1,479 megawatts (MW) of additional generation capacity, mainly from new hydro (570 MW) and coal (600 MW) power plants, during 2007-15. If this ambitious plan is realized, the current level of hydropower generation would more than double.

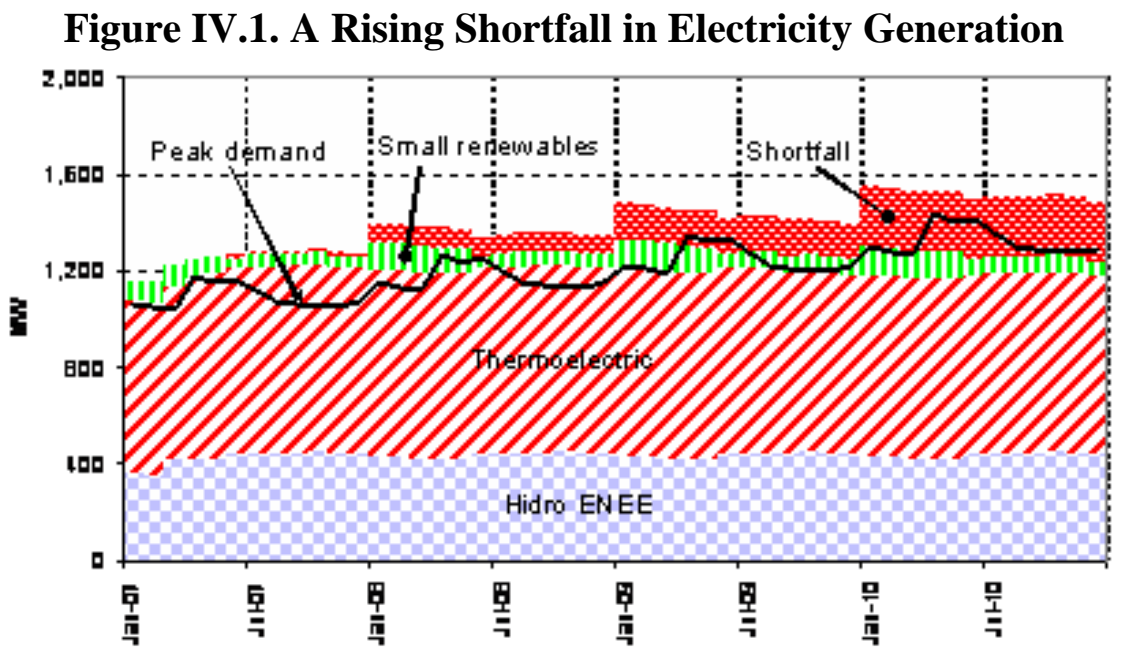

Source: Supply/demand balance for 2007-10 based on ENEE projections, reported by World Bank (2007).

Even though Honduras has significant untapped hydropower resources (estimated at around 5,000 MW to 6,000 MW), developing even a small fraction of this potential has run into difficulties. The lower Patuca river basin - a site of two major planned hydropower projects (Patuca II and Patuca III) - is a protected area in the Mesoamerican Biological Corridor. In the past, initiatives to develop the Patuca II project were unsuccessful due to the opposition of international environmental groups and nongovernmental organizations (NGOs). The project continues to cause social unrest and protests. Development of the Patuca river basin and other hydropower projects requires careful consideration of the environmental impacts in the downstream area and a complex process of public consultation with native populations and local communities, which have substantial political clout and international support. 


\section{$\operatorname{Roads}^{17}$}

By regional standards, Honduras has low road density, with a road density index of 29 compared to the average for Central America of 55. ${ }^{18}$ Only 20 percent of the 13,600 kilometer $(\mathrm{km})$ official road network is paved, and generally Honduras has a shortage of adequate road corridors for existing traffic levels. The Road Investment Plan, developed as part of the 2005-09 Multiyear Investment Plan linked to the Poverty Reduction Strategy, envisions an increase in annual public investment in the roads subsector from the current level of about 1.3 percent of GDP (a low level by regional standards) to 2.7 percent of GDP. The resources will be spent mainly on upgrading the existing Corredor Logistico (or Corredor Interatlántico) which runs through the most developed part of the country from the Pacific to the Atlantic coast.

Although the Ministry of Public Works and Housing (SOPTRAVI) in charge of road planning recently launched a campaign to promote private sector investment through road concessions and Public Private Partnerships (PPPs), the focus remains on efficient preservation and improvement of the existing road network. In addition, earmarked taxes directly tied to road use (fixed fees and taxes as a percentage on sales of fuel) finance operations of the Road Fund, a central government agency responsible for road maintenance of the existing official road network in Honduras.

Other state entities, such as the State Forestry Agency AFE-Cohdefor, the Honduran Coffee Institute, the Honduran Telecommunications Enterprise (HONDUTEL), the Honduran Fund for Social Investment, and other state agencies also build or maintain roads, but they are not monitored or regulated by SOPTRAVI. The size of this network ranges from $7,000 \mathrm{~km}$ to $12,000 \mathrm{~km}$ - possibly as extensive as the official network-and no precise estimates are available. As the decentralization of conservation tasks proceeds in the road subsector, it is expected that municipalities will begin to play an increasingly important role in maintaining the local road network (red básica municipal).

\section{Ports}

Five main ports in Honduras (Puerto Cortés, Tela, La Ceiba, and Puerto Castilla, on the Atlantic, and Henecán (or San Lorenzo), on the Pacific) are under the auspices of the National Port Enterprise (ENP), and a private company manages the port of Roatán. The port sector serves the needs of four high-potential economic sectors: agriculture, the forest industry, maquilas, and tourism. Puerto Cortés-which handles 81 percent of domestic cargo - has long waiting times and low productivity in transferring cargo compared to international standards, resulting in comparatively higher costs to users. ${ }^{19}$ With a high rate of growth in cargo shipment, which averaged 7 percent per year during 2000-06, and potential for further growth following the entry into force of the free trade

\footnotetext{
${ }^{17}$ These sections are based on World Bank (2003) and World Bank (2007b).

${ }^{18}$ Appendix Figure 2 shows alternative indicators of road density in Honduras compared to other countries in the region.

${ }^{19}$ Appendix Figure 3 indicates that "maritime connectivity" is lower in Honduras than in any other country in the region.
} 
agreement with the United States, improving port operations is critical for ensuring competitiveness of these sectors. Increased private sector participation in port management, particularly through PPPs, is the main strategic option that has been recommended to improve port efficiency (World Bank 2003, 2007b).

The 1994 Port Master Plan pointed out the need to strengthen environmental management and monitoring of the ports and surrounding areas, including water quality monitoring and establishing environmental control systems. These measures have not been effectively implemented. The rising pressure to upgrade port facilities and engage the private sector in port management increases the urgency of improving port environmental management and strengthening the monitoring and enforcement capacity at the municipal level.

\section{Water and Sanitation}

Water and sanitation services in Honduras are provided by the National Water and Sewerage Service (SANAA), municipalities, and around 2,000 community organizations in rural areas (Juntas de Agua y Saneamiento, JAS). Historically, SANAA operated about half of the urban water and sewer systems, but the sector is undergoing reforms that will decentralize provision of water and sanitation services to the municipal level. The Framework Law on Potable Water and Sanitation in 2003 has given impetus to institutional reforms in the sector: establishment of the National Council on Potable Water and Sanitation (CONASA) with sectoral planning functions, and the Regulatory Authority for Potable Water and Sanitation Services (ERSAPS). The role of SANAA will be transformed from that of a service provider to a technical secretariat, which will provide technical support to CONASA, ERSAPS, municipalities, and service providers.

In the course of sectoral reforms, the Government has defined investment targets to increase coverage and improve reliability and quality of water and sanitation services, as specified in the 2006 Strategic Plan for Modernization of Potable Water and Sanitation Sector (PEMAPS). The role of the private sector in service provision will most likely increase. In San Pedro Sula water and sanitation services are already provided through a concession, servicing nearly 16 percent of the country's population; and three other municipal water and sanitation supply systems are operated by companies with mixed public-private financing.

Decentralization of water and sanitation management functions to municipalities and increasing participation of the private sector in service provision are at the core of the reform strategy in Honduras. But global experience with decentralization in this subsector is mixed and it points to the crucial role of regulation in order to ensure successful outcomes. This is a particularly important lesson for Honduras, where, as recognized by the Honduras Strategic Modernization Plan of the Water and Sanitation Sector (PEMAPS), most municipalities face the challenge of developing adequate institutional capacity to manage decentralized service provision. 


\section{Environmental Management of Infrastructure Projects in Honduras}

A range of complementary policy instruments have been used across the region to mainstream environmental considerations in infrastructure planning: Strategic Environmental Assessment (SEA), standard setting (e.g., ambient quality standards or building codes), land use planning and zoning approaches, project-level Environmental Impact Assessment (EIA), as well as sectoral policies in the area of subsidy provision and tariff-setting.

The primary instrument for managing the environmental implications of infrastructure investments in Honduras is the Environmental Impact Assessment (EIA). EIA is a relatively new process in Honduras and has been legally regulated since 1993. As in many other countries in Latin America, EIA in Honduras is a process driven by the need for environmental approval and licensing. According to Article 5 of the General Law for the Environment, all commercial and industrial projects and all public or private activities that may pollute or degrade the environment need an environmental license and thus, more than 863 environmental license applications have been submitted in 2007, a number that is beyond the capacity of the environmental authority to review and consider. ${ }^{20}$

Despite impressive efficiency gains ${ }^{21}$ at the Ministry of Natural Resources and Environment (SERNA), the agency is overburdened and unable to manage the environmental implications of the country's current projects, let alone an ambitious increase in infrastructure-related projects. The solution to this problem entails not only efficiency gains due to improved processes, equipment, and training ${ }^{22}$; it must include a new approach to environmental management. EIA became the main (and sometimes only) management tool to minimize or mitigate environmental impacts to third parties, due to the absence of regulations for pollution control, zoning, and water management. Only by designing and implementing additional environmental policy instruments (for example, regulations for pollution control, zoning, and water management) will Honduras be able to get efficient, effective, and affordable environmental management.

The new regulations should include environmental standards for the design, construction, and operation and maintenance of infrastructure. By adapting these standards, localized, direct impacts would be managed through the engineering process and be subjected to normal enforcement mechanisms rather than through the EIA process. The EIA would, nonetheless, still play an important role in regulating infrastructure projects that may have significant impacts according to a more selective screening process. The screening criteria may include, among others: protected areas, impacts on vulnerable groups, and vulnerability to natural disasters.

Reliance on Strategic Environmental Assessment (SEA) as a complementary tool of environmental management can improve the effectiveness and efficiency of the

\footnotetext{
${ }^{20}$ Data for 2005 from SERNA.

${ }^{21}$ Due to an inclusion list (lista taxativa) that describes four categories of projects (according to their potential environmental impact or risk) and their corresponding EIA types.

${ }^{22}$ This report includes recommendations with regard to these aspects.
} 
assessment process. Project level EIA - the main instrument of environmental management in Honduras - does not normally capture cumulative impacts of infrastructure projects, for example the effect of construction of several dams in the same watershed, or several roads in the same area. It also does not facilitate comparison of alternatives, for example comparison of environmental impact of alternative areas for tourism development or alternative sites for hydropower plants. These types of analysis can be effectively undertaken through SEA (see Box IV.2.)

\section{Box IV.2. The Role and Practice of Strategic Environmental Assessments}

The Strategic Environmental Assessment (SEA) extends the application of Environmental Impact Assessments (EIA) from projects to policies, programs, and plans. There are several definition of a SEA, but one widely cited definition describes it as "the formalized, systematic, and comprehensive process of evaluating the environmental effects of a policy, plan, or program and its alternatives, including the preparation of a written report on the findings of that evaluation, and using the findings in a publicly accountable decision making." 23

SEAs can be a powerful tool to efficiently and effectively address the environmental implications of infrastructure expansion because: (a) including environmental costs and benefits alongside economic, social, and political concerns allows government authorities to make a more informed decision; (b) including environmental considerations in the decision-making process offers the opportunity to influence the kinds of projects that will be implemented; (c) SEAs may lower the subsequent compliance costs of individual projects and have the potential to streamline inefficient environmental licensing processes; and (d) analyzing programs (rather than isolated projects) facilitates the consideration of cumulative and synergistic impacts of multiple projects.

SEAs are regularly applied in both developed and developing countries, and there is a wealth of established methodologies. Several Latin American countries have used them successfully. In Honduras, the primary instrument for managing the environmental implications of infrastructure investments is the EIA. Reliance on SEA and other complementary tool of environmental management can help make significant progress towards improved environmental and social sustainability of infrastructure projects in Honduras.

The planning capacity of sectoral authorities (especially SOPTRAVI) should also be strengthened. Although SOPTRAVI represents the chief policymaking and planning institution for the transport sector, it does not have the capacity to carry out necessary sector planning activities. This has resulted in the absence of an intermodal vision and sector investment plan to guide the allocation of resources in the sector, which in turn increases the social and environmental costs of projects. In the water and sanitation sector, enhancing the planning capacity at the municipal level is becoming increasingly important with the movement towards decentralized service provision.

\section{Environmental implications of tariff-setting policies for infrastructure services}

Tariff-setting for infrastructure services-water, electricity provision and transportation-has significant social and environmental implications. Defining subsidy and tariff-setting policies is the subject of much controversy and debate, and reforming utility subsidies is politically difficult. The inability of the poor to afford cost recovery

\footnotetext{
${ }^{23}$ Definition by Therivel et al. 1002, as cited in Sánchez-Triana and Enríquez 2005 (p. 1).
} 
tariffs is a common motivation for extending subsidies, which are common across the Latin America and the developing world.

However, subsidies are often poorly targeted and thus benefit higher income consumers more than the poor. A recent review of global experience of subsidy provision for utility services has shown that most common subsidy instruments tend to perform poorly compared with most other transfer mechanisms (e.g., connection subsidies and targeted income transfers) (Komives and others 2005). In the case of SANAA, for example, more than half of its income is derived from external net transfers. To the degree that poor households are not connected to a water or sanitation source, their contributions to the tax base of the country through, say, sales taxes would be a regressive contribution to the running of SANAA (World Bank 2003).

Furthermore, improving service quality and cutting losses in service delivery has proven difficult for publicly funded utilities that set tariffs far below cost recovery levels. When infrastructure services are highly subsidized, financial constraints often prevent utility providers and transportation companies from improving service quality, improving network efficiency, reducing water and energy losses in the system, and extending service coverage to new areas. Besides their impact on financial sustainability of the utilities, subsidies may contribute to the inefficient use of water and energy resources. By keeping consumer rates below that of the cost of provision, consumers are not encouraged to value the service perpetuating wasteful consumption habits.

In Honduras, water, energy and transportation services receive substantial subsidies and tariffs tend to be far below cost recovery levels (Box IV.3). Conversely, raising utility tariffs may be justifiable from financial and environmental perspectives, but policy reforms need to pay careful attention to poverty impacts and be accompanied by social assistance measures to mitigate adverse welfare impacts on vulnerable households. Improving the efficiency of water and energy use must also be an important consideration in the process of devising tariff policy in the water and sanitation and energy sectors. 


\begin{abstract}
Box IV.3. Subsidy provision for infrastructure services in Honduras
The prices charged by the Servicio Autonomo Nacional de Acueductos y Alcantarillados (SANAA) are highly subsidized; it funds only 28 percent of its total expenditure from user charges. Most of SANAA's capital spending is financed through central government transfers, which implies a significant subsidy from general tax revenues to households connected to piped water, which generally tend to be better-off. Similarly, the average price charged for domestic electricity consumption is lower than the average residential rate of private utilities charged in El Salvador and Guatemala. Some of the distortions associated with excessive subsidization of the sector were recently rectified by fixing the total amount budgeted for electricity subsidies per year and distributing it in lump-sum fashion across all customers that use less than 300 kilowatt-hours per month.

Water subsidies promote inefficient use of water resources-a particularly important concern in areas with water scarcity or seasonal water shortages. Subsidizing gasoline and diesel may have high environmental costs in the areas of public health (through increased local air pollution) and climate change (through emission of greenhouse gases). It might seem evident that removing water or electricity/energy subsidies will adversely affect the poor. However, it is important to distinguish cases where the poor do not have access to an infrastructure service from those where they do. In the former, the poor are not directly affected by subsidy removal. In the latter, sudden removal of subsidies could severely hurt the poor, and even make them switch to cheaper and more polluting energy sources, like fuelwood, resulting in indoor air pollution and consequent respiratory diseases. In such cases, some assistance may be required to help poor households obtain cleaner fuels and modern energy services.
\end{abstract}

\title{
3. Recommendations
}

In order to be able to implement the ambitious infrastructure development targets and respond to the emerging new realities brought about by climate change, and the growing number of actors in the infrastructure sectors, Honduras needs effective and credible policy processes to achieve the pressing need to develop infrastructure while preserving the country's natural capital. It can be achieved through improvement in the regulatory and institutional environment, and through enhancing the effectiveness and efficiency of the environmental assessment process (including the use of complementary instruments such as SEA) at the central government and local levels.

\section{Strengthening Regulatory Capacity and Institutions at the Central and Local Levels}

Regulatory arrangements differ from sector to sector in Honduras and will require varied approaches to strengthening. Recent reforms in the water and sanitation subsector aim to achieve a separation of powers by creating the National Council on Potable Water and Sanitation (CONASA) with planning functions and the Regulatory Authority for Potable Water and Sanitation Services (ERSAPS), while service provision is to be managed at the municipal level and by rural community organizations. In the energy sector, policymaking functions are formally assigned to an Energy Cabinet chaired by the president or to the Ministry of Natural Resources and Environment (SERNA), but the National Electricity Company (ENEE), part of SERNA's institutional structure, acts as policy planning body. The transport sector, by contrast, lacks a coherent regulatory framework or an agency with multimodal transport planning functions. With the growing pressures to expand the country's electricity generation capacity and upgrade the road network, it is particularly important to improve policy planning and regulatory functions 
in these sectors. Countries across the region have found that the planning of roads on a network basis can be an effective tool to protect critical habitats and optimize resource allocation from an economic point of view (Box IV.4).

Institutional strengthening needs to occur not only at the central government level, but also at municipal departments with infrastructure planning and environmental management functions. This is particularly urgent in water resources management because of the decentralization process that has begun. Successful outcomes are possible with a long-term strategic vision-in Bogotá efforts to enhance municipal planning capacity, combined with investment in civil works, resulted in restoration of urban wetlands, rehabilitation of wastewater treatment facilities and better flood protection of the city. ${ }^{24}$

\section{Box IV.4. Making roads environmentally sustainable through regional planning in Tocantins}

The Sustainable Regional Development Project in the state of Tocantins, Brazil, has used a regional planning approach to achieve optimal allocation of the statewide road network and enhance environmental assessment and conservation. This was achieved by planning roads as a network within the framework of a broader regional development project and using such tools as land management, agroecological zoning (AEZ) and ecological-economic zoning (EEZ).

This approach is radically different from the classic road-by-road planning. AEZ, completed by the State Highway Management Project, consists of a set of maps characterizing the existing potential and restrictions for the use of land. It serves as a basis for developing EEZ - a more elaborate tool that combines agroecological and economic data and relies on participatory processes to reconcile demands of economic development with ecological conservation and achieve optimal resource use in the state. This is an example of SEA in the road sector.

The regional approach to road planning allows optimal allocation of resources to foster economic growth, guide future development, and at the same time prioritize critical habitats that need to be protected. In Tocantins, it has increased public and government awareness of the need for conservation of critical habitats and identified priority areas for economic development outside these habitats through such measures as public hearings, local development forums and small-scale zoning plans drawn up with strong community involvement.

Note: This World Bank-supported project has been active since December 2003 and is scheduled to close by the end of December 2009. Source: Quintero 2007.

In the water supply and sanitation sector, multi-jurisdictional arrangements can help overcome such problems as the loss of economies of scale, service fragmentation, and the

${ }^{24}$ The wetlands, moorlands and mountain lakes in Bogotá are a valuable asset for the city's long-term development, but they have been severely degraded. A series of engineering works and an innovative architectural design have helped restore ecosystem services generated by these wetlands through an awardwinning project. In addition to civil works to improve the city's water network and wastewater treatment, parks and playgrounds were established in strategically important flood-prone areas, and the project has strengthened environmental planning and assessment capacity at the municipal level. A new environmental department was created within Bogotá's public Aqueduct and Sewer Company (EAAB). It developed a comprehensive program to reduce water losses and ensure sufficient flow to maintain ecosystems health. New equipment and software were purchased to measure water flows, and a water quality monitoring system was established. The engineering works, institutional reforms and public awareness campaigns, have resulted in a renewed drive to restored approximately 500 ha of urban wetlands remaining in the city. 
risk of political and regulatory capture that often emerge in the process of decentralization (World Bank 2004). Even in industrialized countries as France and the United States, the limited capacity of small central governments has provided incentives to serve clusters of political jurisdictions. Multi-jurisdictional coverage has prevented the water provider there from being captured by any one local body - the company or the municipality and the local political elite - and has helped maintain separation between the company and local policymakers. Bolivia's water law explicitly allows multimunicipal companies, and Colombia has permitted its regulatory agency to enforce mergers of nonviable municipal companies.

\section{Recommendations for Enhancing Environmental Sustainability in the Infrastructure Sector}

This Country Environmental Analysis (CEA) report makes six recommendations for enhancing social and environmental sustainability in the infrastructure sector, summarized in Table IV.1:

1. Using complementary instruments - including zoning and Strategic Environmental Assessments (SEAs) —will improve infrastructure planning and assessment of environmental impacts. The advantage of SEAs is the possibility to assess cumulative effects (for example, impacts of building several rather than one hydropower plant in the same river basin, or building a chain of hotels in the same area) and compare alternatives that are not assessed in the standard EIA process. Using these complementary tools can enhance the EIA process and reduce its costs.

2. Information and environmental monitoring systems are urgently needed, particularly in the roads, ports, and water and sanitation subsectors. Thus, little information is available on roads outside of the transport government agency's (SOPTRAVI) jurisdiction; yet the size of this unofficial road network is comparable to the official network monitored by SOPTRAVI.

3. Development of standards - ranging from ambient quality to construction standards and building codes - can reduce arbitrariness in different stages of the EIA process from the initial assessment to drafting and enforcement of mitigation contracts. For repetitive projects with well-known and predictable environmental effects, standards can substitute the need for in-depth EIAs.

4. Zoning plans can be instrumental in guiding official and unofficial road network development and can help avoid critical habitats. Urban zoning plans can help identify areas with high risk of natural disasters and reduce uncontrolled settlement in those areas.

5. The decentralization process increases demand for accountability to the public. Greater community involvement in infrastructure planning and assessment of social and environmental impacts can benefit the infrastructure sector by reducing 
social opposition to large infrastructure projects. Public involvement can be achieved through specifying the modalities of public participation in the infrastructure planning process, in the drafting of mitigation contracts as part of EIAs, and in implementation of ex ante and ex post disaster mitigation measures.

6. The quality of regulation is a key factor behind success or failure of infrastructure concessions. Independent regulation and separation of powers between the planning/regulatory agencies and the operators is particularly important in environments with weak overall governance. Benefits of independent regulation include reduced risk of regulatory capture by local political institutions or by service provider.

7. Provision of subsidies for infrastructure services has significant social and environmental health implications (e.g., provides access to improved sanitation and cleaner fuels to poorer households) that need to be considered in the process of devising tariff policy for infrastructure services.

Specific changes can improve the effectiveness and efficiency of the EIA process. These measures include (a) refinement of EIA screening criteria, (b) reliance on multiple indicators to screen out least-favorable siting options for such projects and hydroplanes, (c) development of norms and construction standards to facilitate assessment of the adequacy of mitigation plans and compliance, (d) strengthening of environmental supervision teams at the local and central government levels, (e) improving staff continuity and knowledge accumulation in environmental units of sectoral agencies, (f) a series of legal measures to specify enforcement sanctions in mitigation contracts, and $(\mathrm{g})$ ensuring community involvement by formally requiring it in relevant stages of the EIA process through such participatory mechanisms such as mesa de concertación and public hearings. By increasing EIA's transparency and reducing bottlenecks, the government would improve the overall investment climate and reduce regulatory risks. This will facilitate private sector participation and improve the government's terms in negotiation of infrastructure concessions.

These recommendations will not only help to better incorporate environmental considerations into infrastructure plans. They will also improve the overall competitive environment by reducing bottlenecks and by setting overall development priorities, enhancing economic growth, and helping reduce poverty. 
Table IV.1. Specific Recommendations by Sector and Issue

\begin{tabular}{|c|c|c|c|}
\hline Sector/Issue & Objective & Planning Tools & Specific Measures \\
\hline $\begin{array}{l}\text { Power, } \\
\text { hydro }\end{array}$ & $\begin{array}{l}\text { Need to compare } \\
\text { alternatives: } \\
\text { - Alternative sites for } \\
\text { hydro projects } \\
\text { - Hydro with other } \\
\text { energy projects and } \\
\text { efficiency } \\
\text { improvements }\end{array}$ & $\begin{array}{l}\text { - Multiple indicators for } \\
\text { project screening (e.g., for } \\
\text { siting of hydropower } \\
\text { projects), zoning maps, } \\
\text { SEAs }\end{array}$ & $\begin{array}{l}\text { - Create an independent planning agency and } \\
\text { a regulator } \\
\text { - Develop municipal capacity for } \\
\text { environmental planning and enforcement } \\
\text { - Rely on multiple indicators as EIA } \\
\text { screening criteria } \\
\text { - Require community involvement in the } \\
\text { drafting and socialization process of } \\
\text { mitigation plans }\end{array}$ \\
\hline Roads & $\begin{array}{l}\text { - Information on } \\
\text { official and } \\
\text { unofficial road } \\
\text { network } \\
\text { - Overcome impasse } \\
\text { over the extractive } \\
\text { industries law by } \\
\text { identifying sensitive } \\
\text { and nonsensitive } \\
\text { areas }\end{array}$ & $\begin{array}{l}\text { - Geographic Information } \\
\text { Systems (GIS) data to map } \\
\text { location roads outside of } \\
\text { SOPTRAVI's jurisdiction } \\
\text { - Zoning maps/overlays of } \\
\text { agro-ecological factors } \\
\text { with maps of planned road } \\
\text { network } \\
\text { - Identify most sensitive } \\
\text { areas in need of in-depth } \\
\text { monitoring } \\
\text { - Strengthen municipal } \\
\text { capacity }\end{array}$ & $\begin{array}{l}\text { - Refine EIA criteria (e.g., to require EIA for } \\
\text { road rehabilitation and maintenance if it } \\
\text { occurs in sensitive areas) } \\
\text { - Map location of roads even if they are } \\
\text { outside of SOPTRAVI's jurisdiction } \\
\text { (unofficial) } \\
\text { - Develop norms and standards for unofficial } \\
\text { road network } \\
\text { - Enhance SOPTRAVI's planning and } \\
\text { enforcement capacity by better staff } \\
\text { continuity (retain a key group of competent } \\
\text { staff independent of electoral cycles; training) } \\
\text { - Develop municipal capacity for } \\
\text { environmental planning and enforcement }\end{array}$ \\
\hline Ports & $\begin{array}{l}\text { - Monitoring } \\
\text { environmental } \\
\text { quality }\end{array}$ & $\begin{array}{l}\text { - Use zoning maps and } \\
\text { SEA in addition to EIA }\end{array}$ & $\begin{array}{l}\text { - Refine EIA criteria } \\
\text { - Develop municipal capacity for } \\
\text { environmental planning and enforcement }\end{array}$ \\
\hline $\begin{array}{l}\text { Water } \\
\text { supply and } \\
\text { sanitation }\end{array}$ & $\begin{array}{l}\text { - Create a regulatory } \\
\text { framework for water } \\
\text { use (Water Law) } \\
\text { Issues specific to } \\
\text { decentralization: } \\
\text { - Avoid the risk of } \\
\text { service } \\
\text { fragmentation and } \\
\text { the lost economies of } \\
\text { scale } \\
\text { - Avoid regulatory } \\
\text { capture } \\
\text { - Guarantee adequate } \\
\text { water quality (e.g., } \\
\text { facilitate public and } \\
\text { private investment in } \\
\text { wastewater } \\
\text { treatment) }\end{array}$ & $\begin{array}{l}\text { - Promote } \\
\text { multijurisdictional } \\
\text { arrangements for water } \\
\text { supply } \\
\text { - Pass the general Water } \\
\text { Law to regulate water use } \\
\text { and mitigate future } \\
\text { pressures in water-scarce } \\
\text { areas } \\
\text { - Water quality monitoring } \\
\text { data }\end{array}$ & $\begin{array}{l}\text { - Ensure independence of the regulator (e.g., } \\
\text { by guaranteeing financing, making staff } \\
\text { appointments independent of electoral cycles) } \\
\text { - Develop municipal capacity for } \\
\text { environmental planning and enforcement }\end{array}$ \\
\hline $\begin{array}{l}\text { Disaster risk } \\
\text { mitigation }\end{array}$ & $\begin{array}{l}\text { - Enhance ex ante } \\
\text { mitigating measures } \\
\text { - For ex post, assess } \\
\text { feasibility of } \\
\text { regional disaster } \\
\text { insurance schemes }\end{array}$ & $\begin{array}{l}\text { - Multisectoral planning, } \\
\text { coordination across } \\
\text { agencies, zoning, SEA, } \\
\text { public education to raise } \\
\text { awareness of disaster } \\
\text { mitigation measures }\end{array}$ & $\begin{array}{l}\text { - Protect critical environmental assets } \\
\text { (wetlands, mangroves, and mountain lakes) } \\
\text { - Include standards and norms to minimize } \\
\text { vulnerability to disasters in building/ } \\
\text { construction contracts and zoning in urban } \\
\text { areas to reduce urban sprawl into high- risk } \\
\text { areas } \\
\text { - Public education campaigns }\end{array}$ \\
\hline
\end{tabular}




\section{Forest Resources and Management}

\section{Forest resources—a source of income and economic opportunities in Honduras}

Forest resources are an important source of income for the rural poor world-wide and their sustainable use can make a large contribution to economic growth, particularly in rural areas. Yet forest resources are under severe pressure-Honduras experiences one of the highest deforestation rates in the region of 2.5 percent per year compared with the average of 0.4 percent for the Latin America and Caribbean region and 0.1 percent in the world during 1990-2005. Forest resources are a major component of the overall natural capital of Honduras, and, as recognized by the Government in its recent attempts to improve the regulatory and institutional framework for forest resources, their conservation and sustainable use are urgently needed.

The relationship between people and forests in Honduras has some particular characteristics, and understanding these characteristics is vital to any analysis to determine the adequacy of forest management in a legislative and institutional context. Forest resources offer large untapped potential for achieving higher economic growth and benefits to the poor in Honduras for several reasons: ${ }^{25}$

- Poverty in Honduras is strongly concentrated in rural areas: About $74 \%$ of the country's poor people, and $86 \%$ of the extremely poor, live in rural areas.

- Honduras has very significant forest resources, covering an estimated $57,916 \mathrm{~km}^{2}\left(51.5 \%\right.$ of the national territory), of which $32,855 \mathrm{~km}^{2}(56.7 \%$ of forests, or $29.2 \%$ of national territory) is considered to have potential for forest management.

- Forest resources are suffering from high rates of deforestation, largely as a result of clearance to establish more profitable land uses, and degradation, due to a combination of uncontrolled fires and poor silvicultural management.

- Little use is made of the forest resource in practice as a means of generating income and employment for the rural poor: only a small proportion of the area with potential for forest management (31\% in 2005-2006) is covered by forest management plans, and only $15 \%$ of forest owners make commercial use of timber.

- Minimal investment is made in protecting the regenerative potential of forest resources: Although 78\% of the forests under management plans were found to have received some form of silvicultural treatment, over $86 \%$ of this area consisted solely of selective felling; only $4 \%$ had received pre-commercial thinning and 3\% liberation of seed trees.

- A large share of forest resources cannot legally be used at present due to the lack of clear definition of tenure and usufruct rights: national forests account for a

\footnotetext{
${ }^{25}$ These key statistical facts are based largely on the results of the 2005-06 Inventory of Trees and Forests (Zea and Salgado 2006).
} 
very large proportion (45.7\%) of the forest estate, however with around $60 \%$ of this nationally-owned forest there is no formal registry of tenure, and around $12 \%$ has 'informal' occupants (with no legal status).

- The organizational and technical capacity of forest owners is generally weak: Only an estimated $39 \%$ of forest owners belong to some type of organization (cooperatives account for only 8\% of forest owners), and only around $10 \%$ of forest owners and occupiers have received technical assistance (with only $4 \%$ this has been in relation to forestry issues).

The forest resources in Honduras, in silvicultural, ecological, commercial, and socioeconomic terms, are highly heterogeneous. This heterogeneity stems from a combination of the country's climatic and topographical conditions, and the history of human influence on the resource. The role that forest resources play in economic growth and poverty reduction, and pressures they experience vary by forest type and socioeconomic conditions (see Box V.1).

\section{Box V.1. Diverse forest types, pressures and uses of forest products in Honduras}

- Virtually monospecific Pinus oocarpa forests in the mountainous interior of the country: This forest type occupies 36 percent of the total area of accessible forest resources and around 18 percent of their total volume. At higher altitudes $P$. oocarpa tends to give way to a number of other less common pine species. The selective felling of this forest type has been the principal focus of the forest industry in Honduras. The main pressures affecting this resource are the inadequate attention paid to protecting the forest's regenerative capacity when carrying out selective felling (for example the inadequate protection of seed trees and damage to forest soils); forest fires, which - when they occur at a low frequency and intensity - serve to perpetuate this type of forest growth, but-when fires are excessively frequent or intense-inhibit regeneration and kill mature trees; and the conversion of forests to agriculture and pasture.

- Tropical broadleaved forest in the humid north: This forest type occupies 51 percent of the total area of accessible forest resources and 70 percent of their total volume. It contains a large diversity of usable species. However, forestry activity is focused on the highly selective creaming off of a very limited number of species, principally mahogany (Swietenia macrophylla) and cigar-box cedar (Cedrela odorata). The main pressure affecting this resource is its conversion to agriculture and pasture, a process that is facilitated by the typically limited governance conditions at the agricultural frontier and that has been exacerbated (particularly during the process of agrarian reform from the 1960s to the 1990s) by the influx of migrant farmers. Selective felling degrades the structure and ecology of the forest and facilitates its conversion to agriculture and pasture.

- Dry forest and shrub: This vegetation type occurs naturally on the Pacific slopes (up to around 800 meters) and coastal plains surrounding the Gulf of Fonseca and also in numerous valleys in the interior that are affected by rain shadows. ${ }^{26}$ It has been heavily impacted by agricultural and grazing activity and only a few isolated and heavily disturbed remnants of closed canopy forest remain. In the flat cultivable valleys and coastal plains, the elimination of vegetation has been almost complete. However, on the steeper slopes of the Pacific drainage the original forest has been replaced by an "agroecosystem" with large numbers of scattered trees and stumps of diverse species.

- The "agro-ecosystem" in areas throughout the country affected by human activities: This area accounts for most of the 48.5 percent of the country not under forest cover. It contains large numbers

${ }^{26} \mathrm{~A}$ rain shadow is a region of reduced rainfall on the wind-sheltered side of high mountains. 
of trees, in fence lines, scattered throughout pastures and fields and secondary regrowth in temporary fallows. Trees in these circumstances play a major role in livelihood support as sources of timber, firewood, fruit, fodder, and other products, and also support a large proportion of the country's biodiversity, albeit in conditions that have been highly altered by human influence. In some areas, such as the smallholdings of the dry south, this resource is managed in a sustainable manner in traditional agroforestry systems (Barrance and others 2003). However, in other areas it is under threat from agricultural intensification and the replacement of agriculture by extensive pastures.

- Cloud forests, above around 1,800 meters altitude: These largely broadleaved forests play vital hydrological roles as they capture moisture from clouds, facilitate water infiltration, and buffer against extreme stream flows and landslides. They are also very important for wildlife conservation, because they have high levels of endemism and also serve as "stepping stones" for migrant birds. They suffer from high rates of deforestation and degradation, largely due to the establishment of coffee farms, pasture, vegetable farms, and staple grains.

- Pinus caribaea savanna: This forest type is largely concentrated in the isolated Mosquitia region, although more limited populations of $P$. caribaea also occur elsewhere along the north coast. The main threat affecting this vegetation type is grazing practices, which suppress natural regeneration, and fires. The damage by fire has in some cases been exacerbated by overzealous attempts to control fire outbreaks, which have led to the accumulation of large amounts of fuel.

- Mangroves, principally around the Gulf of Fonseca, on the country's Pacific coast: Mangroves play vital roles as breeding areas for fish, as wildlife reserves, and as buffers against coastal erosion. The principal pressures that these face include the extraction of timber and firewood, and the establishment of shrimp farms, either in the mangrove areas themselves or in the mudflats with which their ecology is inextricably linked.

\section{Main Areas of Potential Contribution of the Forest Sector to Reducing Poverty}

This report focuses on those aspects of forest resource management covered in the draft law that are most relevant in the fight against poverty. The following sections address these aspects of the law.

\section{Community-based Forest Management}

In theory, community-based forestry management has the potential to generate benefits for the rural poor through the sale of the forest products and the provision of paid employment, as well as giving rural communities control over how the forest resources on which they depend for income, subsistence products, and water supply are managed. This activity also has the potential to generate indirect benefits for the poor, through the payment of stumpage and taxes to the government, which can then be invested in social, economic, and infrastructure development programs that benefit the poor.

The legal and institutional foundations for community-based forest management in the country were laid with the establishment of the Social Forestry System (SSF) in the 1970s, and the passing of the 1974 COHDEFOR Law, which established the Honduran Forestry Corporation (COHDEFOR). There are serious questions regarding the economic viability of community-based forest management, specifically in species-diverse tropical broadleaved forests, where significant markets exist for only a limited proportion of the species present (as is the case in Honduras). In theory, increases in access to niche 
markets and premium markets following forest certification can improve this viability to some extent. However, this has yielded significant and lasting results in only a limited number of cases. In truth, forest management under these conditions is likely to be viable only if the non-timber values of the forest, specifically environmental services in the form of hydrological protection and carbon sequestration, are recognized and internalized.

\section{Commercial/Industrial Forest Management}

The management of forests by commercial companies also has the potential to generate employment among the rural population and to generate fiscal revenue through the payment of stumpage and taxes. Industry interests also argue that commercial companies have greater technical and commercial capacities for forest management than community-based enterprises, and as a result are able to make more efficient use of the forest resource and generate greater net benefit for the national economy. Conversely, local communities and civil society groups often argue that the employment generated by the forest management carried out by private industry does not necessarily favor local communities, and also that external private interests have limited motivation to invest adequately in durable infrastructure, the avoidance of negative environmental impacts (for example, on water courses), and the promotion of natural regeneration of tree populations.

\section{Protection of Environmental Services}

The rural poor are both producers and consumers of environmental services. The effective conservation of forest resources is a major factor in the sustainability of their livelihoods, given their typically high levels of dependence on forests for the provision of subsistence products and water, and for the buffering of extreme climatic events. The appropriate management of protected areas has an important role to play in providing these benefits, as does the effective protection of production forests and trees in agricultural landscapes. Meanwhile, as managers of trees and forests, particularly on hillsides, they also affect the flows of environmental goods and services, on which they and others downstream depend. There is potential for the costs and benefits associated with this role to be internalized through a payment for environmental services program, which could contribute to their income and also motivate them to invest more in resource protection.

\section{The Timber Processing Industry}

The timber processing industry has a strong indirect role to play in the combat of rural poverty. Given the currently limited technical and financial capacities of rural farming groups, timber processing is likely to continue to be concentrated principally in the hands of the private/industrial sector for the foreseeable future, and specifically in centralized locations where there is good access to services and labor. The existence of a thriving private sector is therefore essential for the viability of the rural farm sector, for the purchase, transport, and transformation of the timber it produces, and the marketing of the resulting products. The employment generated by the timber processing industry is 
principally concentrated in urban centers, and therefore offers little direct benefit for the rural poor.

\section{Forestry Plantations}

The establishment and maintenance of forest plantations, and the harvesting and transformation of their products, has the potential to generate significant employment for the rural poor. Forest plantations also have the potential to generate income, forest products, and environmental services. This depends, however, on a number of factors, including (a) access to secure long-term land tenure, which the majority of the rural poor do not enjoy (with some exceptions such as organized groups associated with the Social Forestry System and the Agrarian Reform), and (b) the scale and type of silvicultural regimes employed. Small woodlots and agroforestry systems are more likely to be compatible with the livelihood systems of the rural poor, to produce the kinds of products and services that they need, and to be feasible under their prevailing conditions of tenure, than are large monospecific plantations, which in some cases risk contributing to the marginalization of the poor from the land available for farming. Diverse, multilevel tree systems are also more compatible with sound watershed management than are pure plantations, which in some cases can actually exacerbate erosion problems. Meanwhile, the potential of naturally regenerated trees on farms to generate goods and services in a manner that is highly compatible with farmers' traditional production systems is frequently neglected.

\section{Trees in Farming Systems}

Trees play a fundamental role in the farming systems and livelihoods of the rural poor, as a source of diverse products and services such as fence posts, building materials, firewood, fruit, fodder, nitrogen fixation, slope stabilization, and microclimate moderation for domestic and cropping areas. The relationships between trees, farming systems, and livelihoods vary widely between the different agro-climatic and ecological zones in the country, and in general are poorly understood and inadequately reflected in the design of both rural development programs and regulatory instruments. In many cases (for example in the robust agro-ecosystem of the dry south), the potential of naturally regenerated on-farm trees to be harvested sustainably as a source of timber and firewood is underestimated. Similarly underestimated are the opportunities that exist to increase the number of trees on farms, either by planting or natural regeneration, without negative effects on crop production and with positive implications for livelihood diversification, income generation, and environmental risk reduction. 
Table V.1: Implications of Forest Resource Management for the Rural Poor

\begin{tabular}{|c|c|}
\hline $\begin{array}{l}\text { Forms of Tree and Forest Resource } \\
\text { Management }\end{array}$ & Relevance for the Situation of the Rural Poor \\
\hline $\begin{array}{l}\text { Community-based forest management } \\
\text { by cooperatives and rural farming } \\
\text { groups }\end{array}$ & $\begin{array}{l}\text { - Direct income for cooperative/group members through the } \\
\text { sale of forest products } \\
\text { - Employment for nonmembers in forest protection, harvesting, } \\
\text { transformation, and transport } \\
\text { - Generation of revenue for reinvestment in community } \\
\text { projects, through fiscal income and sale of products from } \\
\text { municipal forests } \\
\text { - Influence of cooperative/group members over how the forest } \\
\text { resource is managed }\end{array}$ \\
\hline $\begin{array}{l}\text { Commercial/industrial forest } \\
\text { management }\end{array}$ & $\begin{array}{l}\text { - Employment for nonmembers in forest protection, harvesting, } \\
\text { transformation, and transport } \\
\text { - Generation of revenue for reinvestment in community } \\
\text { projects, through fiscal income and sale of products from } \\
\text { municipal forests }\end{array}$ \\
\hline $\begin{array}{l}\text { Protection of environmental service } \\
\text { supply }\end{array}$ & $\begin{array}{l}\text { - Protection of natural capital on which livelihood } \\
\text { sustainability depends } \\
\text { - Generation of income through payment for environmental } \\
\text { services }\end{array}$ \\
\hline Timber processing industry & $\begin{array}{l}\text { - Employment (though largely concentrated in urban centers) } \\
\text { - Provision of markets and services on which community-based } \\
\text { enterprises depend }\end{array}$ \\
\hline Forest plantations & $\begin{array}{l}\text { - Employment } \\
\text { - Income from sale of products (though most common } \\
\text { beneficiaries will be the less poor) } \\
\text { - Possible marginalization of rural poor from access to land }\end{array}$ \\
\hline Management of trees on farms & $\begin{array}{l}\text { - Provision of goods and services of importance for livelihoods } \\
\text { and farming systems }\end{array}$ \\
\hline
\end{tabular}

\section{Policy, Institutions, and the Legal Framework}

\section{Evolution of Forest Sector Policies and Institutions}

In Honduras, the agency responsible for the administration and management of forest resources is the State Forest Administration (AFE-COHDEFOR). Established in 1974, it is part of the country's agricultural sector, and is a decentralized entity. Until a few years ago, AFE-COHDEFOR was considered one of the most important forest services, not only in the region, but in the world. However, numerous policy changes and conflicting priorities have weakened the institutional capacity.

In 1993, the passage of the Law for the Modernization of Agriculture began eliminating certain activities of AFE-COHDEFOR, converting the body into a basic regulatory agency. One of the most remarkable aspects of this law was the creation of the Social 
Forestry System, which defines the sustainable use of forests with the participation of local farmers, in the form of cooperatives and other forms of association.

The reforms in the macroeconomic policies of modernization and institutional reform have an impact on legislation and on the administrative organization of the public institutions responsible for managing not only the forest sector but also the management of natural resources in general.

The goal of AFE-COHDEFOR is to achieve the optimum use of the forest resources available to the country, and to ensure the protection, enhancement, and conservation of the resources. The lack of a long-term forest policy is a constant concern, but AFECOHDEFOR has begun to address the issue with the preparation of the Forestry Action Plan 1996-2015 (PLANFOR). The action plan remains in its infancy, however.

This first phase of general policy included the definition of basic programs, guidelines, and strategic actions that somehow stimulated the inclusion of the forest sector within the broader national policies and priorities. In 1991, it issued a decree transferring the management of protected areas and wildlife to the AFE-COHDEFOR administration. The responsibility for these policies and their evaluation rests with the Ministry of Environment and Natural Resources (SERNA), which has also coordinated the National System of Protected Areas of Honduras (SINAPH) since 1993.

In 2000, the Secretariat of Agriculture and Livestock (SAG) and AFE-COHDEFOR, in the context of a Honduran Diary Forest, led the design of the Forestry Policy, the Protected Areas and Wildlife 2000-2025.

As mentioned, however, this policy was not continued by subsequent administrations. After several decades, in 2000 a plan was developed, similar to PLANFOR of 1996, and most recently this policy has been refined as the National Forestry Program (PRONAFOR).

Despite putting into practice these different policies, Honduras has been unable to effectively implement a long-term forestry policy. Based on the above, it seems clear that Honduras has not had a strong tradition of forest policy and long-term planning. However, some facts elicited from various government institutions show an increase in governmental interest in the forest sector. 
Box V.2. The National Fund for Protected Areas: a Promising Alternative for the Conservation of Biodiversity in Honduras.

\section{Biodiversity in Honduras}

Honduras contains a wealth of biodiversity and natural resources, with ecosystems stretching from coral reefs off the Caribbean coast to mountainous tropical forests further inland. Their protected areas are integral part of the Mesoamerican Biological Corridor and include some areas of habitat of global biodiversity importance that are critical for species and ecosystem processes. Moreover, their natural resources are critical for indigenous and ladino communities who directly depend on the social and economic opportunities that they represent as well as the cultural values it safeguards.

\section{Status of the National Protected Areas System}

Honduras has 98 protected areas, of which only 35 have a firm legal basis. The rest are to become protected areas as stipulated by Presidential Agreement 1118-92. Almost all are severely understaffed and lack resources; many do not have basic information on size and limits. Currently, responsibility for protected areas lies with SERNA and AFE-COHDEFOR. SERNA is responsible for natural resources and the environment, and for policies related to protected areas. AFE-COHDEFOR is responsible for their management, and in some cases delegated to nonprofit, nongovernmental organizations (NGOs).

\section{Honduran Protected Areas Fund - A First Step}

The National System of Protected Areas (SINAP) is staffed by dedicated professionals but severely under funded and often lack the capacity and legal frameworks necessary to carry out their mandate. The creation of the Honduran Protected Areas Fund (Fondo Hondureño para la Conservación de la Naturaleza FHCN) to be administered by the Honduran Protected Areas Foundation (Fundación Hondureña de Áreas Protegidas) is a direct answer to SINAP's need for support and a firm step forward towards its long term sustainability. The Fund was created by Executive Decree No. 0685 for the protection and conservation of protected areas. The new forest law creates a Forest Reinvestment Fund and restates the legal provision for the Protected Areas Fund.

The FHCN has been supported by, among others, the World Bank and has the potential to become a solid institution that can grow as a stable source of funding for conservation activities. The new Fund can build on previous experiences where protected areas have been supported by NGOs using specific Funds (i.e. the Honduras-Canada Environmental Management Fund [FMMAHC] implemented by CARE and the now closed Fundación Vida Protected Areas Fund). These Funds have supported the institutional development and consolidation of the SINAPH.

\section{Looking Ahead}

Proposals for the creation of funds are not new in Honduras. For example the Forestry Law of 1971 created a Forestry Fund, which was cancelled after a few years; subsequently the Forestry Incentives Law of 1993 created a series of incentives, but regulations for this law were never produced with the result that the law as a whole was never applied. The FHCN may face similar or even more cumbersome challenges. The allocation and management of funds as well as the performance of the screening committee will be under continuous scrutiny.

\section{The Legal Framework}

On 13 September 2007-after public discussions that lasted for three Presidential terms $^{27}$ - a new General Forestry Law was approved by the Honduran National Congress. It is expected that the law will be fully regulated and applied by mid-2008. This section examines the degree to which institutional conditions exist for the intent of the new law

\footnotetext{
${ }^{27}$ At the time of writing (October 2007), the law was undergoing a final review. To take effect it still requires ratification by the President of the Republic, and regulations need to be drafted and approved.
} 
to be translated into reality, and highlights specific areas in which institutional strengthening is required. The report pays particular attention to the potential for the law to be applied in such a way as to contribute to the reduction of poverty.

\section{The Main Implications of the New Law}

The law aims to raise the profile of forestry issues, revitalize the state forestry authority, reactivate the Social Forestry System, provide incentives for sound forest management and conservation, and increase the effectiveness of forest protection.

The new law will:

- Differentiate forestry as a sector in its own right, rather than part of the agricultural sector as at present.

- Create a new lead institution in the forestry sector, the Institute for Forestry Conservation and Development (ICF), which will be attached to the Presidency of the Republic rather than to the Ministry of Agriculture.

- Eliminate the budgetary dependence of the forestry authority on income from auctions of timber on public lands.

- Increase provisions for public participation and consultation, through the formulation of Consultative Councils at the national, departmental, municipal, and community levels.

- Establish funds and incentives for forestry management and protection.

- Formalize the contractual arrangements for forest management, with the introduction of short-, medium- and long-term contracts and the replacement of usufruct agreements with usufruct contracts.

The formal recognition by this law of forestry as a sector in its own right, and its reformulation of the lead institution of the sector, are important milestones in the history of Honduran forestry. In other aspects, however, the law serves principally to consolidate and reinforce the provisions of existing legislation. By reactivating the Social Forestry System, it seeks to give continuity and reality to the ideal of community-based forest management contained in the 1974 Law for the Creation of COHDEFOR; it does not contradict the provisions of the 1992 Law for the Modernization of the Agricultural Sector, which returned ownership rights of trees and forests to the owners of the land on which they stand; and it seeks once again to provide incentives for forestry activities, as did the Law for Forestry Incentives (unsuccessfully) in 1994.

\section{Principal Bottlenecks for the Implementation of the New Law}

Conflicts and polarization of stakeholder positions are central causes of the current failure of the forest sector to contribute adequately to combating poverty. The new law proposes unprecedented opportunities for this problem to be resolved, including the formation of Consultative Councils at a number of levels. These would be completely new and unproven entities, however, and at present their intended participants do not 
have the necessary negotiation and conflict management skills to enable them to take advantage of this opportunity and negotiate and resolve their differences in a constructive manner. Limited capacities for conflict management also constitute a major risk to the successful nationwide replication of the process of regularization of forest land use and tenure rights, currently being supported on a pilot basis by the World Bank-supported Forests and Rural Productivity Project (PBPR), and which is an essential prerequisite for the realization of forestry activities by community-based groups under the Social Forestry System.

Capacities of forest user groups: The abilities of community-based cooperatives and other forest user groups to participate competitively in forest management, and to take advantage of funding opportunities, continue to be constrained by their limited technical, administrative, commercial, and organizational capacities. This situation is in turn perpetuated by limitations in capacities among institutions such as COHDEFOR and their federation FEHCAFOR to provide them with support. The provision of such support is foreseen as one of the mandates of the new ICF; compliance with this responsibility will again depend on the institution's capacity to attract sufficient budgetary allocations, and the establishment of the required institutional structures and logistical resources.

Expertise of forest professionals: The new draft law places a large amount of responsibility on forestry technicians and modifies the nature of their relations with other stakeholders. Under the new law, foresters will in the future require increased social awareness and negotiation skills, in contrast with their typical focus at present on more narrowly technical aspects of silviculture, management planning, and supervision, a situation that at present is perpetuated by the nature of the training delivered by educational institutions. The effectiveness of the Forest Guards that are proposed in the current draft of the law will also depend heavily on them being provided with adequate training, and on the abilities of educational institutions to expand their physical and financial capacities to provide it.

Institutional funding: The new law gives major responsibilities to the ICF, certain of which in particular (such as supervision and the provision of technical support) assume high levels of funding access. The proposed change in the funding modality of COHDEFOR, when it is transformed into the ICF, is positive because it will reduce its dependence on timber auctions for its income. There is no guarantee, however, that its budgetary allocation will be adequate for it to meet these multiple responsibilities. The ability of the new institution to attract a sufficient budget will depend on its ability to "reinvent itself" and project a positive image both of itself and of the forest sector as a whole, free from the accusations of operational ineffectiveness and corruption to which COHDEFOR has historically been subject. The effective application of forestry regulation will also require the adequate provision of funding to the Environmental Prosecutor's office, which at present is able to process only a small proportion of infractions but which will have a significantly increased workload given the proposed emphasis under the new law on classifying infractions in the forest sector as crimes rather than misdemeanors. 
Institutional efficiency: At present COHDEFOR faces problems of institutional inefficiency, for example, in the disbursement of expenditure and the approval of forest management plans, delays in which constitute serious problems for community-based forest management groups. The new ICF will face the additional challenge of having to adapt to unprecedented requirements for stakeholder consultation under the new law. To be effective, the "reinvention" of the new institution will have to include the development of internal procedures and organizational structures in order to guarantee efficiency.

Capacity of municipal governments: Municipal governments have major potential to contribute to forestry governance at the local level, and this is recognized in the draft law, which gives them a wide range of responsibilities. Many municipal governments, however, have limited financial, administrative, and technical capacities to assume these responsibilities. With some notable and promising exceptions, municipalities with significant areas of eijdo forests fail to take advantage of the potential of these to generate income, and other municipalities do not collect all of the fiscal revenue due to them.

\section{Recommendations}

The new legal framework offers important opportunities for promoting pro-poor forest management. It also represents a major opportunity for realizing the economic potential of the forest sector and reforming relevant institutional structures in such a way as to overcome the stagnation and loss of credibility that have affected them to date. The next few months and years, following the recent approval of the law by Congress, will constitute a crucial window of opportunity for support by cooperation agencies such as the World Bank, the effectiveness of which is likely to determine how the forest sector will develop over the coming several decades.

Key areas of support should include the following:

- Development of pilot experiences with Consultative Councils, across a range of biophysical, productive, and socioeconomic contexts, backed up by training of participants in negotiation skills, training of members of the ICF, municipalities, and nongovernmental organizations (NGOs) in facilitation, and systematization and replication of experiences.

- Scaling-up of capacities in alternative conflict management, including logistical, funding, and methodological support to an increased number of pilot experiences (for example, within the context of the regularization processes currently supported by PBPR), and training of members of municipalities, NGOs, civil society groups, and the ICF. This will be of particular relevance to the processes of regularization provided for in the new law and will also serve to create a favorable climate for investment in the forestry sector, which is essential for the functioning of the Social Forestry System that the new law seeks to reactivate.

- Follow-up to regularization processes, continuing the support provided under the PBPR project, in order to ensure consolidation of the capacities of the institutions 
involved, based on lessons learned in the PBPR pilot, and taking advantage of the supportive legal environment offered by the new law.

- Development of lasting capacities for the provision of support to forest user groups, in accordance with the focus of the new law on reactivating the Social Forestry System. This may be achieved either directly through the ICF, through private and NGO service providers, or through direct alliances between the forest user groups and private service providers.

- Strengthening and broadening of forestry education, in order to equip forestry professionals to address social and environmental issues in accordance with the spirit of the new law, and to enable ground-level staff to function effectively in their supervisory role.

- Scaling-up of successful experiences with municipal support to sustainable forest management, focusing especially on the development of technical capacities for resource planning and supervision, administrative capacities in order to ensure sustainability, and mechanisms for social control and participation as provided for under the new law.

- Reinventing the institutional profile and culture of the forest authority, taking advantage of the transformation under the new law of COHDEFOR into the ICF, and complementing Inter-American Development Bank support to infrastructure, technological, and administrative aspects.

Even under the favorable legislative conditions provided by the new law, communitybased forest management (CBFM) is likely to continue to face significant challenges as a mechanism for conferring benefits to the rural poor, including the difficulty in practice of regularizing tenure and use rights on national forest lands, and its limited profitability under prevailing market conditions. CBFM should therefore be seen as only one of a suite of strategies for realizing the potential of tree and forest resources to combat poverty. Others include:

- Forest management by the private sector where appropriate, in order to make use of the available yield that the rural farming sector does not have the capacity to harvest, thereby generating jobs and fiscal revenue. The implications of this for the rural poor depend, however, on the existence of adequate controls to ensure that environmental and social norms are respected.

- The application of schemes to market the environmental services provided by forests, thereby complementing the income generated from CBFM and increasing the ability of forest cover to compete with alternative land uses. The development of methodologies for the application of such schemes on a large scale is still in its infancy.

- Promotion of the role of trees as sources of goods and services to the livelihoods and farming systems of the rural poor. The complex relations between trees and livelihoods are still inadequately reflected in the design of many rural development programs and are undermined by a broad-brush and restrictive regulatory environment. 


\section{Conclusions and Recommendations}

Honduras, a small country in which natural capital is an important share of total wealth, needs to accelerate its economic growth to reduce urban and rural poverty. To do so, however, the government needs to ensure that the best affordable environmental and natural resource management is in place to secure sustainable economic development. The benefits of further improvements to the environmental institutional and regulatory frameworks will be substantial not only to facilitate and sustain economic growth, but in terms of preserving both the natural resource base on which economic growth depends and the health of the people in Honduras.

These benefits will not come from simply scaling-up the Ministry of Natural Resources and Environment's (SERNA's) current activities by increasing its budget and staff. The study suggests that most of these objectives can be achieved in a short time with minor adjustments of the existing framework of environmental management, which are likely to be implemented by executive orders. In the long term, deeper reforms to the legal framework for water and territorial management, and transparency, would be needed, but they need longer periods of maturation, consensus building, and negotiation, and ultimately congressional approval. Therefore, the study makes the following recommendations.

\section{Operationalize the Environmental Policy of Honduras}

One of the greatest institutional weaknesses identified is the lack of an environmental policy that orients the country toward specific goals. Although SERNA has issued an environmental policy, it lacks clear short-, medium-, and long-term priorities. SERNA should transform the good principles established in its policy into goals and actions.

In the short term, the policy should (a) establish what it aims to achieve during the rest of the current administration, with measurable results that focus on resolving only environmental priorities, and (b) clearly define responsibilities among different institutions.

\section{Strengthen the Role of SERNA as a Sectoral Leader}

The General Law for the Environment (1993) calls for SERNA to establish environmental policies and norms. To date, SERNA has centered its efforts on evaluating Environmental Impact Assessments (EIAs) but has shown less capacity in planning national environmental policy and in monitoring and enforcement. For this reason, the report recommends that the Ministry of Natural Resources and Environment (SERNA) prioritize its role in managing governance instruments such as environmental laws, regulations, and enforcement actions and decentralize some of its implementation responsibilities.

Specifically, the report recommends: 
(a) Activitating the National Advisory Council for the Environment (COCONA) to serve as an advisory board to the Ministry for policy and regulation. The Council should, at a minimum, have the responsibilities to:

- Provide recommendations on the formulation and design of sectoral policies and norms.

- Recommend actions that support compliance with the legal framework.

- Present initiatives that support the development of new norms.

- Promote programs on pollution prevention, environmental education and information, and dissemination.

- Act as an information source in order to support transparency.

The Council should be expanded to comprise all stakeholders that have environmental responsibilities, including representatives of the public and private sectors, civil society, NGO's, academia, and indigenous groups. To ensure that the Council is effective, it should meet biannually and provide biannual reports on its actions. Once the Council has been formed, it is recommended that SERNA seek support from UN-system or bilateral donors in overseeing the Council's recommendations.

(b) Decentralizing responsibilities. SERNA has multiple responsibilities but few resources to fulfill them, which in turn limits the coverage and capacity of the country's environmental management. As such, the report recommends developing a strategy to increase the efficiency and effectiveness of environmental management via the selective decentralization of environmental functions. Only a few municipalities with strong installed capacity would initially be eligible. This strategy would begin with an initial phase of decentralizing the receipt and management of environmental assessment applications (only Category 1 and 2 projects) and information requests, and later be extended to include environmental oversight and analysis functions.

\section{Address Regulatory Gaps}

This report recommends the modification or issuance of the following legal instruments:

(a) A General Law for the Environment, a Forestry Law, and a Zoning Law in order to harmonize the responsibilities established by them.

(b) Standards for:

- Activities that have a predictable and measurable environmental impact

- Ambient quality particularly for water and air.

(c) Regulations on solid waste management. 
(d) A National Environmental Impact Assessment System (SINEIA) in order to selectively decentralize environmental licensing and EIA evaluation (Category 1 and 2 projects).

\section{Promote Coordination with Municipalities}

Given that many environmental responsibilities fall under the jurisdiction of municipalities, which are autonomous government entities, it is essential that SERNA collaborate with municipalities for the following reasons:

(a) To provide technical standards, technical assistance, and training that will improve municipalities' performance in carrying out their responsibilities; and

(b) To promote the establishment or strengthening of municipal environmental units that support the development of municipal projects, including those that support environmental protection and can enforce and oversee the protection of natural resources and mitigation of environmental damage due to municipal activities.

\section{Improve Effectiveness and Efficiency of the EIA System}

The Government of Honduras is achieving progress in evaluating environmental and social impacts associated with development projects. Despite significant limitations in resources, SERNA has made noticeable progress in the implementation of an EIA system. The following key recommendations are provided to assist the government in continuing to improve the efficiency and effectiveness of the EIA process. The first two recommendations are meant to improve the "environmental management system" by developing and applying additional instruments. The remaining recommendations are aimed at improving the components of the EIA process.

(a) Develop and Implement Additional Regulations. There is an overall lack of key environmental legislation and regulations. Despite whatever improvements could be made to the EIA process in Honduras, there remains a crucial need to implement key regulatory standards for discharges to air, soil, and water. This should be a priority and form a key part of improving the environmental management process by not overburdening the EIA process and bringing in additional instruments better suited to deal with most pollution problems.

(b) Strengthen links between the EIA and other management instruments, particularly Strategic Environmental Assessments (SEAs) and zoning. With the assistance of the Bank and the donor community, conduct SEAs. Prospective projects include the following:

- Small hydroelectric dams

- Tourism

- Mining

(c) Improve the Use of Environmental Assessment Tools 
- Improve the efficiency of the environmental screening process. As it stands now, the screening process does not include an assessment of the severity of impact of proposed projects. It is recommended that the screening process be overhauled and that the inclusion list be strengthened to reduce uncertainty in impact category.

- Develop best environmental practice manuals for certain industries (for example, mining). These could easily be developed from existing World Bank Group resources such as the International Finance Corporation (IFC) Environmental Health Safeguards (EHS) guidelines.

\section{(d) Strengthen the Follow-up and Compliance Process}

Implement a review and follow-up process by establishing a dedicated "follow-up" unit. Provide both personnel and resources to do so. Undertake the following:

- Link the monitoring and follow-up unit to the legal compliance unit;

- Prepare a manual on EIA follow-up and develop standardized procedures;

- Make resources available for follow-up in the field-vehicles, test kits, administrative procedures for expenses, and so forth.

(e) Strengthen public participation in the EIA process by:

- Developing a standard guide to public consultation in SERNA that will be available to all proponents;

- Undertaking training programs in public consultation in SERNA so that EIA professionals are familiar with best practices and approaches; and

- Undertaking pilot projects in various large infrastructure projects as demonstration projects to show the benefits of public consultation.

(f) Improve the Institutional Capacity of SERNA and the Environmental and Planning Units in Key Sectors.

Once the role that EIA will play has been decided, (in light of the additional management instruments that must be developed), an analysis of EIA capability in SERNA should be conducted. This should include a review of technical capabilities, salaries, work conditions, and standardized administrative procedures and the provision of a comprehensive and inclusive training program.

The planning capacity of other sectoral authorities, particularly the Ministry of Public Works and Housing (SOPTRAVI), should also be strengthened to develop sector action plans in an integrated manner (including environmental considerations). 


\section{Improve Environmental Information}

(a) Coordinate Environmental Information Systems. Honduras has created several (isolated) information systems. Although they do store useful environmental information, this information is not gathered in a way sufficiently comprehensive to be useful to decisionmakers. Those information systems most used include the National Environmental Information System (SINIA), the National Territorial Information System (SINIT), and the information system at the National Property Administration (SINAP).

To create a coordinated information system in which data are gathered in a format consistent with other database systems, the report recommends that in the short term SERNA identify both the institutions that collect data in the country and the information available. To support the monitoring of environmental indicators, an agreement should be reached among these institutions on frequency of reports, data collection instruments, and responsibilities for data collection.

(b) Introduce Environmental Accounting by Measuring the Costs of Natural Resource Depletion and Environmental Degradation. The richness of natural resources and environmental deterioration in Honduras make a strong argument for the role of environmental resources in reducing poverty, fighting hunger, and lowering child mortality. Policymakers setting environmental standards need to be aware of the likely consequences for the economy, while economic (and sectoral) policymakers must consider the environmental implications of current and projected patterns of consumption and production. SERNA should develop a scheme to introduce environmental accounting.

\section{Promoting Compliance}

One of greatest challenges to the sector is compliance with environmental laws, regulations, and standards. Compliance has centered on the use of environmental assessments. A definition of what constitutes environmental damage and how to estimate it are lacking, making it difficult to apply appropriate sanctions. However, the system is designed to sanction or prohibit actions that the country does not have the capacity to monitor. To confront these challenges, the report recommends developing incentives to promote compliance accompanied by credible sanctions that are based on clear and costeffective standards and enforced by well-staffed agencies.

\section{Promote Public Participation}

The report recommends that:

(a) The Consultative Council play an active role in policy formation and interinstitutional coordination. 
(b) Consultation mechanisms on proposed policies, laws, regulations, and norms be improved, by organizing workshops or target groups to discuss proposals.

(c) The coverage and frequency of both public disclosure programs and environmental education be increased.

\section{Environmental Health}

(a) Water, Sanitation, and Hygiene. The report shows that most measures to improve the water supply and sanitation facilities in rural areas yield benefits in excess of costs under most assumptions. The programs are also justified because the benefits are concentrated primarily among the poor. These measures include drinking water disinfection, handwashing, improved rural water supply, and safe rural sanitation. The highest priority should be given to the drinking water disinfection and hand-washing programs.

(b) Indoor Air Pollution. The analysis presented here supports the unqualified recommendation to shift households that have unimproved stoves to improved ones. The results of other interventions, such as from unimproved stoves to liquefied petroleum gas (LPG) or from improved stoves to LPG, depend on the costs and benefits used. Hence, a more detailed analysis needs to be conducted for such changes, looking at specific cases and taking into account other benefits.

(c) Urban Air Pollution. Rapidly increasing urban populations and accompanying vehicle growth, coupled with inadequate regulations and monitoring, will impact the air quality in cities such as Tegucigalpa unless appropriate actions are taken. Recognizing some of these issues, the Government of Honduras is in the process of preparing a comprehensive air quality management plan. As part of improving the Honduran air quality management system, a detailed and integrated emission inventory for Tegucigalpa and San Pedro Sula should be developed.

There is also a need to establish a health and air quality indicator system. Separately, establishing and implementing an Alert Plan for managing high air pollution levels related to forest fires in Tegucigalpa and urban air pollution episodes should be a priority. Additional measures are needed to improve the regulatory framework for air quality management in Honduras.

\section{Infrastructure and the Environment}

The report makes the following recommendations for enhancing social and environmental sustainability in the sector:

(a) Using complementary instruments - including zoning and SEAs - will improve infrastructure planning and assessment of environmental impacts.

(b) Strengthening information and environmental monitoring systems, particularly in the roads, ports, and water and sanitation subsectors. 
(c) Development of standards-ranging from ambient quality to construction standards and building codes - can reduce arbitrariness in different stages of the EIA process, from the initial assessment to drafting and enforcement of mitigation contracts.

(d) Zoning plans can be instrumental in the guiding of official and unofficial road network development and help to avoid critical natural habitats. Urban zoning plans can help identify areas with high risk of natural disasters and reduce uncontrolled settlement in those areas.

(e) Greater community involvement in infrastructure planning and assessment of social and environmental impacts can benefit the infrastructure sector by reducing social opposition to large infrastructure projects. Public involvement can be achieved through specifying the modalities of public participation in the infrastructure planning process, in the drafting of mitigation contracts as part of EIA, and in implementation of ex ante and ex post disaster mitigation measures.

(f) The quality of regulation is a key factor behind the success or failure of infrastructure concessions. Independent regulation and separation of powers between the planning/regulatory agencies and the operators is particularly important in environments with weak overall governance.

(g) Improve the effectiveness and efficiency of the EIA process (see Recommendation 5).

\section{Strengthen Forestry Management}

The new legal framework offers important opportunities for promoting pro-poor forest management. It also represents a major opportunity for "relaunching" the forest sector and its associated institutional structures. Key areas of support should include the following:

(a) Development of pilot experiences with Consultative Councils and systematization and replication of successful experiences.

(b) Scaling-up of capacities in alternative conflict management, including logistical, funding, and methodological support to an increased number of pilot experiences (for example within the context of the regularization processes currently supported by the Forests and Rural Productivity Project [PBPR]).

(c) Scaling-up of successful experiences with municipal support to sustainable forest management, focusing especially on the development of technical capacities for resource planning and supervision, administrative capacities in order to ensure sustainability, and mechanisms for social control and participation as provided for under the new law. 